\title{
Title: Evolution and New Horizons in Modelling Crack Mechanics of 3D Printing Polymeric Structures
}

\author{
Feiyang $\mathrm{He}^{\text {Corresponding Author, Cranfield University }}$ \\ College Road, Cranfield, UK \\ E-mail Address: Feiyang.he@ cranfield.ac.uk
}

Vijay Kumar ${ }^{\text {Cranfield University }}$

College Road, Cranfield, UK

E-mail Address: vijay.kumar@cranfield.ac.uk

Muhammad Khan ${ }^{\text {Cranfield University }}$

College Road, Cranfield, UK

E-mail Address: Muhammad.A.Khan@cranfield.ac.uk 


\section{ABSTRACT}

3D printed parts are widely used to fabricate polymeric structures in industrial applications. The continuous use of these components in practical applications make them prone to fracture due to crack propagation. Extensive research articles and reviews have been published to introduce the phenomenon and significance of crack propagation behaviour of polymeric structures. However, when these are reviewed with a critical eye, it has been found that a comprehensive effort is still required to compile all these previous research with an emphasis on thermo-mechanical couple loads. During the presented critical review effort, it has been found that the existing research and their conclusions are limited in expressing the true crack growth phenomenon for real applications. Therefore, this review concludes that the analytical and empirical study about the crack growth behaviour of polymers under the time-dependent coupled loading conditions can be a novel contribution in the academic domain.

Keywords: Fatigue; Crack propagation; Polymer; Thermo-mechanical Loads, 3D Printing 


\section{Introduction}

The manufacturing industry uses a variety of materials to fabricate parts and structures. From the wooden structure of the building to the metal crankshaft of the engine, one can observe the development of numerous types of materials throughout history. Most of the prominent materials are made of either wood, ceramics, metals or polymers [1]. Out of these prominent ones, the use of polymers increases immensely in the past few decades. Polymers become a high-quality choice suitable for structural applications because of the low cost and lightweight features such as wind blades and aircraft wings [2][3].

Different manufacturing processes for polymeric structures have developed in order to satisfy the increasing industrial demand. These processes include different types of moulding (such as injection, rotation and blow), extrusion, vacuum forming, polymer casting and 3D printing. These can further categorise into two types: Conventional Manufacturing and Additive Manufacturing (AM). Conventional Manufacturing parts have been widely used in mass production industries. However, compared with it, the rapid development in AM has attracted more attention from academia and industry [4]. Primarily, 3D printing AM gives lots of advantages, including customisation freedom, cost-effectiveness and less waste production. So it has been applied to fabricate polymeric components and structures for the applications used in aerospace, automotive, medical and biomechanical sectors [3] [5] [6]. Due to its specific advantage to create highly customised plastic part designs or prototypes, the medical industries apply it to create prosthetics and implants.

No matter how the structures are fabricated, they work under the complex and harsh working environment such as the pressure sensors and sensor pads, as shown in Figure 1- 
1 [2] [7]. These polymeric structures may experience various damages due to fatigue, corrosion, impact and puncture [8]. Although the research has also observed possibilities of damages due to chemical and environmental conditions [9], most of the past research focused on cracks and damages, which were primarily due to mechanical loads [8]. They described the mechanics about how cracks initiate and propagate in real applications under the mechanical loads. However, because the coupled thermo-mechanical load is more common in an actual working environment, understanding the crack propagation behaviour for such loading conditions is more significant [10]. The previously published work mostly considered time-independent or quasi-static load conditions while characterising crack behaviour [11].

In contrast, the fracture theory also suggests that the load range and frequency could lead to a different crack propagation phenomenon. The modelling of the relationship between these load conditions and crack propagation is helpful to predict the structural potential failure. The load history can be used to calculate the real-time crack state thereby estimate fatigue life and avoid the final failure. Therefore, it is essential to understand the crack growth behaviour for polymeric structures under dynamic loads to predict and prevent their fracture.

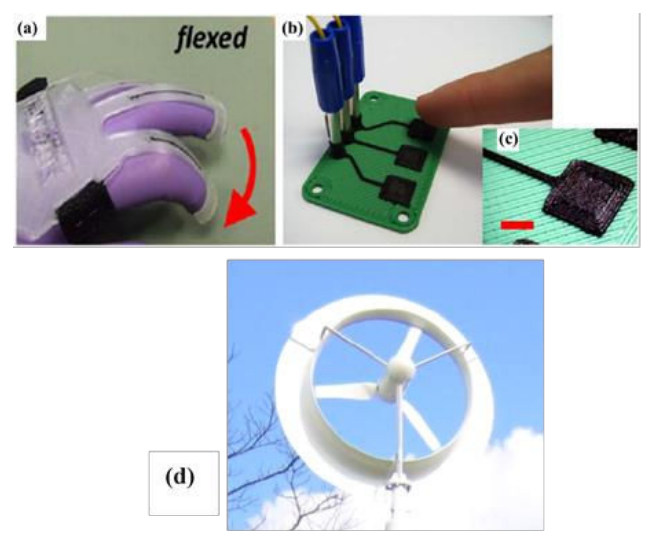

Figure 1-1 Several 3D printed polymers applications (a) Piezoresistive sensors (b) Capacitive sensors (c) Sensor pads (scale bar 5 mm) [7] (d) Wind-lens turbine [2] 
In contrast to the conventional manufactured polymeric structures, crack propagation in 3D printing polymeric structures is more complicated. Because there are significant differences in microstructure due to these two manufacturing methods. Apart from load range and frequency, a variety of 3D printing parameters may affect the rupturing of the parts. The relationship between these parameters and potential crack growth properties is significant to understand the evolution of damage in printed parts.

Extensive research articles and reviews have explained the phenomenon and significance of crack growth behaviour of polymeric structures. However, when reviewing these studies critically, a comprehensive effort is still required to emphasise the effect of thermo-mechanical couple loads on crack propagation. Therefore, the presented review compiles all these previous research and considers the influence of thermo-mechanical loads on crack growth. It has been found that the actual crack growth phenomenon for real applications is different from the previous research and their conclusions. Therefore, an analytical and empirical study about the crack propagation of polymeric structures under the dynamic thermo-mechanical loads can be a novel contribution in the fracture area.

A brief overview of the main polymers applied in conventional manufacturing and 3D printing will be described next. Because as the raw material of the structure, their mechanical properties will potentially affect the crack propagation in polymeric structures. 


\section{Major Polymers Used in Industries}

Most polymers described in this review are plastic materials. They are widely used in industries due to their excellent plasticity, which means they can be moulded or shaped easily. Generally, plastics also have other excellent properties such as high strength-toweight ratio, low thermal conductivity and low electrical conductivity. These benefits allow plastics to be used in various industries [12]. These plastics can be divided between thermoplastics and thermosets polymers. Specifically, thermoplastic polymers are introduced below because the review focuses on 3D printing polymers. Table $2-1$ lists the main commercially employed polymers and their properties.

Fundamentals about crack growth will be described next. These fundamentals are the cornerstones of advanced research. Authors believe that a review of current advances in fracture of materials is incomplete without discussing them in brief.

\section{Fundamentals of Crack Growth in a Structure}

Crack propagation starts soon after the crack birth at microscale under the influence of the applied load. Significant cyclic loads lead this crack to macroscale in the form of visible damage [13]. These repetitive loads generate various stress conditions surrounding the crack tip, which promote cracks propagate up to failure. Therefore, it is significant to understand the relation between the crack tip's stress and the fatigue crack growth (FCG) rate. Published research theoretically correlated these two parameters and demonstrated their interdependencies with different material properties and load conditions [14]. Brief details about these parameters are provided below. 


\begin{tabular}{|c|c|c|c|}
\hline Materials & Chemical Structure & $\begin{array}{c}\text { Tensile Modulus } \\
(\mathrm{MPa})\end{array}$ & $\begin{array}{l}\text { Flexural Modulus } \\
\quad(\mathrm{MPa})\end{array}$ \\
\hline $\begin{array}{l}\text { Acrylonitrile butadiene styrene (ABS) } \\
\text { buta-1,3-diene;prop-2-enenitrile;styrene }\end{array}$ & $\left.-\mathrm{CH}_{2}-\mathrm{CH}=\mathrm{CH}-\mathrm{CH}_{2}\right]_{x}-\mathrm{CH}_{2}-\mathrm{CH}_{y},\left[\mathrm{CH} \mathrm{H}_{2}-\mathrm{CH}=\mathrm{CH}-\mathrm{CH}_{2}\right]_{z}$ & 2027 & 2096 \\
\hline $\begin{array}{c}\text { Polyvinyl chloride (PVC) } \\
\text { poly(1-chloroethylene) }\end{array}$ & & 2834 & 3316 \\
\hline $\begin{array}{c}\text { Polypropylene(PP) } \\
\text { Poly(1-methylethylene) }\end{array}$ & & - & 1551 \\
\hline High-density polyethylene (HDPE) & & - & 1379 \\
\hline $\begin{array}{c}\text { Polyether ether ketone (PEEK) } \\
\text { poly(oxy-1,4-phenyene-oxy-1, 4-phenyene) }\end{array}$ & & 3378 & 4068 \\
\hline $\begin{array}{c}\text { Polycarbonate (PC) } \\
\text { 4-[2-(4-hydroxyphenyl)propan-2-yl]phenol }\end{array}$ & & 2379 & 2379 \\
\hline $\begin{array}{c}\text { Polyethylene terephthalate (PET) } \\
\text { Poly(ethyl benzene-1,4-dicarboxylate) }\end{array}$ & & 2758 & 2758 \\
\hline $\begin{array}{c}\text { Nylon } 66 \\
\text { Poly[imino(1,6-dioxohexamethylene) iminohexamethylene }]\end{array}$ & 0 & 3241 & 2827 \\
\hline
\end{tabular}

Table 2-1 Main Polymers structures and mechanical properties 


\subsection{Stress Condition at Crack Tip}

In 1898, Kirsch proposed the linear elastic solution for stress conditions surrounding a hole in an infinite plate [15], as shown in Equation 3-1 to 3-3. The hole has radius $r$, and the polar coordinates are $r$ and $\theta$. Where $\sigma_{\infty}$ is uniaxial tension stress, $\sigma_{r r}$ and $\sigma_{\theta \theta}$ are the stresses along the radial and circumferential directions and $\tau_{r \theta}$ is the shear stress.

$$
\begin{gathered}
\sigma_{r r}=\frac{\sigma_{\infty}}{2}\left[1-\left(\frac{a}{r}\right)^{2}\right]+\frac{\sigma_{\infty}}{2}\left[1-4\left(\frac{a}{r}\right)^{2}+3\left(\frac{a}{r}\right)^{4}\right] \cos (2 \theta) \\
\sigma_{\theta \theta}=\frac{\sigma_{\infty}}{2}\left[1+\left(\frac{a}{r}\right)^{2}\right]-\frac{\sigma_{\infty}}{2}\left[1+3\left(\frac{a}{r}\right)^{4}\right] \cos (2 \theta) \\
\tau_{r \theta}=-\frac{\sigma_{\infty}}{2}\left[1+2\left(\frac{a}{r}\right)^{2}-3\left(\frac{a}{r}\right)^{4}\right] \sin (2 \theta)
\end{gathered}
$$

The above equations can only provide stresses available on a circular hole and limit the application on any other crack geometry. Later in 1913, Inglis proposed the solution for the stress field surrounding an ellipse and overcame the geometry-based limitation. It was the crucial next step during the development of linear elastic fracture mechanics (LEFM) theory [16]. Similar to Kirsch's solution for the circular hole, Inglis used an infinite isotropic plate in uniaxial tension for his model. However, due to elliptical geometry, his model applied to an infinite number of different scenarios by changing the values of major and minor axes. His solution proposed that the maximum stress $\sigma_{\max }$ is $\sigma_{\infty}\left(1+2 \frac{a}{b}\right)$. Where $a$ and $b$ were the half width and heigrht of ellipse, respectively.

In 1939, Westergaard developed the exact solution for the stress surrounding the crack plane. It had two advantages over Inglis's solution. Firstly, Westergaard's solution provided stresses on general crack geometry and not on an ellipse. Secondly, the stresses 
can be obtained in rectangular coordinates that were easy to understand as compared to the elliptical ones. The stress expression at any locations around the crack tip is shown in Equation 3-4,

$$
Z(z)=\frac{\sigma_{\infty}}{\sqrt{1-\left(\frac{a}{z}\right)^{2}}}
$$

Where $Z(z)$ is the complex numbers for the stress solution at any point, $\sigma_{\infty}$ is the static stress applied on the structure, $a$ is the crack length, $z$ equals $x+i y$ as the position of the point [17]. A Taylor series expansion of equation 2-4 was essential to calculate the stress around the crack through dividing it into its real and imaginary parts. The imaginary part made the solution complex to understand the stress state surrounding a crack. Irwin resolved this complexity and proposed the definition of stress intensity factor (SIF) $K$ as a near-crack-tip approximation in 1957. He greatly simplified Westergaard's result to an approximate solution in the area closely near the crack tip, as shown in Equation 3-5 to 3-7 [18].

$$
\begin{gathered}
\sigma_{x x}=\frac{\sigma_{\infty} \sqrt{\pi a}}{\sqrt{2 \pi r}} \cos \frac{\theta}{2}\left(1-\sin \frac{\theta}{2} \sin \frac{3 \theta}{2}\right) \\
\sigma_{y y}=\frac{\sigma_{\infty} \sqrt{\pi a}}{\sqrt{2 \pi r}} \cos \frac{\theta}{2}\left(1+\sin \frac{\theta}{2} \sin \frac{3 \theta}{2}\right) \\
\tau_{x y}=\frac{\sigma_{\infty} \sqrt{\pi a}}{\sqrt{2 \pi r}} \cos \frac{\theta}{2} \sin \frac{\theta}{2} \cos \frac{3 \theta}{2}
\end{gathered}
$$

Where $\sigma_{x x}$ and $\sigma_{y y}$ are the stresses along with two axis directions, $\tau_{x y}$ is the shear stress, $r / \theta$ are polar coordinates of the location near the tip. Irwin replaced $z=x+i y$ in Westergaard's solution by $z=\mathrm{a}+r e^{i \theta}$. Then Irwin simplified the equation in the 
following algebraic calculation based on the inequality $r \ll a$. He also applied the polar coordinates to simplify the calculation by Euler's identity rather than the Taylor series expansion. These simplifications led to the final stress was calculated accurately only near the crack tip, as shown in Figure 3-1.

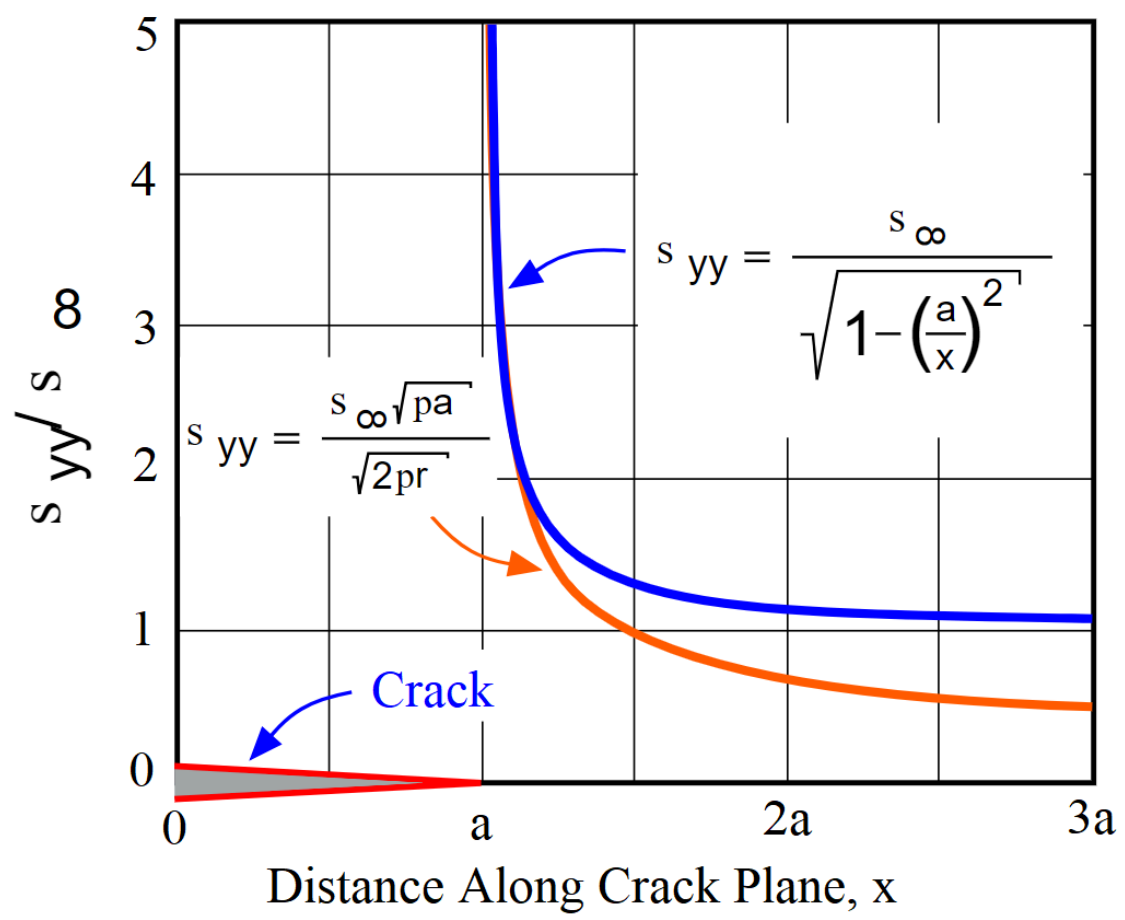

Figure 3-1 Stress modelling near crack tip [19]

There are the same expression $\sigma_{\infty} \sqrt{\pi a}$ in Equation 3-5 to 3-7. The expression of $\sigma_{\infty}$ and $a$ fully represents the stress condition around the crack tip. Irwin recognised this as SIF firstly, which causes the different crack initiate and propagate as the various stress state at a crack tip [20].

\subsection{Modelling of Stress Condition and Crack Propagation}

A large amount of research used above approximate stress solutions at crack tip to develop the analytical relations about crack growth. Most of them aimed to link the stress 
condition to the crack growth rate. Irwin's research was used by Paris, Gomez and Anderson to introduce the idea that the FCG rate was strongly dependent on the SIF. The reason was due to the maximum SIF $K_{\max }$ and SIF range $\Delta K$ give both the intensity and variation of loading and geometry [21]. They proposed the famous Paris' Law as an empirical crack growth rate equation (Equation 3-8). It showed the relationships between the SIF range and subcritical FCG in a specific fatigue life stage [22].

$$
\frac{d a}{d N}=C(\Delta K)^{m}
$$

Where $\frac{d a}{d N}$ is the FCG rate, $C / m$ are parameters determined by the materials, environmental conditions and stress ratio, and $\Delta K$ is the range of the SIF during the fatigue cycle. SIF in Equation 2-8 is defined as a parameter based on the static loads. The range of SIF cannot represent the dynamic loads. Radon further simplified this relationship, as shown in Equation 3-9,

$$
\frac{d a}{d N}=F \emptyset^{\alpha}
$$

where $\varnothing$ is a function about the SIF. $F$ and $\alpha$ are two coefficients. Radon also pointed out that the crack propagation characteristics cannot be reflected by a single analytical da/dN "law" appropriately. The formula can only partially represent regression values of the data derived from a huge amount of tests due to the influence of the experimental environment. Essentially, this crack growth rate model is based on semi-analytical methods, so the coefficients $F$ and $\alpha$ are dependent on experimental setup [23]. Despite all the limitations, which we have discussed above, much research has used this formulation for estimating the crack growth in polymers. 


\section{Crack Propagation of Polymeric Structures under}

\section{Mechanical Loads}

Irwin and Paris's results were commonly applied to investigate the crack growth in polymeric structures [24][25]. Odahara performed the FCG test of a wind-lens blade manufactured with Dicyclopentadiene material. The relationship between FCG rate and $\Delta K$ was obtained as the format of Paris Law, as shown in Equation 4-1 and Figure 4-1 $[2]$.

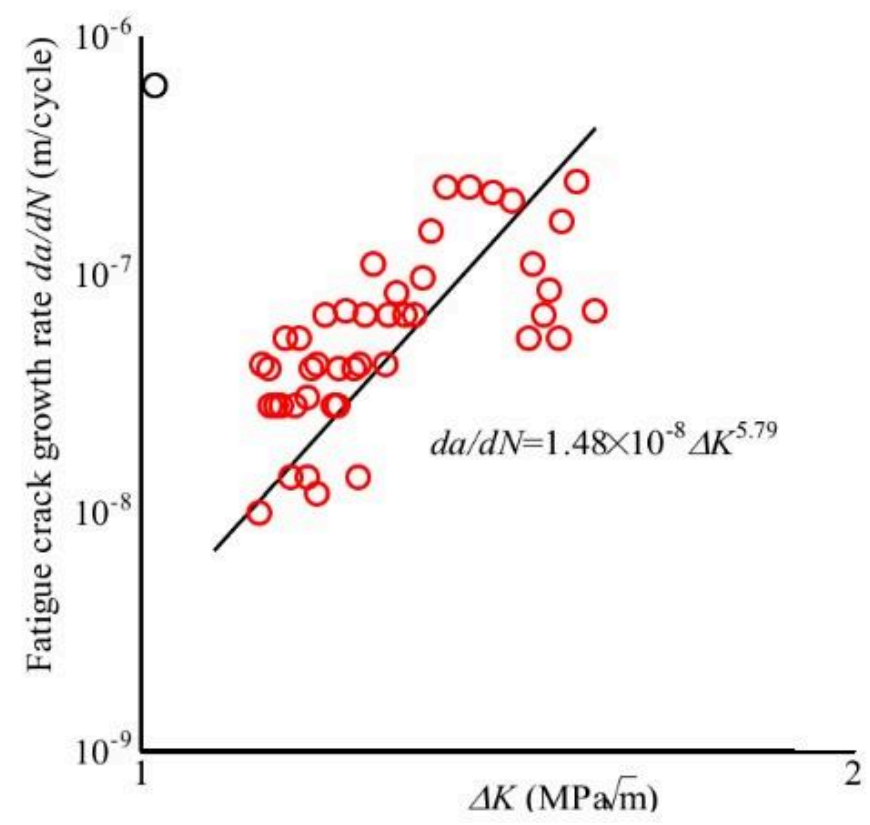

Figure 4-1 $d a / d N$ - $\Delta K$ relation of Dicyclopentadiene material (replotted) (1 mm initial crack depth, 1.1 to $1.5 \Delta K$ range, $4.5 \mathrm{MPa}$ stress amplitude, $5.5 \mathrm{MPa}$ average stress, stress ratio $\mathrm{R}=0.1$ and $2 \mathrm{~Hz}$ cycle frequency) [2]

$$
\frac{d a}{d N}=1.48 \times 10^{-8} \Delta K^{5.79}
$$

Suyitno and Lazuardi analysed how the load ratio R can affect the FCG rate in ultrahigh molecular weight polyethene (UHMWPE). They carried out experiments with compact tension (CT) specimens. The experimental results showed that higher load ratio $\mathrm{R}$ 
increased the fatigue crack propagation resistance, which resulted in the lower FCG rate, as shown in Figure 4-2. [26]

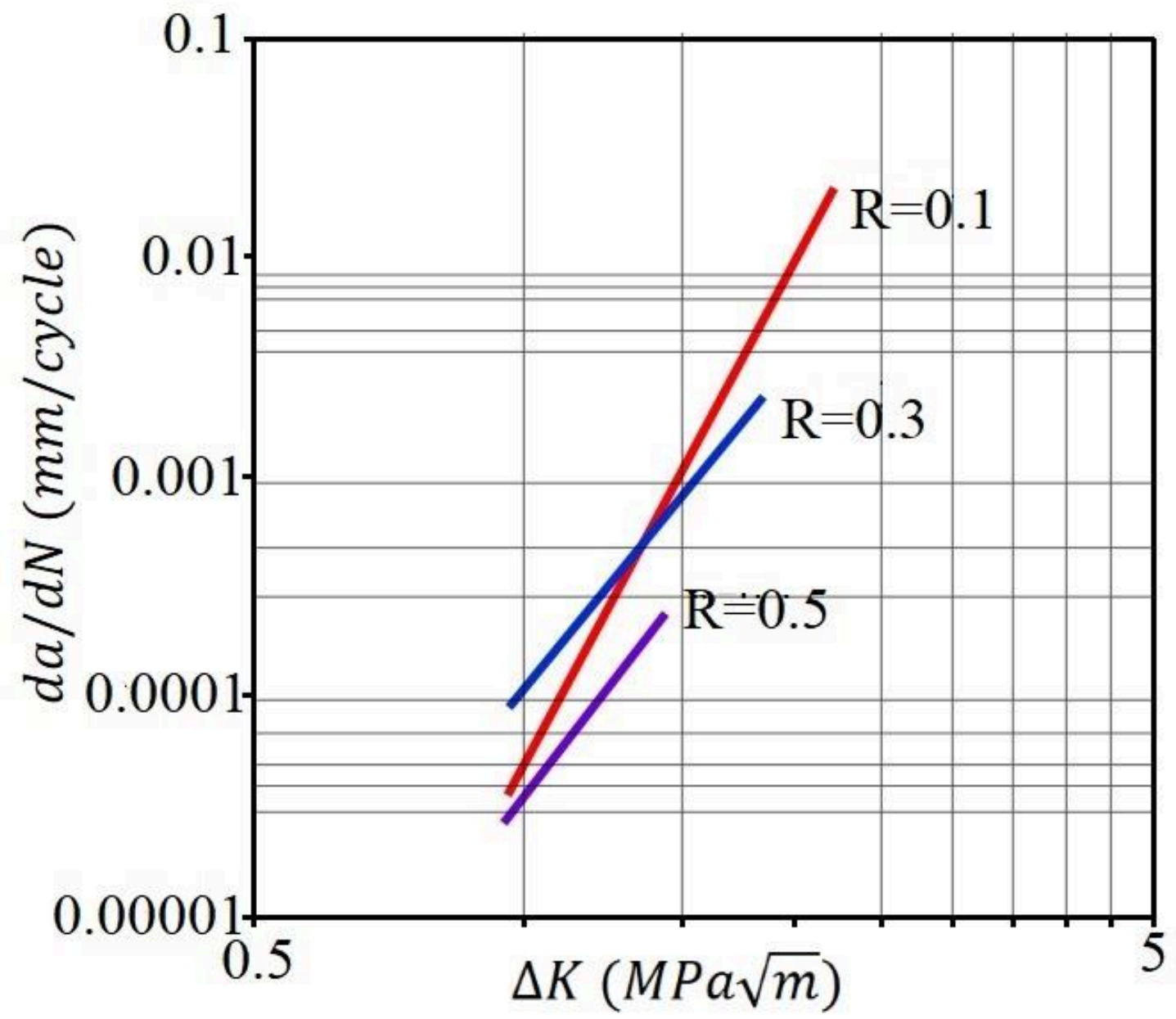

Figure 4-2 Effect of load ratio on fatigue crack behaviour of PE (replotted) (fully tensile cyclic loading with a constant amplitude of $630 \mathrm{~N}$ and a constant loading frequency of 10 Hz) [26]

Li et al. carried out several related studies about the crack propagation in plastic alloys. They experimentally investigated the mixed-mode fracture toughness for polycarbonate (PC) and Acrylonitrile Butadiene Styrene (ABS) alloy [27]. In another research, Fang, Li and Wang [28] compared the FCG rate in PC and PC/ABS alloy experimentally. A $3 \mathrm{~Hz}$ cyclic tensile load with 0.1 load ratio was applied to a compact tension specimen. The test data demonstrated that PC/ABS alloy had a higher crack growth resistance than PC 
at the same SIF range. The crack growth rate in PC specimen was three times that of PC/ABS alloy because of the larger plastic zone near the crack tip in PC/ABS alloy compared with PC. The research also formulated the Paris' Law for PC/ABS alloy under 3Hz fatigue load (Eq.4-2),

$$
\frac{d a}{d N}=9.5587 \times 10^{-5}(\Delta K)^{2.88381}
$$

However, in another research, they formulated another Paris Law (Equation 4-3) for the FCG rate of PC/ABS alloy with $3 \mathrm{~Hz}$ loads on account of the overload effects [29].

$$
\frac{d a}{d N}=1.166 \times 10^{-4}(\Delta K)^{2.77}
$$

The above empirical equations explain that the application of Paris law has to consider many parameters, including loading conditions. Its applicability is not as extensive as the analytical models.

Apart from crack propagation, effects of some other crack properties are also investigated by using the Paris Law. Okayasu et al. investigated the crack growth characteristics of a recycled short carbon fibre reinforced plastic (rCFRP) from linear elastic fracture mechanics (LEFM) formulations [30]. The work on effort proposed that the Paris Law relations for polymer, especially in slow growth rate regimes, were affected by severe crack closure. Same observations were reported for other polymeric materials (Polyvinyl chloride (PVC), Poly(methyl methacrylate) (PMMA) and Polyamide (PA)) [31]. Mazidi, Aghjeh and Abbasi used LEFM to investigated fracture properties of ABS. They evaluated the influence of crack scale and rubber amount to the microscopic failures and estimated macroscopic crack propagation behaviour of the specimens as given in Equation 4-4 [32][33]. 


$$
\frac{d a}{d N}=1.48 \times 10^{-8} \Delta K^{5.79}
$$

Few amounts of research used a numerical approach to estimate crack growth. Lack of representative numerical models for crack growth in polymers causes difficulties in crack propagation prediction even under controlled stress conditions. Critical phenomenon such as crack closure and plastic zone influences the crack growth with a too complicated mode, which means it is challenging to develop a perfect numerical model even with some appropriate assumptions [34-36]. Ding et al. [37] developed a numerical method to estimate the FCG rate for polymers. They assumed that the crack propagation is related to the 'dissipated energy in the plastic zone' surrounding the crack tip. They formulated the FCG rate as shown in Equation 4-5.

$$
\frac{d a}{d N}=\frac{d W_{p} / d N}{\left(d W_{p} / d a\right)_{c r}}
$$

Where $d W_{p} / d N$ is 'the accumulation rate of plastically dissipated energy, determined from numerical model'. $\left(d W_{p} / d a\right)_{c r}$ is 'the critical value of plastically dissipated energy required per incremental increase in crack length', as a material property and represented Paris Law with a practical or physical meaning rather than an empirical model. The value of $\left(d W_{p} / d a\right)_{c r}$ was determined through the experiment with the Equation 4-6,

$$
\left(d W_{p} / d a\right)_{c r}=\frac{\left(d W_{p} / d N\right)_{s i m}}{(d a / d N)_{\text {exp }}}
$$

They simulated the crack growth rate for PC, Polystyrene (PS) and Nylon 66 under different loading frequencies and estimated the parameters of Paris law well in agreement with experimental results [37]. Above research all modelled the crack propagation in 
polymers according to Paris Law. However, a large amount of research just carried out the experimental work and explained the crack propagation in real polymeric applications without taking help from Paris law. A description of a few prominent investigations is provided below [38][39].

Some research focused on the application of Polyether ether ketone (PEEK) polymer [4042]. Koike et al. investigated the failure mechanism of polymeric bearings made with PEEK in an underwater environment. They conducted the rolling contact fatigue test for studying and observing the crack propagation on the inner ring of the bearing, as shown in Figure 4-3. There were mainly three types of cracks, semi-circular, surface and subsurface cracks. The observation showed that the main surface and subsurface cracks propagation directions were the same as the bearing rolling. The rolling aluminium balls applied the shear stress and then led to the main subsurface cracks propagation from the artificial notch. As for the semi-circular cracks, the tensile stress resulted in it on the raceway surface, as shown in Figure 4-4 [43].

Similarly, some research also focused on the rolling fatigue crack propagation in polymer bearings [44-48]. Shi, Kida and Kashima observed the surface crack of polyphenylene sulphide (PPS) polymer thrust bearings under water. The flaking from the defects occurred on the track surface (Figure 4-5). This observation indicated that the propagation and connections of the surface cracks caused flaking and final failure of the bearing [49][50]. 


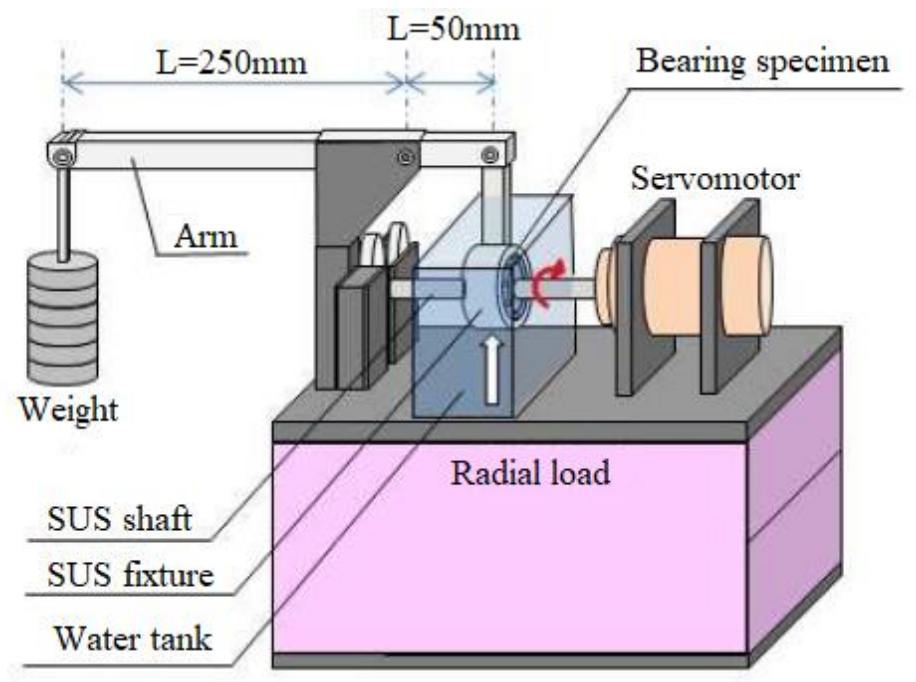

Figure 4-3 RCF test machine scheme [43]

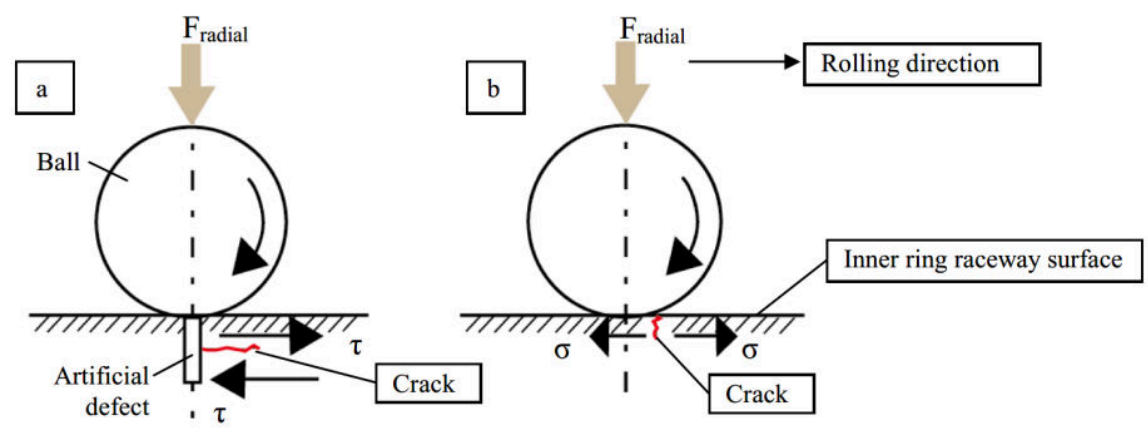

Figure 4-4 Two different crack types and associated growth directions: (a) subsurface cracks, (b) semi-circular cracks[43]

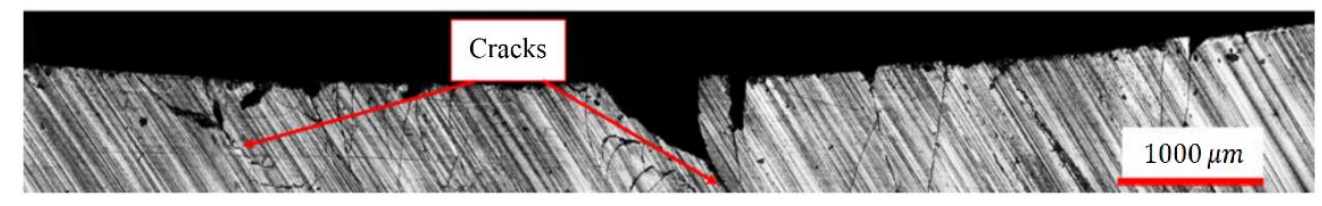

Figure 4-5 Crack observation in cross-section of top race track [49] 


\section{Crack Propagation of Polymers under Thermo-mechanical}

\section{Loads}

The polymeric structures in practical applications are worked under more complex load conditions [2]. A coupled thermo-mechanical load condition is usually observed in critical applications which significantly affects the crack propagation in polymers quite differently as compared to the single load condition, as discussed in Section 4 [7]. Couple loads such as cyclic strain with relatively high-temperature values allow a crack to propagate but makes its behaviour more dependent on properties like damping, viscoelasticity and thermal conductivity [11]. An increase in temperature decreases the structural stiffness. The specimen deforms, and deflection occurs due to the stiff ness loss. These mechanical properties change affects the fracture roughness and then change the FCG behaviour when applied the mechanical loads.

Section 5 reviews the efforts related to crack propagation in polymers under different temperature conditions, different load frequencies and combination of temperature and mechanical loads. Moreover, some other influence parameters such as the overloaded condition and geometry of polymeric structures are also described.

\subsection{Temperature Effect on Crack Propagation}

Many investigations proposed that FCG rate can be affected by environmental temperature [51-58]. Different polymeric materials have been tested on a range of temperatures, as shown in Table 5-1. The testing temperatures in most of the cases were set below $100^{\circ} \mathrm{C}$ because of the lower polymeric glass transition temperatures. 
Waller et al. [59] investigated the crack onset strain (COS) for brittle coatings on polymer substrates with the consideration of temperature influence. The research proposed that the temperature significantly influenced the crack growth behaviour of the structure with tensile loads. However, various types of material played a more critical role in actual failure performance. The experiments showed that higher temperature decreased the COS below the glass transition temperature. However, it is more critical for the substrate softening effects and associated shrinkage behaviour over the glass transition temperature, which increased the COS at an elevated temperature.

Similarly, Zhang et al. tested the fracture behaviour for a glass fibre-reinforced polymeric joint. The research proposed that the temperature cannot influence the crack initiation loads when it was lower than the material glass transition temperature. However, another different conclusion is that lower temperature accelerated the FCG rate. The reason for it was that higher temperature increased the critical strain energy release rate required in crack initiation and growth process [60].

Luo et al. proposed that temperature affected the crack growth behaviour in rubber polymer with the influence of the structural tear energy. They proposed the prediction model for FCG rate based on the critical tear energy, as shown in Figure 5-1. [61] The model showed that higher temperature promoted the crack propagation in rubber.

Martin and Gerberich investigated the FCG properties of PC with the consideration of environmental temperature. FCG behaviours were tested between a temperature range $100-373 \mathrm{~K}$. Then it was further evaluated to build an empirical model according to fracture toughness. The model's parameters are shown in Table 5-2 
Table 5-1 FCG test for polymers under different temperatures

\begin{tabular}{|c|c|c|c|}
\hline Testing Method & Material & Temperature Range & Authors/Year of study \\
\hline Tension FCG Test & PC & $-173^{\circ} \mathrm{C}$ to $127^{\circ} \mathrm{C}$ & Martin and Gerberich (1976) \\
\hline Tension FCG Test & PS & $-60^{\circ} \mathrm{C}$ to $60^{\circ} \mathrm{C}$ & Mai and Williams (1979) \\
\hline Tension - Relax FCG Test & Polypropylene (PP) & $-20^{\circ} \mathrm{C}$ to $20^{\circ} \mathrm{C}$ & Iwamoto, Jinen and Suzuki (1988) \\
\hline Tension FCG Test & PEEK & $39^{\circ} \mathrm{C}$ to $100^{\circ} \mathrm{C}$ & Brillhart and Botsis (1992) \\
\hline Tension FCG Test & ABS & $-50^{\circ} \mathrm{C}$ to $80^{\circ} \mathrm{C}$ & Kim, Wang and Abdullah (1994) \\
\hline Tension FCG Test & Chlorinated polyvinyl chloride (CPVC) & $-10^{\circ} \mathrm{C}$ to $70^{\circ} \mathrm{C}$ & Irfan-ul-Haq and Merah (2003) \\
\hline Tension FCG Test & CPVC & $-10^{\circ} \mathrm{C}$ to $70^{\circ} \mathrm{C}$ & Merah, Irfan-Ul-Haq and Khan (2004) \\
\hline
\end{tabular}




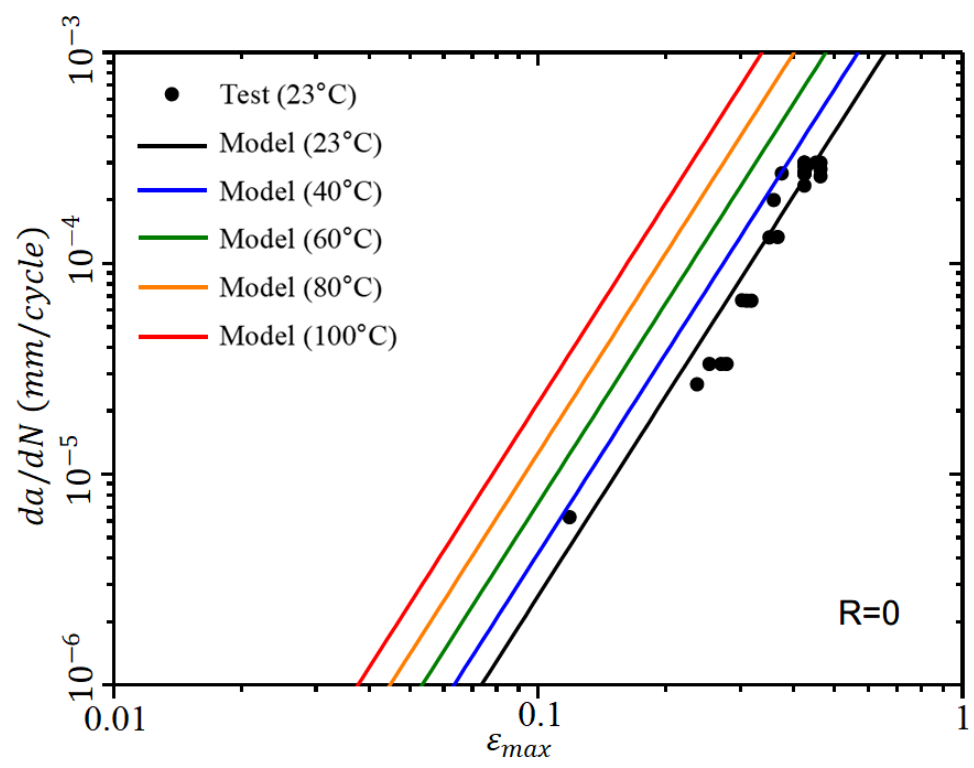

Figure 5-1 Modelling results of FCG rate at temperatures above $23{ }^{\circ} \mathrm{C}$ [61]

Table 5-2 Paris law parameters for PC [62]

\begin{tabular}{|c|c|c|}
\hline Temperature $\left({ }^{\circ} \mathrm{C}\right)$ & $\alpha(\mathrm{mm} /$ cycle $)$ & $m$ \\
\hline-172 & $5.2^{*} 10^{-6}$ & 6.5 \\
\hline-150 & $1.9 * 10^{-6}$ & 8.4 \\
\hline-125 & $1.6^{*} 10^{-6}$ & 10.0 \\
\hline-100 & $1.8^{*} 10^{-5}$ & 7.2 \\
\hline-75 & $8.8^{*} 10^{-6}$ & 9.8 \\
\hline-50 & $2.9 * 10^{-5}$ & 10.7 \\
\hline-21 & $2.5^{*} 10^{-5}$ & 8.6 \\
\hline 0 & $9.4 * 10^{-6}$ & 7.5 \\
\hline 25 & $2.7 * 10^{-4}$ & 3.9 \\
\hline 40 & $2.4 * 10^{-4}$ & 3.2 \\
\hline 50 & $1.1 * 10^{-4}$ & 4.1 \\
\hline 100 & $1.4 * 10^{-3}$ & 1.2 \\
\hline
\end{tabular}

PC was least tough at $223 \mathrm{~K}$ rather than $100 \mathrm{~K} .223 \mathrm{~K}$ seems to be the transition point. Fatigue crack resistance increased with an increase in temperature more than $223 \mathrm{~K}$. 
Below $223 \mathrm{~K}$, fatigue crack resistance increased with decreasing temperature, as shown in Figure 5-2 [62].

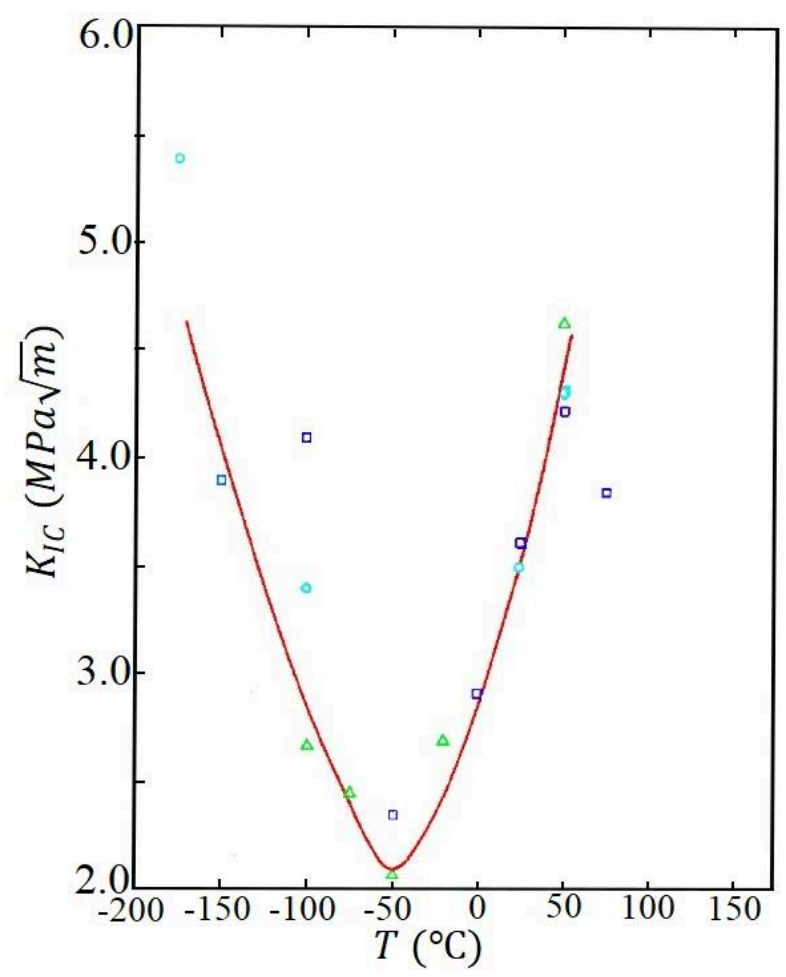

Figure 5-2 Fracture toughness variation with the temperature for PC (replotted) (run at 1 Hz in sinusoidal oscillation) [62]

Mai and Williams (1979) conducted fatigue tests on PS notched specimens at different mean stress conditions with a temperature range between -60 and $60{ }^{\circ} \mathrm{C}$. Specimens were tested dipped in detergent and corn oil. The experimental results were plotted in Figure 5-3. The research calculated the Paris law parameters with these SIF range-FCG rate curve. They also investigated the effects of the environmental temperature and load range. The empirical parameter values in Paris law, as shown with Table 5-3, showed wide ranges of the parameters $\mathrm{A}$ and $\mathrm{m}$. So it was challenging to give physical meanings to their values [62]. 
Table 5-3 Paris law parameters for PS [63]

\begin{tabular}{|c|c|c|c|}
\hline$T\left({ }^{\circ} \mathrm{C}\right)$ & $\log _{10} A$ & $m$ & $\begin{array}{c}d a / d N \\
(\mu \mathrm{m} / \mathrm{cycl})\end{array}$ \\
\hline 60 & 0.91 & 3.1 & 0.3 to 20 \\
\hline 40 & 0.76 & 3.7 & 0.2 to 10 \\
\hline 30 & 0.74 & 3.8 & 0.1 to 10 \\
\hline 20 & 0.39 & 4.3 & 0.1 to 7 \\
\hline 0 & 0.07 & 3.6 & 0.1 to 2 \\
\hline-20 & -0.26 & 2.6 & 0.1 to 1 \\
\hline-60 & 0.48 & 7.4 & 0.01 to 0.2 \\
\hline
\end{tabular}
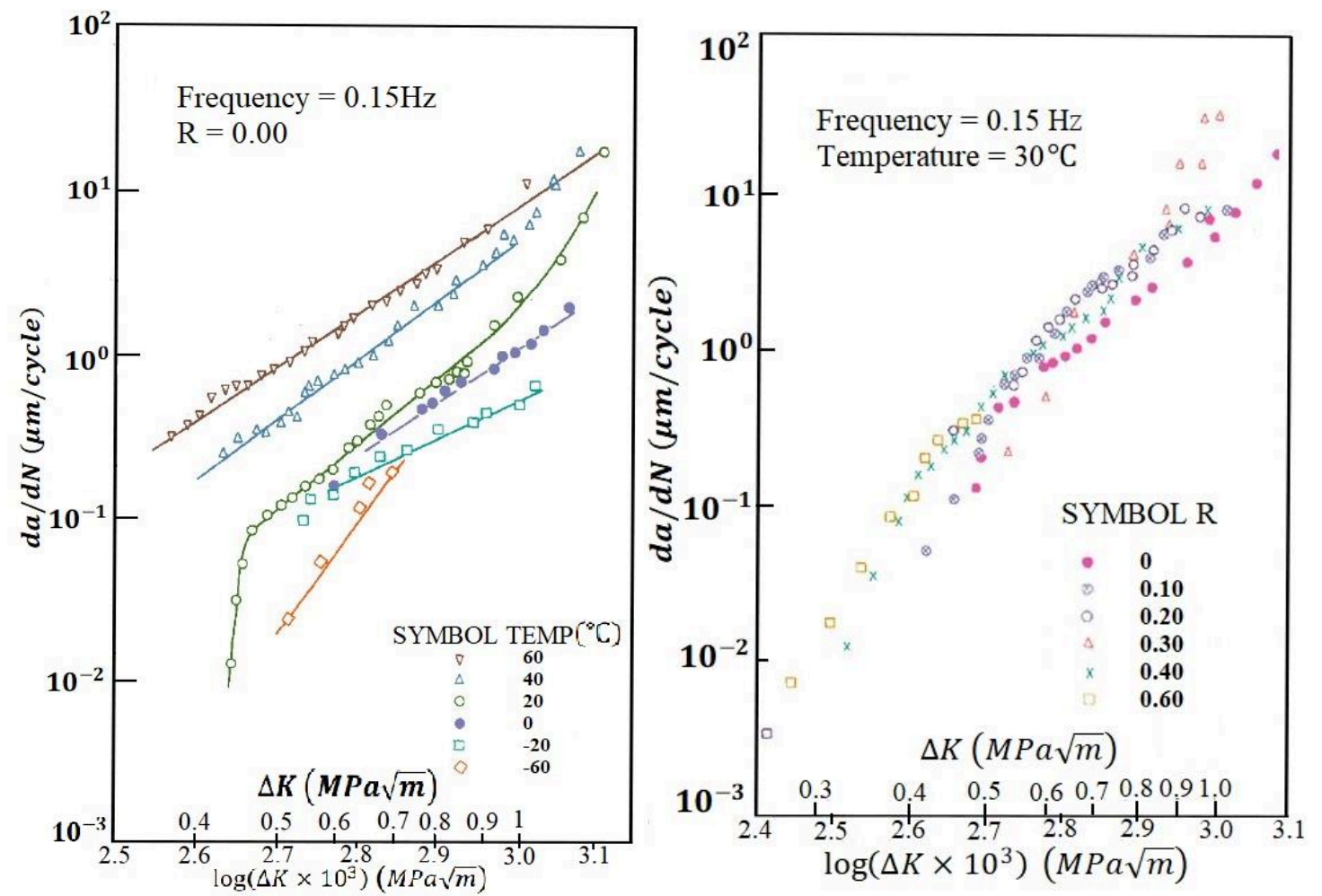

Figure 5-3 Influence of temperature and R Ratio to da/dN (replotted)(150mm*50mm SEN specimen with $9 \mathrm{~mm}$ initial crack depth, $0.15 \mathrm{~Hz}$ test frequency) [63]

Kim and Mai (1993) investigated how temperature affected the FCG in an un-plasticised polyvinyl chloride (uPVC) pipe-grade polymer during the temperature ranges from -30 
to $60{ }^{\circ} \mathrm{C}$. They proposed that it is appropriate to use the Arrhenius relationship between FCG rate $d a / d N$, and temperature T to model the FCG process with the independence of the SIF range $\Delta K$. This developed model is shown in Equation 5-1,

$$
\frac{d a}{d N}=B \exp \left[\frac{-\left(\Delta H_{t h}-\gamma \log \Delta K\right)}{R T}\right]
$$

Where $B$ is a constant, $\Delta H_{t h}$ is 'the thermal activation energy independent of mechanical work' and $\gamma \log \Delta K$ is a 'SIF biased term'. They proposed that different activation energies corresponded to two specific crack propagation processes. Shear mechanism played a significant role under low temperature. However, multiple crazing mainly led to the final fatigue failure when the temperature was high [64].

Furthermore, Kim, Wang and Abdullah (1994) studied the crack propagation in a commercial $\mathrm{ABS}$ with the temperature ranges $-50^{\circ} \mathrm{C}-80^{\circ} \mathrm{C}$. They utilised the above Equation 4-1 to calculate the constants in Paris law and then carried out the comparison with the experimental values. The data are shown in Figure 5-4. They pointed out that the FCG rate increased more rapidly at temperatures from $19{ }^{\circ} \mathrm{C}$ to $80{ }^{\circ} \mathrm{C}$ than from $-50{ }^{\circ} \mathrm{C}$ to $19{ }^{\circ} \mathrm{C}$ due to two modes of crack growth under these different temperature ranges [65].

Lugo et al. experimentally investigated the structure-property relationships of ABS for crack propagation and extended the microstructure-based fatigue model from metal to ABS with appropriate parameter identification. They mentioned that the generated heat increased the surface temperature during fatigue tests, as Figure 5-5 showed. Also, the reasons for it were the stretch and ordering of polymer chains[66]. 


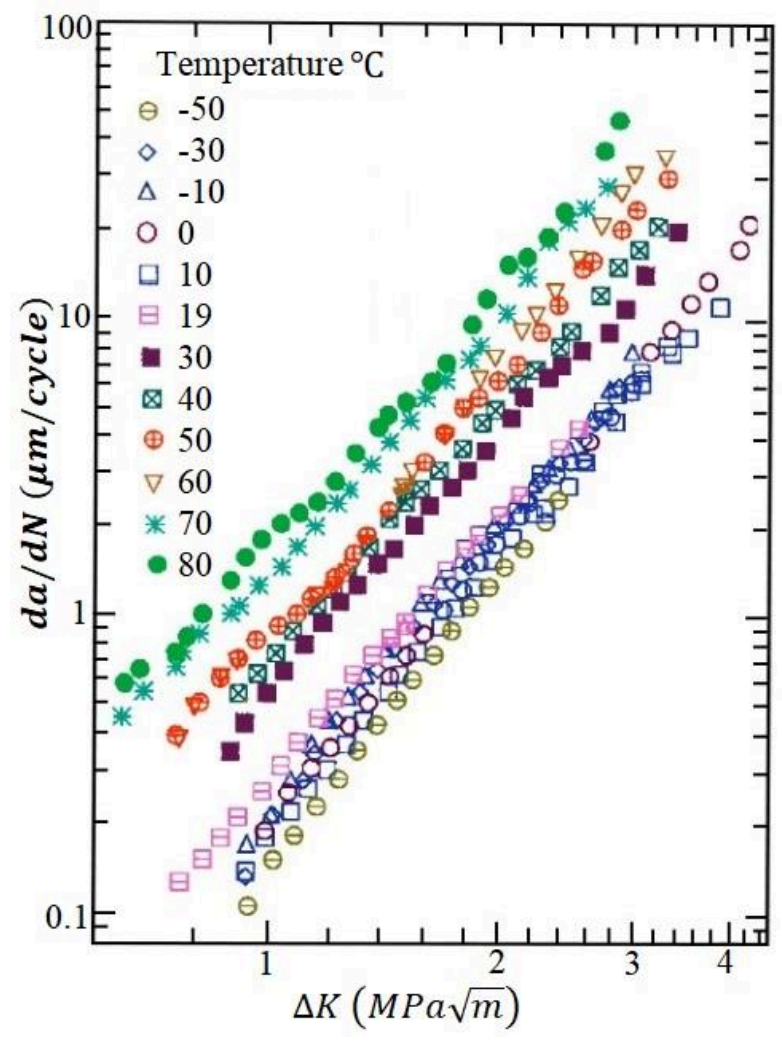

Figure 5-4 Effect of temperature to da/dN of ABS (replotted) $(70 \mathrm{~mm} * 120 \mathrm{~mm}$ SEN specimen, $5 \mathrm{~Hz}$ loading frequency, stress ratio $\mathbf{R}=\mathbf{0 . 1}$ )[65]

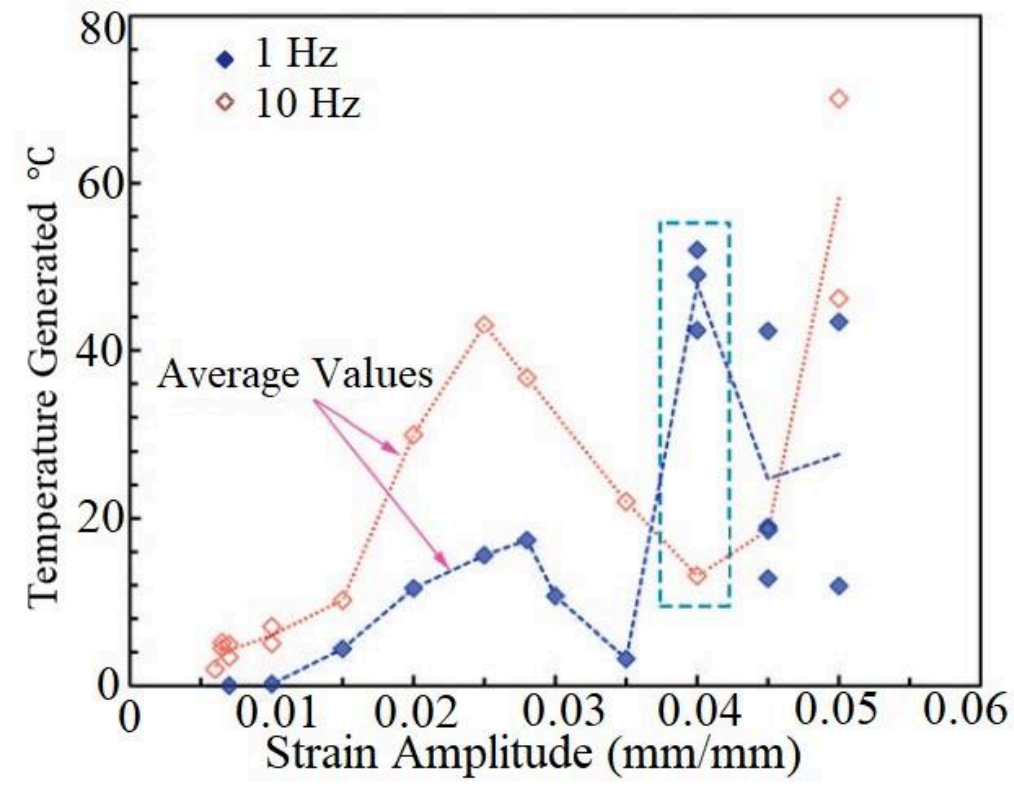

Figure 5-5 Self-heating effect in the test at $1 \mathrm{~Hz}$ and $10 \mathrm{~Hz}$ at corresponding strain amplitudes. (replotted) [66] 
Kuronuma et al. [67] presented the characterisation for crack propagation of the carbon nanotube (CNT)-based polymer applied with cyclic loads through a semi numerical semiexperimental approach. They performed the FCG test using cracked CNT/PC composites plate samples under room temperature/77 $\mathrm{K}$, respectively. The experimental data were represented by FCG rates da/dN with a similar Paris law form relationship (Equation 52),

$$
\frac{d a}{d N}=C(\Delta J)^{m}
$$

Where $\mathrm{C}$ and $\mathrm{m}$ are constant terms fitted according to the experimental data plot. $\mathrm{J}$ integral (strain energy release rate) range $\Delta J$ was determined by two-dimensional elastoplastic finite element analysis. da/dN curve is shown in Figure 5-6.

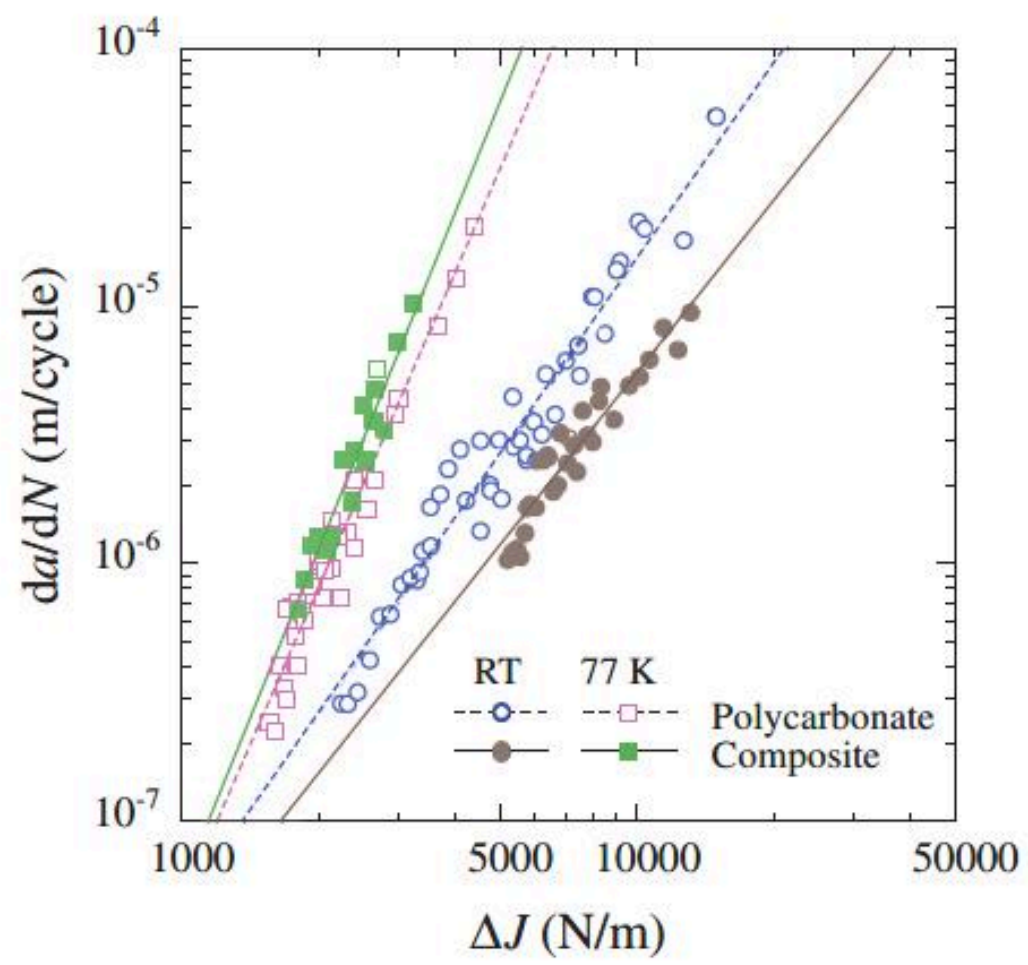

Figure 5-6 da/dN of $\mathrm{PC}$ at room temperature and $77 \mathrm{~K}$ (replotted) $($ load ratio $\mathrm{R}=0.1,3 \mathrm{~Hz}$ load frequency) ( [67] 
The crack growth relationships for a neat PC and a multi-walled nanotube /PC composite at room temperature were determined, as shown in Equation 5-3:

$$
\left\{\begin{array}{c}
\frac{d a}{d N}=1.26 \times 10^{-15}(\Delta J)^{2.52} \quad(P C) \\
\frac{d a}{d N}=6.38 \times 10^{-15}(\Delta J)^{2.23} \quad(\text { Composite })
\end{array}\right.
$$

The Paris law relationships for the $77 \mathrm{~K}$ data were estimated, as shown in Equation 5-4:

$$
\left\{\begin{array}{c}
\frac{d a}{d N}=3.22 \times 10^{-20}(\Delta J)^{4.06} \quad(P C) \\
\frac{d a}{d N}=4.73 \times 10^{-21}(\Delta J)^{4.35} \quad(\text { Composite })
\end{array}\right.
$$

Merah et al. investigated the crack growth in the weld zone of a CPVC pipe fitting with the consideration of temperature effect. They observed that the crack initiated on the knit line at one of the inner corners of the ring specimen. Following the initiation period, the crack grows first, in the axial (longitudinal) direction. As for the radial direction, small cracks were observed to initiate along the weld line before the main crack tip. These small cracks form in the craze zone that has lighter (whitened) colour. They also evaluated the influence of temperature on FCG behaviours, as shown by Figure 5-7. Craze zone surrounding the crack tip was longer at higher temperatures. Fewer secondary small cracks have been observed to initiate ahead and around the main crack tip for both $50^{\circ} \mathrm{C}$ and $70^{\circ} \mathrm{C}$ when compared with room temperature. It explained that the FCG resistance decreased under higher temperature. [68]

Some other research also investigated the heat generated from the craze zone during crack propagation [69-72]. Estevez et al. analysed the mode I crack of glassy polymers with the temperature influence. Their research proposed that the visco-plastic shear yielding and crazing generated the heat. It increased the temperature and affected the toughness of 
the material. Crazing was considered as the primary heat source, so the thermal effect due to high loading rates needs to be considered in future experiments.[73]

Chen and Liu also investigated the heat generation in the near-tip zone due to the crack growth for a PC film. They applied the thermal imaging infrared camera to record the temperature change in the moving crack tip, as shown in Figure 5-8. The experimental results indicated that the higher FCG rate increased the temperature at the crack tip. It might be a potential reason for the higher FCG rate in the specimen under high environmental temperature. [74]

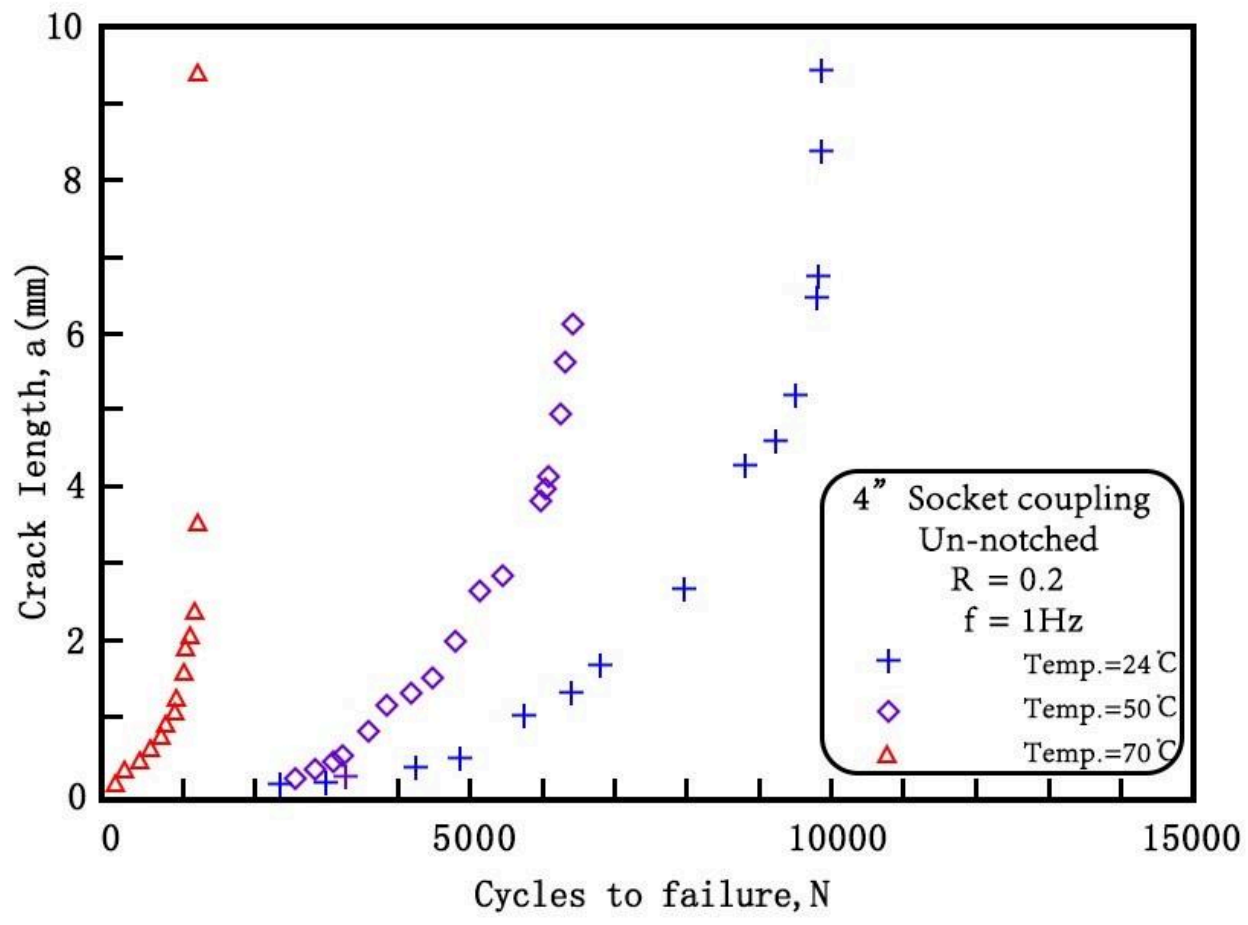

Figure 5-7 Temperature influence on FCG in CPVC fitting weld zone (replotted) [68] 


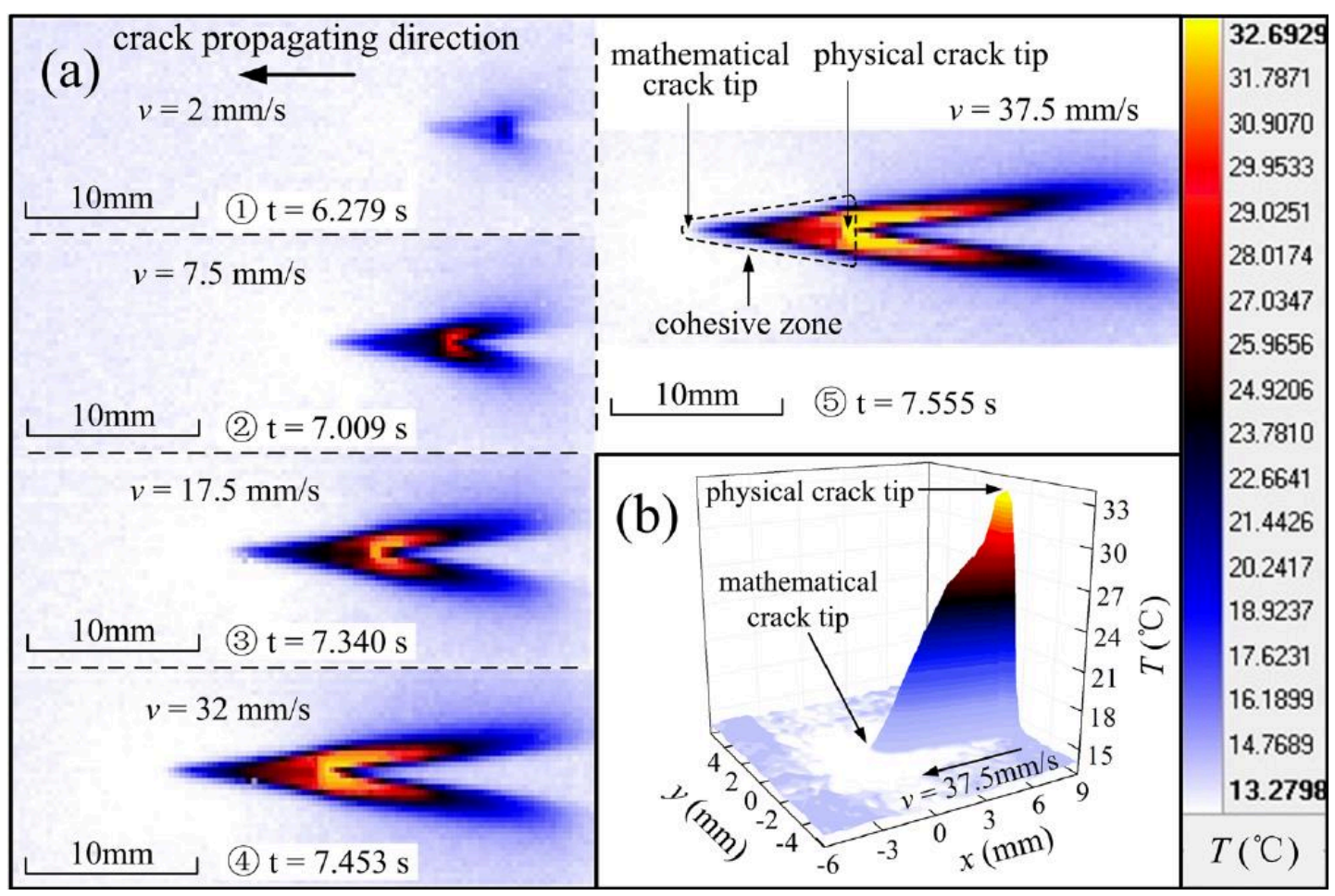

Figure 5-8 Contour map for the thermal distributions close to crack tip [74]

\subsection{Effects of Frequency of Applied Load on Crack Propagation}

Apart from the temperature influence, the load frequency also affects the FCG rate in polymers. A large amount of research investigated the relationship between them, as shown in Table 5-4.

Hertzberg, Manson and Skibo evaluated the frequency of applied load influence on the FCG rate of various polymers between a range from 0.1 to $100 \mathrm{~Hz}$. They proposed that the FCG rate declined and fatigue resistance remarkably increased with higher load frequency for PMMA, PS and PVC. On the other hand, PC, poly bisphenol-A sulfone (PSF), Nylon-66, and polyvinylidene fluoride (PVF2) exhibited a slight increase in FCG rate with an increase in test frequency [75-77]. The reason for it was due to the different Young's Modulus-frequency sensitivity for different polymers. 
Table 5-4 FCG Previous research for Polymers with Different Load Frequencies

\begin{tabular}{|c|c|c|c|c|}
\hline Testing Method & Material & Specimen Geometry & $\begin{array}{l}\text { Frequency } \\
\text { Range (Hz) }\end{array}$ & Authors/Year of study \\
\hline Tension FCG Test & PMMA/PVC/PS/PC/Nylon 66 & SEN Specimen & 0.1 to 100 & $\begin{array}{c}\text { Hertzberg, Manson and } \\
\text { Skibo (1975) }\end{array}$ \\
\hline Tension FCG Test & PC \& Nylon 66 & SEN Specimen & 0.3 to 10 & (Manson et al., 1975) \\
\hline $\begin{array}{c}\text { Tension-Compression FCG } \\
\text { Test } \\
\end{array}$ & $\begin{array}{c}\text { Poly Propene (PP) \& Polybutylene } \\
\text { terephthalate (PBT) }\end{array}$ & Dog Bone & 0.063 to 20 & $\begin{array}{l}\text { Radon and Culver } \\
\text { (1975) }\end{array}$ \\
\hline Tension FCG Test & Nylon 66 & CT Specimen & 1 to 50 & Hahn et al. (1982) \\
\hline Tension FCG Test & PMMA & SEN Specimen & 0.1 to 10 & Chou and Sun (1983) \\
\hline $\begin{array}{c}\text { Tension \& Compression } \\
\text { FCG Test }\end{array}$ & high-density polyethylene (HDPE) & $\begin{array}{l}\text { Centrally cracked } \\
\text { tension (CCT) } \\
\text { specimen } \\
\end{array}$ & 0 to 8 & $\begin{array}{l}\text { Dumpleton and } \\
\text { Bucknall (1987) }\end{array}$ \\
\hline Tension FCG Test & Nylon & CT Specimen & 0.1 to 5 & $\begin{array}{c}\text { WYZGOSKI, NOVAK } \\
\text { and SIMON (1990) }\end{array}$ \\
\hline $\begin{array}{c}\text { Tension \& Compression } \\
\text { FCG Test } \\
\end{array}$ & HDPE & CT Specimen & 0.01 to 1 & Parsons et al. (2000) \\
\hline $\begin{array}{c}\text { Tension FCG Test \& } \\
\text { Tension-Compression FCG } \\
\text { Test }\end{array}$ & PP Composite \& PA Composite & Dog Bone & 0.125 to 20 & $\begin{array}{l}\text { Eftekhari and Fatemi } \\
\text { (2016) }\end{array}$ \\
\hline Tension Fatigue Test & PEEK & Dog Bone & 0.25 to 2 & Shrestha et al. (2016) \\
\hline
\end{tabular}


Williams (1977) investigated the relationship between the FCG rate and the loading frequency based on semi-analytical methods. In their research, frequency effects in the crack growth were deduced from the viscoelastic mechanical properties of polymeric materials. Young's Modulus of polymers is time-dependent since the material is viscoelastic. Substituting the time-dependent $E$ into the expression of SIF with the crack opening displacement (COD), they proposed potential relationships, as shown in Equation 5-5,

$$
\frac{d a}{d N} \propto f^{n}
$$

Where $f$ is the load frequency, and $n$ is the coefficient. With this relationship, research modelled the FCG rate for PMMA, as shown in Equation 5-6.

$$
\frac{d a}{d N} \propto f^{-0.43} K_{\text {mean }}^{2.13} \Delta K^{2.39}
$$

The relationship fitted well by regression analysis with the experimental results [78].

Besides, some other research also carried out the experimental tests to investigate the frequency effect [79-87]. Ford et al. investigated the FCG mechanisms in PC polyurethane (PU), which is a potential material for the orthopaedic joint replacement application, with respect to frequency effects. The research observed that primary crack propagated along the two-dimension plane when load frequency was 2 or $5 \mathrm{~Hz}$ without strong crack deflection. However, $10 \mathrm{~Hz}$ load frequency led to a large deflection in the crack tip, and specimens occurred multiple crack fronts [88][89].

Hartwig and Knaak proposed an interesting explanation about the frequency influence on the FCG rate in polymers. They conducted the fatigue test at $77 \mathrm{~K}$. This low temperature 
eliminated the viscoelastic influence, so the load history and frequency did not affect mechanical deformations. However, tensile-compression loads still showed a significant dependency on frequency. The phenomenon may be caused by the thermal stresses resulted from self-heating of the samples [90].

\subsection{Effects of Temperature and Frequency combination on Crack}

\section{Growth}

Numerous researchers [91-94] investigated the dual influence of temperature and the frequency of applied load to FCG of structural polymers. Generally, the FCG rate increases at the higher temperature, but decreases under higher frequency load.

Radon and Culver $[95,96]$ investigated the crack propagation in PMMA and PC under different temperatures from -60 to $21{ }^{\circ} \mathrm{C}$ at 0.1 to $100 \mathrm{~Hz}$ load frequency range. They concluded that the FCG rate was positively related to environmental temperature but had a negative correlation with load frequency in the evaluated range. The FCG rates increased distinctly when the temperature rose from $-60{ }^{\circ} \mathrm{C}$ to $27^{\circ} \mathrm{C}$. This increasing percentage was up to $60 \%$ and $90 \%$ for PC and PMMA, respectively. The effect of load frequency on crack propagation was extremely slow at higher values of frequency and reduced by one order of magnitude when increasing load frequency from 5 to $100 \mathrm{~Hz}$.

Cheng et al. conducted experiments to evaluate the FCG in PMMA. They investigated how temperature and cyclic frequency affected FCG rate. The test was carried out with the frequencies of $1 / 10 / 50 / 100 \mathrm{~Hz}$ under the environmental temperature range between $30{ }^{\circ} \mathrm{C}$ and $100{ }^{\circ} \mathrm{C}$. Compared with Radon and Culver's research, one exception was reported that the FCG rate increased with frequency increase at high temperature. The 
reason for the exception was that hysteretic heating at a higher temperature area softened the material and led to larger chain mobility, which accelerating the FCG rate[97].

Kim and Wang [98] investigated the effect of temperature and load frequency on FCG rate. They developed an FCG rate model for estimating the function between FCG rate, temperature and frequency, as shown in Equation 5-7,

$$
\frac{d a}{d N}=f^{-n m} C e^{-\frac{\Delta H_{t h}-\gamma \log \Delta K}{R T}}
$$

Equation 4-7 represents the coupled influences of frequency and temperature on the FCG rate. They validated the Equation 4-7 on un-plasticised polyvinyl chloride (uPVC) and calculated the FCG rate under various temperatures and frequencies.

Moreover, they [99] modelled temperature and load frequency influence on crack growth in ABS empirically. The FCG tests were conducted at $10^{\circ} \mathrm{C}$ to $70^{\circ} \mathrm{C}$ temperature range with 0.01 to $10 \mathrm{~Hz}$ frequency. Results are shown in Table 5-5 and Figure 5-9. They indicated that higher frequency reduced FCG rates at all temperature ranges. Although either temperature or frequency can affect the crack propagation, the influence of frequency on $\mathrm{FCG}$ rate in $10{ }^{\circ} \mathrm{C}$ did not appear to be as critical as at elevated temperature.

Table 5-5 Paris law parameters $A$ and $m$ of $\mathrm{ABS}(\mathrm{da} / \mathrm{dN}$ in $\mu \mathrm{m} / \mathrm{cycle}, \Delta \mathrm{K}$ in $\mathrm{MPa} \sqrt{\mathrm{m}})$ [99]

\begin{tabular}{|c|c|c|c|}
\hline Frequency $(\mathrm{Hz})$ & Temperature $\left({ }^{\circ} \mathrm{C}\right)$ & $A$ & $m$ \\
\hline \multirow{2}{*}{0.01} & 50 & 2.301 & 2.94 \\
\hline \multirow{3}{*}{0.1} & 30 & 0.934 & 3.13 \\
\cline { 2 - 4 } & 50 & 1.583 & 2.79 \\
\cline { 2 - 4 } & 70 & 2.280 & 2.79 \\
\hline \multirow{3}{*}{1} & 30 & 0.552 & 3.05 \\
\cline { 2 - 4 } & 50 & 0.990 & 3.06 \\
\hline
\end{tabular}




\begin{tabular}{|c|c|c|c|}
\hline & 70 & 1.422 & 3.01 \\
\hline \multirow{3}{*}{10} & 30 & 0.390 & 3.14 \\
\cline { 2 - 4 } & 50 & 0.598 & 3.07 \\
\cline { 2 - 4 } & 70 & 0.890 & 2.98 \\
\hline
\end{tabular}

Apart from the external environmental temperature, some research also mentioned the temperature change due to high-frequency vibration might also affect the crack growth rate [100]. Qi et al. tested the crack propagation in HDPE, which was used in the automotive industry, with the different loading frequencies. Their research showed that temperature increased in the test. Higher loading frequency led to more significant temperature change, as shown in Figure 5-10. This increased temperature also affected the crack growth rate in HDPE. This research pointed out that the experimental tests for crack growth in polymers had to consider the non-independent interaction between the load frequency and temperature. [101]
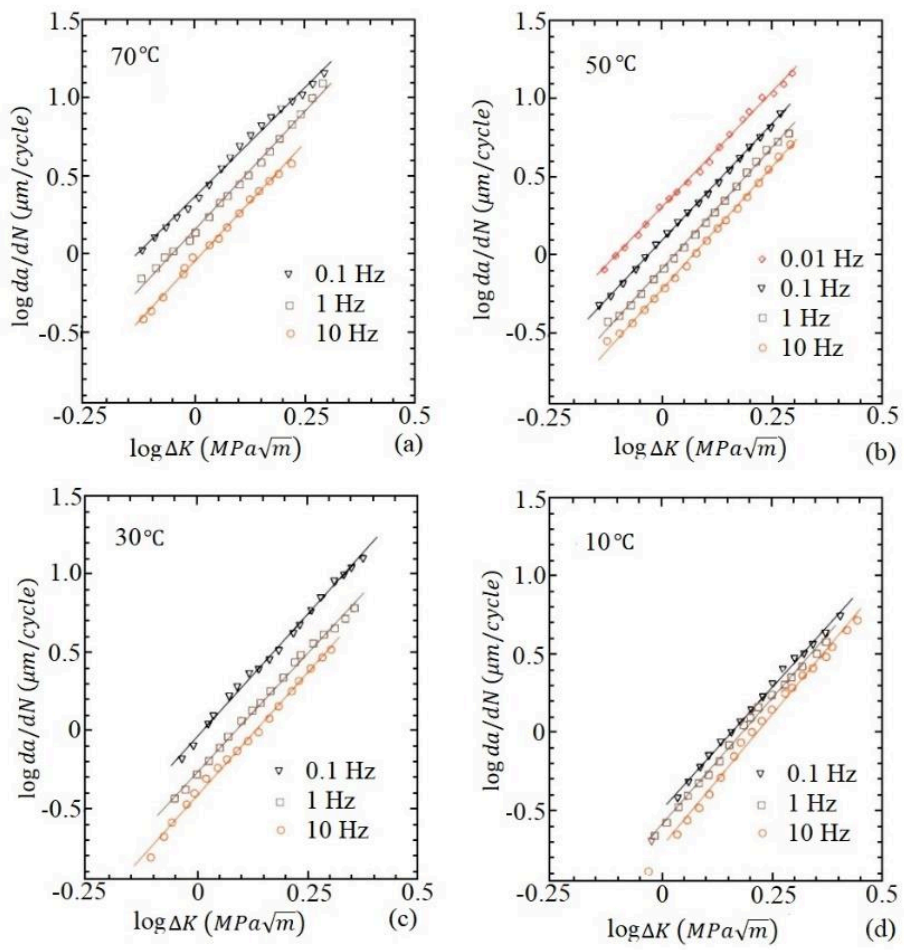

Figure 5-9 FCG rates of ABS at different frequencies and temperatures (replotted) [99] 


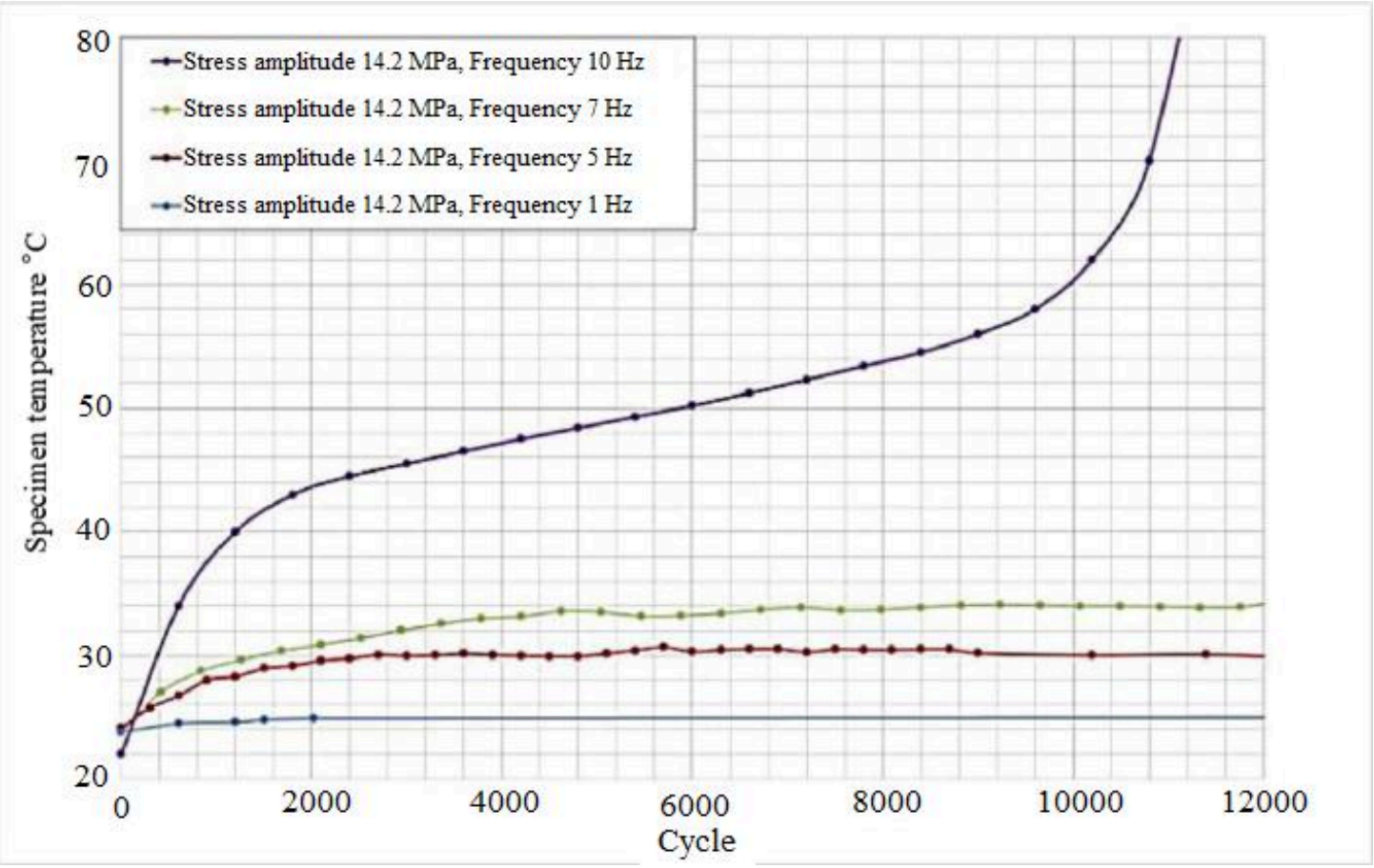

Figure 5-10 Frequency effect on the temperature of the specimen under the same stresses during whole fatigue life [101]

\subsection{Critical Observations about Crack Propagation under Thermo- mechanical Loads}

Most research concluded that higher temperature and lower load frequency increased the FCG rate. The micro molecular behaviour of polymers, including chain repetition and disentanglement, are easier and more frequent at higher temperatures [98]. This chain slippage (Shown in Figure 5-11) is proposed to be the primary molecular motion that causes fatigue failure of the polymer. Therefore, a higher temperature reduced fatigue resistance. It is considered as the reason for the higher FCG rate at elevated temperature. 


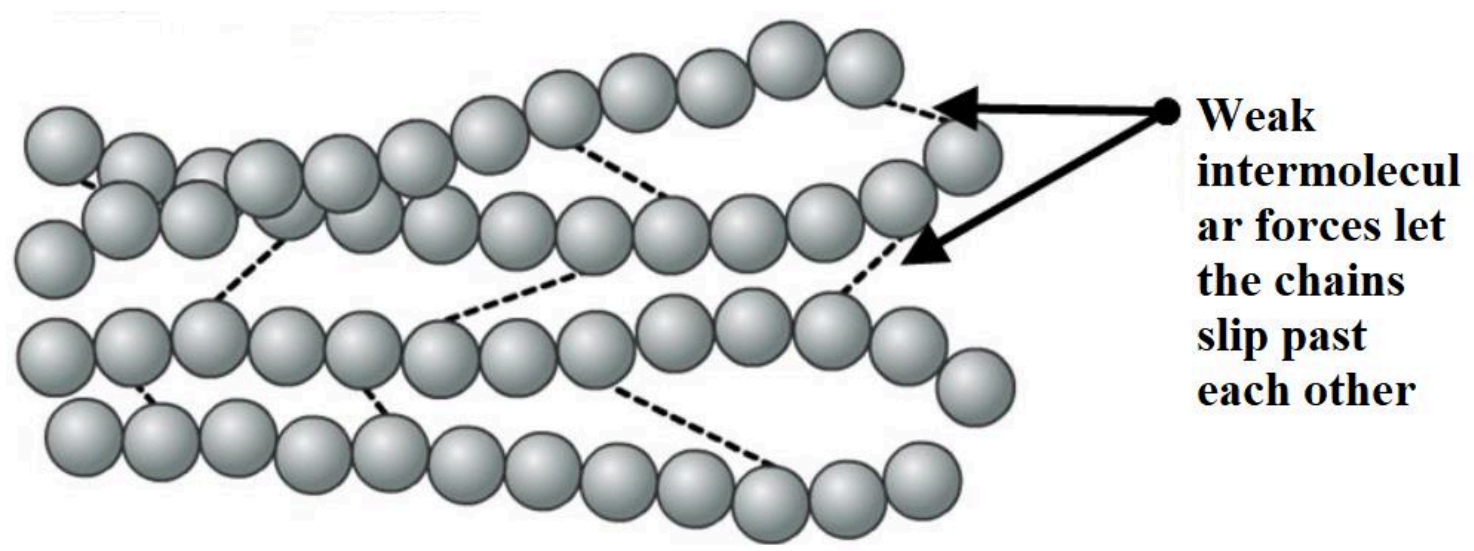

Figure 5-11 Chain slippage in thermoplastic polymers

On the contrary, higher load frequency leads to the stiffer physical state of polymeric structures. It lowers the trend of chain slippage. So FCG rate decreases when applied higher frequency load.

The above research all focused on the cyclic mechanical/thermo-mechanical loads and proposed some conclusions. However, their loads' conditions were all static/quasi-static. The investigation under dynamic loads is still missing. This dynamic load condition means the stress amplitude, environmental temperature and load frequency are timedependent. The research effort needs further study focusing on these time-variable conditions.

\section{Other Factors Affecting Crack Propagation}

Apart from the temperature and load frequency, some other parameters may also influence the rate of crack growth [102-106]. As discussed above, Fang, Wang and Li researched the effect of overloading condition to FCG rate [29]. Similarly, Zhang et al. [107] investigated how compressive loads changed the stress condition at the crack tip and how it affected the FCG rate. Compared with the standard tensile test, the crack growth in the compression-tensile test was more complicated. They proposed that 
maximum stress intensity and compressive stress determined these local crack tip parameters. They presented the modified crack growth model with this conclusion, shown in Equation 6-1. $C, \alpha, \beta$ and $\gamma$ are material constants. $\sigma_{\text {maxcom }}$ is maximum applied compressive stress, $\sigma_{y s}$ is material's yield stress.

$$
\frac{d a}{d N}=C\left[1-\gamma\left(\frac{\sigma_{\operatorname{maxcom}}}{\sigma_{y s}}\right)\right]^{\beta}\left(K_{\max }\right)^{2(\alpha+\beta+1)}
$$

On the other hand, polymeric structural properties can also affect the crack growth rate. Baker, Hastings and Pruitt experimentally investigated the effect of morphology, sterilisation, ageing and temperature in the polymer manufacturing process on the crack propagation behaviour of UHMWPE [108]. Shah et al. evaluated the effect of the structural geometry on crack initiation and growth in polymers [109-111]. The research cut a non-standard specimen from the polyethene (PE) pipe and compared it with the standard CT specimen. Test results demonstrated that crack propagation behaviour in the non-standard specimen, which conserved the pipe geometry could be well replicated using the standard compact tension specimen. Pruitt and Bailey evaluated the influence of manufacturing methods on the FCG rate of UHMWPE [112]. They considered two methods: compression moulding and ram extrusion. They concluded that the parts with a notch direction parallel to the extrusion had lower fatigue threshold.

The above-described reviews are focused on conventional fabricated polymeric structures. The mechanics of crack propagation becomes more complicated if these structures are developed by using additive manufacturing such as 3D printing because different manufacturing methods cause different micro-structures. Several parameters can 
influence the crack growth rate in printed polymers. Therefore, the next section will discuss the crack propagation in printed polymeric structures.

\section{Crack Propagation of 3D printed Polymers}

A very few studies related to the crack growth under the mechanical loads are reported for printed polymeric structures. Authors have found no comprehensive research emphasised the crack propagation, especially in fused deposition (FD) based printed polymers under thermo-mechanical loads. Most of the available literature discussed the fatigue test of FD polymers with an emphasis on printing parameters and their influence on fatigue life. Therefore, Authors have reviewed the studies related to fatigue life and the influence of printing parameters on it.

\subsection{Effect of 3D Parameters to Mechanical Behaviours of FDM}

\section{Polymer}

Mechanical properties of the structure have the relationship to the FCG rate at the microstructure scale [11]. The printing parameters directly affect the microstructural characteristics and thus change the mechanical properties in 3D printed polymers, and hence these parameters also influence the crack growth rate. Therefore, Comprehensive literature in the past has discussed the influence of 3D printing parameters on mechanical behaviours of polymeric materials, such as Young's Modulus and tensile strength [113120]. These researchers investigated the relation between printing parameters and static mechanical properties. They optimised the parameters to improve structural Tensile Modulus, thereby increase the fracture toughness of FDM polymers. 
Popescu et al. presented the comprehensive and systematic review of how FDM process parameters affect the mechanical behaviours of structures. Most past studies focused on ABS, PLA and PEEK material [121].

Rodriguez, Thomas and Renaud determined the mechanical behaviours of FD ABS plastic material through experimental study. The test results showed that the modulus of FD-ABS specimen was reduced by $11 \%$ to $37 \%$, and the strength is reduced by $22 \%$ to 57\% compared with ABS filament. The reason for it was 'the existing voids and loss of molecular orientation due to FD extrusion' [122]. Moreover, they proposed the analytical model for the mechanical behaviours of the resulting parts fabricated with ABS material. They proposed that the anisotropy of the structure affected the stiffness and strength. The research employed the mechanics of material and homogenisation approaches, respectively to build the constitutive model and then predict properties of unidirectional FD-ABS materials. However, the model tended to over-predict the modulus than the actual data. Because the mechanical properties of ABS thermoplastic changed during the FDM process. [123].

Bellini and Güçeri proposed a method [124] to calculate the stiffness matrix for a component fabricated with FDM technique. ABS specimens were experimentally tested in their study. There were nine independent constants in the proposed semi-analytical model. It is essential to identify them to define the mechanical properties of an orthotropic part. Experimental tests were carried out for the identification. So six different specimens with different orientations were tested. The research proposed the mechanical properties of the final components were considerably related to two crucial modelling phases: the printing directions and path [125]. Figure 7-1 showed two modes of building path. 


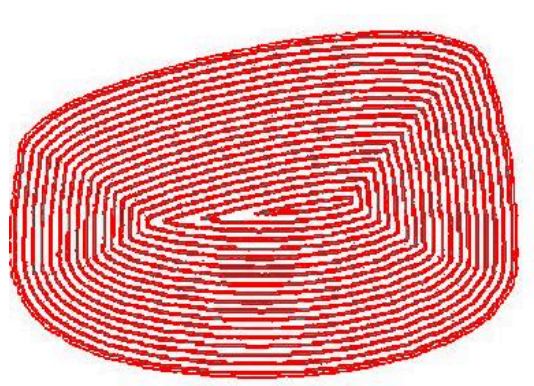

(a)

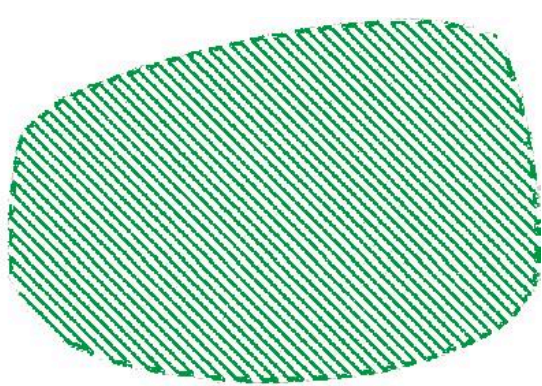

(b)

Figure 7-1 Different building path [125]

Schirmeister et al. modified several FDM parameters including nozzle and support platform temperature, nozzle diameter, extrusion rate and support platform material for improving not only the comprehensive mechanical behaviours but also the surface quality of HDPE. They proposed that either nozzle diameter or printing speed is related to the surface quality without affecting mechanical behaviours due to the outstanding fusion of the polymer filament [126].

\subsection{Effect of 3D Parameters to Crack Propagation of FD Printed}

\section{Polymer}

Although research in Section 6.1 has shown that various 3D printing parameters lead to different mechanical properties. However, only a handful amount of investigations have discussed the relationships between these parameters and crack propagation. Zhang et al. [127] evaluated the creep-fatigue behaviours of ABS specimens through experiments. They systematically characterised the modulus of FDM ABS specimens with specifically considering building orientation. Results showed that the $0^{\circ}$ building orientation had the most excellent mechanical behaviours. Young's modulus was improved to $1.81 \mathrm{GPa}$ while ultimate strength reached $224 \mathrm{MPa}$. 
Ali heidari et al. [128] applied the fracture mechanics to characterise the fracture toughness of FDM ABS specimens with the consideration of nozzle and support plate temperatures. A numerical model determined the J-integral as a measure of the fracture toughness. Their results showed that both higher nozzle and plate temperature led to the larger actual fracture surface area and improved the fracture toughness.

Isaac and Tippur [129] applied the quasi-static and impact fracture tests for FDM ABS specimens with the specific interest to the role of two different print architectures orientations. The test results showed that crack propagated and grew along the printing orientations. Rabbi and Chalivendra [130] did similar work. They carried out the impact test to evaluate the time-dependent fracture of an AM ABS specimen with the consideration of building orientations. Specimens were printed horizontally or vertically. It meant that the printing layer was parallel or perpendicular to the initiated crack, respectively. There were also two raster orientations, $\pm 45^{\circ}$ and $0 / 90^{\circ}$. With the test data, accurate fracture initiation load was determined and derived the dynamic crack initiation resistance. They concluded that dynamic crack initiation resistance was improved by $138 \%$ for a vertical printed specimen compared with horizontal printed one with $0 / 90^{\circ}$ raster orientation. They also presented a dynamic SIF Equation 7-1, which is suitable for all linear elastic specimens if their crack initiation times are long enough.

$$
K_{I D}=\frac{F(t)}{B \sqrt{H}} f\left(\frac{a}{H}\right)
$$

Where $\mathrm{F}(\mathrm{t})$ is the applied load, while $B, H$ and $a$ are the specimen width, height, and precrack length, respectively. 
The above research developed the relation between printing orientations and fracture resistance. However, some other research had different conclusions. One research proposed that $0^{\circ}$ raster orientation has the highest fracture toughness. However, another research pointed out that the printing orientation, which is perpendicular to the pre-crack, can increase the fracture toughness because of the anisotropic mechanical properties of polymeric materials.

\subsection{Effect of 3D Parameters to Fatigue Life of FDM Polymer}

Few numbers of research focused on the FCG rate of 3D printed polymers as shown in Section 5.2. However, comprehensive research is available on how $3 \mathrm{D}$ printing parameters affect the fatigue behaviour. This section provides a critical review of the previous efforts investigating the relation between the 3D printing parameters and fatigue life of the polymeric structure, as shown in Table 7-1.

Jap et al. investigated the fatigue strength for dog-bone specimens of FDM ABS using the cyclic tensile test. They listed the potential factors in Figure 7-2 that may affect fatigue strength and proposed that raster orientation was a critical parameter related to the tensile strength. Because 'the strength of the bonds between adjacent raster and layers' significantly influenced the mechanical behaviours of the components manufactured by FDM at the micro-molecular level. The structural density also had a strong effect on its mechanical behaviours, while voids in components critically reduced the eff ective crosssection area where were taken the stress [131]. 
Table 7-1 Research about the Effect of 3D Printing Parameters to Fatigue Life

\begin{tabular}{|c|c|c|c|c|}
\hline Test Method & Material & $\begin{array}{l}\text { 3D Printing } \\
\text { Parameters }\end{array}$ & Authors/Year of study & Key Findings \\
\hline Tension Fatigue & ABS & Build Orientation & $\begin{array}{l}\text { Ziemian, Sharma and } \\
\text { Ziemian (2012) }\end{array}$ & $\begin{array}{c}\text { The } \pm 45^{\circ} \text { fiber orientation provided the } \\
\text { longest fatigue life }\end{array}$ \\
\hline $\begin{array}{l}\text { Tension - Zero } \\
\text { Fatigue }\end{array}$ & ABS & Build Orientation & Lee and Huang (2013) & $\begin{array}{c}\text { The vertical } 45^{\circ} \text { printing orientation had the } \\
\text { best ultimate stress }\end{array}$ \\
\hline Tension Fatigue & $\begin{array}{l}\text { Polylactic acid } \\
\text { (PLA) }\end{array}$ & Build Orientation & Afrose et al. (2014) & $\begin{array}{l}\text { X-build orientation had the highest tensile } \\
\text { stress }\end{array}$ \\
\hline $\begin{array}{c}\text { Tension- } \\
\text { Compression } \\
\text { Fatigue } \\
\end{array}$ & PLA & Build Orientation & $\begin{array}{c}\text { Letcher and } \\
\text { Waytashek (2014) }\end{array}$ & $\begin{array}{l}90^{\circ} \text { raster orientation had the worst fatigue } \\
\text { life }\end{array}$ \\
\hline Tension Fatigue & ABS & Build Orientation & $\begin{array}{l}\text { Ziemian, Okwara and } \\
\text { Ziemian (2015) }\end{array}$ & $\begin{array}{l}\text { Both } 0^{\circ} \text { and }+45^{\circ} /-45^{\circ} \text { raster orientations } \\
\text { had better fatigue life }\end{array}$ \\
\hline Tension Fatigue & PLA & Build Orientation & Afrose et al. (2015) & $\begin{array}{l}45^{\circ} \text { build orientation showed the highest } \\
\text { fatigue life }\end{array}$ \\
\hline Tension Fatigue & ABS & Build Orientation & $\begin{array}{c}\text { Ziemian, Ziemian and } \\
\text { Haile (2016) }\end{array}$ & $0^{\circ}$ fiber orientation had the best fatigue life \\
\hline Tension Fatigue & Ultem 9085 & Build Orientation & $\begin{array}{l}\text { Fischer and Schöppner } \\
\text { (2017) }\end{array}$ & $\mathrm{Z}$ build orientation had the best fatigue life \\
\hline
\end{tabular}




\begin{tabular}{|c|c|c|c|c|}
\hline Bending Fracture & $\mathrm{ABS}$ & $\begin{array}{c}\text { Crack-tip/laminae } \\
\text { Orientations }\end{array}$ & $\begin{array}{l}\text { Hart and Wetzel } \\
\text { (2017) }\end{array}$ & $\begin{array}{l}90^{\circ} \text { laminae orientation had the highest } \\
\text { fracture toughness }\end{array}$ \\
\hline Rotation Fatigue & PLA & $\begin{array}{c}\text { Layer Height } \\
\text { Fill Density } \\
\text { Extruder Diameter } \\
\text { Printing Speed }\end{array}$ & $\begin{array}{l}\text { Jerez-Mesa et al. } \\
\qquad(2017) \\
\text { Gomez-gras et al. } \\
\text { (2018) }\end{array}$ & $\begin{array}{c}75 \% \text { infill, } 0.5 \mathrm{~mm} \text { nozzle diameter, } 0.3 \mathrm{~mm} \\
\text { layer height provided optimal resistance to } \\
\text { fatigue }\end{array}$ \\
\hline $\begin{array}{l}\text { Tension - Zero } \\
\text { Fatigue }\end{array}$ & $\begin{array}{l}\text { Polycarbonate } \\
\text { urethane (PCUs) }\end{array}$ & $\begin{array}{l}\text { Printing Speeds } \\
\text { Extrusion } \\
\text { Multipliers }\end{array}$ & Miller et al. (2017) & $\begin{array}{l}\text { Increased PCU hard segment content leads } \\
\text { to higher fatigue life }\end{array}$ \\
\hline Tension Fatigue & PCUs & $\begin{array}{c}\text { Printed } \\
\text { Architecture }\end{array}$ & Miller et al. (2017) & Solid architecture had the best fatigue life \\
\hline Tension Fatigue & ABS & $\begin{array}{l}\text { Build Orientation } \\
\text { Extruder } \\
\text { Temperature } \\
\text { Printing Speed } \\
\text { Layer Height }\end{array}$ & Abbott et al. (2018) & $\begin{array}{l}\text { XY building orientation provided the } \\
\text { highest tensile strength } \\
\text { Increasing print speed decreased the tensile } \\
\text { strength } \\
\text { The increasing temperature increased tensile } \\
\text { strength }\end{array}$ \\
\hline Compact Tension & PLA & Build Orientation & Arbeiter et al. (2018) & Three orientations were almost identical \\
\hline Flexural Fatigue & $\mathrm{PC}$ & Build Orientation & $\begin{array}{l}\text { Puigoriol-forcada et al. } \\
\text { (2018) }\end{array}$ & $\begin{array}{l}\mathrm{YZ} \text { orientation provided the longest fatigue } \\
\text { life }\end{array}$ \\
\hline
\end{tabular}




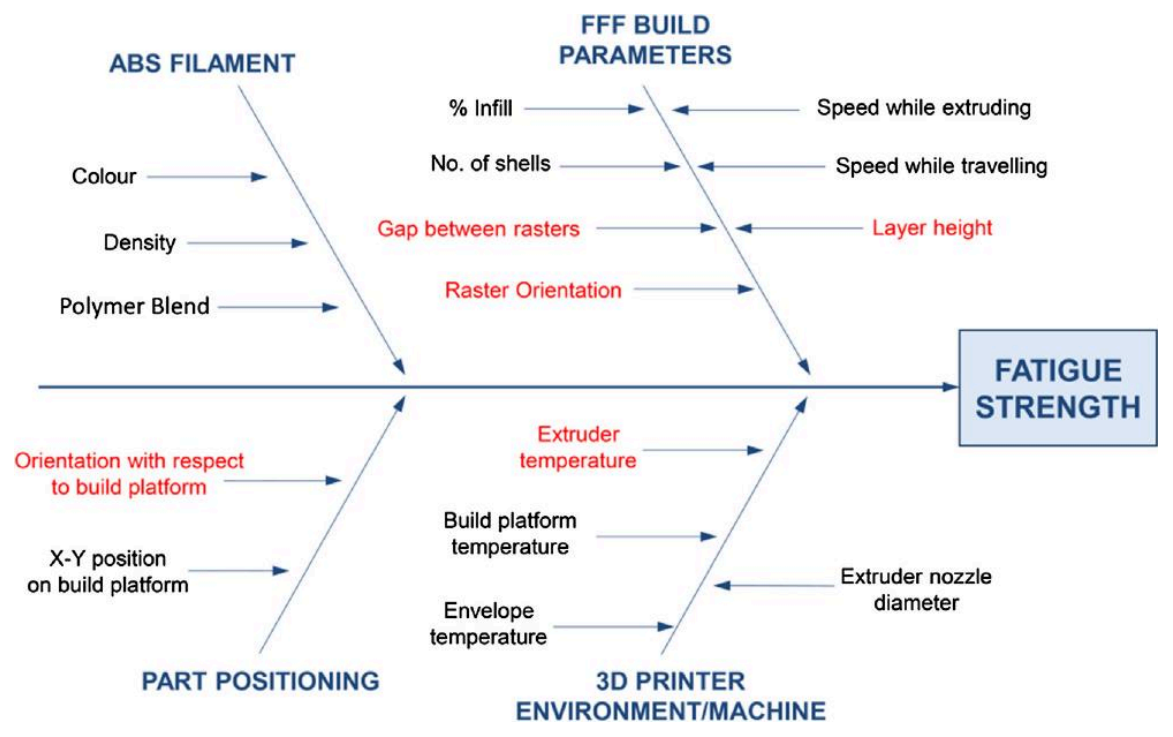

Figure 7-2 Influence parameters to fatigue strength [131]

Imeri et al. [132] investigated the fatigue performance of fibre-reinforced AM nylon structures through tensile tests. They analysed how fibre orientations, infill types, and fibre materials (carbon fibre, Kevlar and Fiberglass) affected the fatigue life. They concluded that the configurations including "isotropic" infill carbon fibre provided the specimen with the highest fracture resistance. Rybachuk et al. [133] researched the anisotropic mechanical behaviours of FDM ABS specimens. They also evaluated the influence of infill orientations on the modulus/strength of structure under tensile and compression loads. They pointed out that infill orientation aligning to the vertical axis gave the specimen the best mechanical properties compared with other configurations. The reason for it was that the direction of the infill layers was perpendicular to the applied load. It allowed layers to unravel individually when applied the load. Suresh et al. modelled the relations between the build orientations and fatigue life. They used Veroclear polymer components with an inherent anisotropy by controlling the printing build orientation parameter. They performed tensile and tensile-tensile fatigue cycle tests to evaluate the difference between parallel and perpendicular building orientations. The 
results showed that parallel building orientation provided higher strength and longer fatigue life, as shown in Figure 7-3. The reason for this is because the crack direction and applied stress in the parallel printed specimen can accelerate the FCG rate more compared with the perpendicular printed specimen. Perpendicular printed specimens showed the crack branching and fibre pull out, which led to the slower crack propagation. [134]

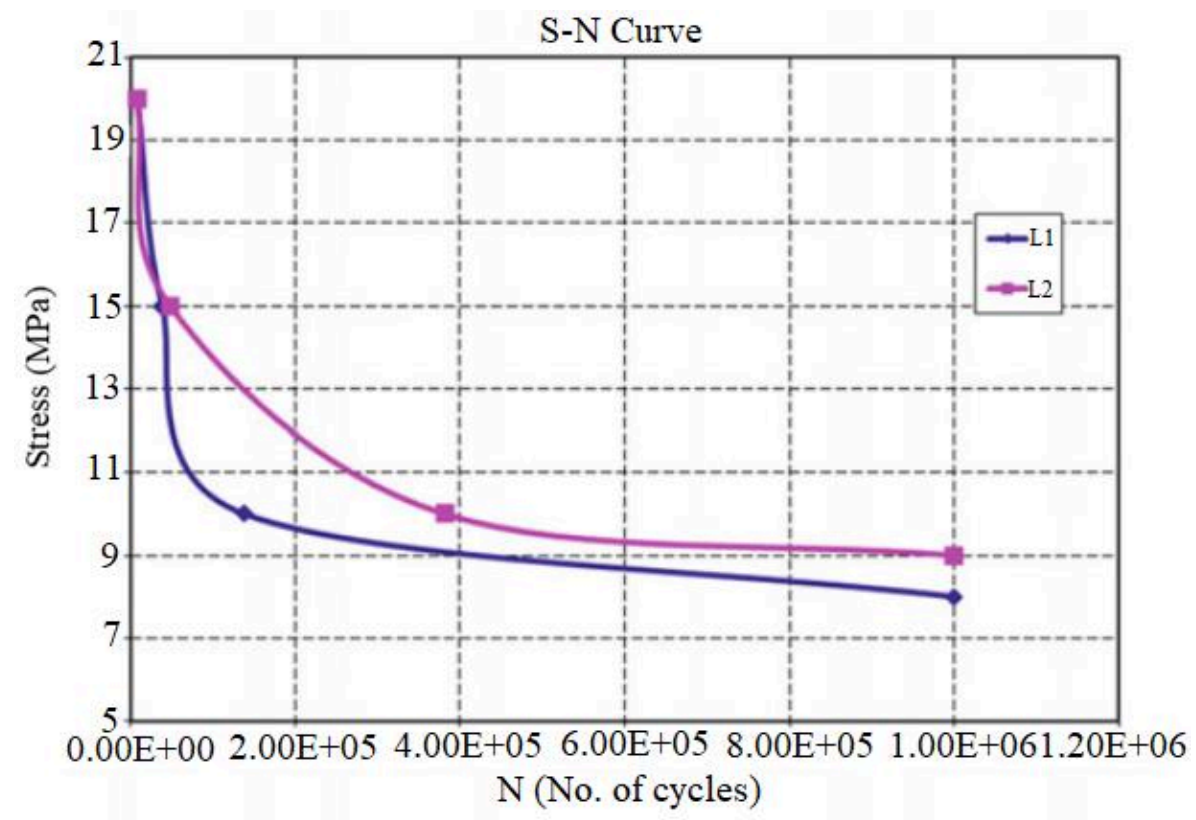

Figure 7-3 Fatigue life of the structures with different build orientation (L1: parallel oriented; L2: perpendicular orientation) [134]

Afrose et al. [135] analysed the relations between the structural building orientations and fatigue life of FDM PLA specimen. The dog-bone parts were fabricated with the consideration of three $\left(0^{\circ}, 90^{\circ}\right.$ and $\left.45^{\circ}\right)$ different building orientations and tested under 50 to $80 \%$ nominal values of cyclic ultimate tensile stress. They concluded that the specimen with $0^{\circ}$ build orientation had the highest tensile stress and $45^{\circ}$ build orientation had the longest fatigue life. 


\section{Conclusion}

Comprehensive reviews are reported with a focus on research efforts for crack propagation of polymers under thermo-mechanical loads. During the review, the paper summarised that higher temperature and slower load frequency could increase the FCG rates in most of the polymeric structures. However, there are still some research gaps and potential research topics.

Most research efforts have ignored a fundamental problem with SIF. SIF is a parameter based on static stress derivation, so it is suitable as a criterion to judge the fracture of the structure under static failure stress. However, most studies used the maximum and minimum value difference in cyclic stress to represent the continuous state of stress change in the cycle. The SIF range $\Delta K$ applied in Paris Law even though loads were varied with time. Realistically, the loads are even far from being cyclic in real load conditions, i.e. dynamic and/or stochastic. It is essential for overcoming this problem to convert the dynamic stress to cyclic condition if one has to use SIF in future research. However, the conversion from the dynamic load history to a cyclic load sequence also significantly modifies the real load impact. This conversion affects the calculation of the FCG rate and concludes that the existing formulation is far from accurate due to their quasi-static remote stress assumption. Therefore, the future work can focus on a real time derivative crack growth equation rather than Paris Law for accurate calculations.

A large amount of research proposes the empirical relations between the FCG rate and stresses for some polymers. However, future work still needs an analytical investigation that can truly represent the crack growth behaviour of polymers under thermo-mechanical loads. A few efforts reported their empirical findings of the crack growth rate under 
different values of temperature on a range of frequency of the applied load. However, they all have tested the structures under tension. Therefore, future research can consider experimental conditions under bending loads, which is also a very common and practical working condition.

There is a considerable research gap about the crack growth in FD printed polymers even though FDM is developed rapidly. Existing research on these polymers are mostly empirical. It evaluated the mechanical performance of FD printed polymer under quasistatic loads and concluded the factors which can affect mechanical properties. So future research can carry out various fatigue test to analyse how 3D printing parameters can affect the fatigue life of printed polymeric structures. Furthermore, no one has provided a comprehensive discussion to introduce the exact crack propagation or growth in such structures. No one has reported the work about the influence of the parameters on the FCG rate in printed polymers. In the future, comprehensive research will be required to investigate the effects of coupled thermo-mechanical loads on crack propagation in $3 \mathrm{D}$ printing polymeric structures.

\section{REFERENCES}

[1] R.S. Stein, Polymer science and engineering: The shifting research frontiers, J. $\begin{array}{lllll}\text { Polym. } & \text { Sci. Part }\end{array}$ https://doi.org/10.1002/pola.1994.080321626.

[2] S. Odahara, Mechanical Strength Properties of Wind-Lens Blades, Nihon Kikai Gakkai Ronbunshu, A Hen/Transactions Japan Soc. Mech. Eng. Part A. 78 (2012) $244-248$.

[3] F. Ning, W. Cong, J. Qiu, J. Wei, S. Wang, Additive manufacturing of carbon fiber 
reinforced thermoplastic composites using fused deposition modeling, Compos. $\begin{array}{lllll}\text { Part } & \mathrm{B} & \text { Eng. } & 80 & \text { (2015) }\end{array}$ https://doi.org/10.1016/j.compositesb.2015.06.013.

[4] W. Gao, Y. Zhang, D. Ramanujan, K. Ramani, Y. Chen, C.B. Williams, C.C.L. Wang, Y.C. Shin, S. Zhang, P.D. Zavattieri, The status, challenges, and future of additive manufacturing in engineering, CAD Comput. Aided Des. 69 (2015) 6589. https://doi.org/10.1016/j.cad.2015.04.001.

[5] I. Zein, D.W. Hutmacher, K.C. Tan, S.H. Teoh, Fused deposition modeling of novel scaffold architectures for tissue engineering applications, Biomaterials. 23 (2002) 1169-1185. https://doi.org/10.1016/S0142-9612(01)00232-0.

[6] J. Long, H. Gholizadeh, J. Lu, A. Seyfoddin, Review: Application of Fused Deposition Modelling (FDM) Method of 3D Printing in Drug Delivery, Curr. Pharm. Des. 23 (2017) 433-439. https://doi.org/10.2174/13816128226661610261.

[7] S.J. Leigh, R.J. Bradley, C.P. Purssell, D.R. Billson, D.A. Hutchins, A Simple, Low-Cost Conductive Composite Material for 3D Printing of Electronic Sensors, PLoS One. 7 (2012) 1-6. https://doi.org/10.1371/journal.pone.0049365.

[8] M. Naebe, M.M. Abolhasani, H. Khayyam, A. Amini, B. Fox, Crack damage in polymers and composites: A review, Polym. Rev. 56 (2016) 31-69. https://doi.org/10.1080/15583724.2015.1078352.

[9] A.A. Baker, R. Jones, R.J. Callinan, Damage tolerance of graphite/epoxy composites, Compos. Struct. 4 (1985) 15-44. https://doi.org/10.1016/02638223(85)90018-2.

[10] F. He, M.A. Khan, B.A. Zai, Material mechanics of crack growth in structural 
$\begin{array}{llllll}\text { dynamics, } & \text { Procedia } & \text { Struct. } & \text { Integr. } & 17 & \text { (2019) }\end{array}$ https://doi.org/10.1016/j.prostr.2019.08.011.

[11] L. Safai, J.S. Cuellar, G. Smit, A.A. Zadpoor, A review of the fatigue behavior of 3D printed polymers, Addit. Manuf. $28 \quad$ (2019) 87-97. https://doi.org/10.1016/j.addma.2019.03.023.

[12] A.L. Andrady, M.A. Neal, Applications and societal benefits of plastics, Philos. Trans. R. Soc. B Biol. Sci. 364 (2009) 1977-1984. https://doi.org/10.1098/rstb.2008.0304.

[13] J.A. Sauer, G.C. Richardson, Fatigue of polymers, Int. J. Fract. 16 (1980) 499532. https://doi.org/10.1007/BF02265215.

[14] J.C. Radon, L.E. Culver, Effect of temperature and frequency in fatigue of polymers, Polymer (Guildf). (1975). https://doi.org/10.1016/00323861(75)90014-2.

[15] E.G. Kirsch, Die Theorie der Elastizität und die Bedürfnisse der Festigkeitslehre, Zeitschrift Des Vereins Dtsch. Ingenieure. 42 (1898) 797-807.

[16] C.E. Inglis, Stress in a plate due to the presence of cracks and sharp corners, Trans. Inst. Nav. Archit. 55 (1913) 219-241.

[17] H.M. Westergaard, Bearing pressures and cracks, J. Appl. Mech. 6 (1939) A49A53. https://doi.org//publication/216756690.

[18] G.R. Irwin, Analysis of Stresses and Strains Near the End of a Crack Traversing a Plate, J. Appl. Mech. 24 (1957) 361-364.

[19]

B.

McGinty,

Fracture

Mechanics,

(n.d.). 
http://www.fracturemechanics.org/sif.html.

[20] G.R. Irwin, Analysis of Stresses and Strains Near the End of a Crack Traversing a Plate, in: Appl. Mech. Div. Summer Conf. ASME, ASME, Berkeley, California, 1957: pp. 361-364.

[21] P.C. Paris, M.P. Gomez, W.E. Anderson, A rational analytic theory of fatigue, Trend Eng. 13 (1961) 9-14.

[22] P. Paris, F. Erdogan, A Critical Analysis of Crack Propagation Laws, J. Basic Eng. (1963). https://doi.org/10.1115/1.3656900.

[23] J.C. Radon, Fatigue crack growth in polymers, Int. J. Fract. 16 (1980) 533-552.

[24] P.E. Bretz, R.W. Hertzberg, J.A. Manson, Mechanisms of fatigue damage and fracture in semi-crystalline polymers, Polymer (Guildf). 22 (1981) 1272-1278. https://doi.org/10.1016/0032-3861(81)90145-2.

[25] J. Michel, J.A. Manson, R.W. Hertzberg, A simple viscoelastic model for fatigue crack propagation in polymers as a function of molecular weight, Polymer (Guildf). 25 (1984) 1657-1666. https://doi.org/10.1016/0032-3861(84)90163-0.

[26] S. Suyitno, L. Pujilaksono, Fatigue crack propagation of ultra-high molecular weight polyethylene, in: 7th Int. Annu. Eng. Semin., 2017.

[27] H. Li, G. Jiang, Q. Fang, T. Wang, Experimental investigation on the essential work of mixed-mode fracture of PC/ABS alloy, J. Mech. Sci. Technol. 29 (2015) 33-38. https://doi.org/10.1007/s12206-014-1205-0.

[28] Q. Fang, H. Li, T. Wang, Fatigue crack growth behavior of PC and PC/ABS, Acta Polym. Sin. (2007) 713-718. 
[29] Q.Z. Fang, T.J. Wang, H.M. Li, Overload effect on the fatigue crack propagation of PC/ABS alloy, Polymer (Guildf). $48 \quad$ (2007) 6691-6706. https://doi.org/10.1016/j.polymer.2007.08.048.

[30] M. Okayasu, T. Yamazaki, K. Ota, K. Ogi, T. Shiraishi, Mechanical properties and failure characteristics of a recycled CFRP under tensile and cyclic loading, Int. J. Fatigue. 55 (2013) 257-267. https://doi.org/10.1016/j.ijfatigue.2013.07.005.

[31] T. SHIRAISHI, H. OGIYAMA, H. TSUKUDA, Effect of Compressive Stress on Fatigue by Crack Propagation in Polymers, J. Soc. Mat. Sci., Japan. 46 (1997) $1255-1260$.

[32] M.M. Mazidi, M.K.R. Aghjeh, F. Abbasi, Evaluation of fracture toughness of ABS polymers via the essential work of fracture ( EWF ) method, J. Mater. Sci. 47 (2012) 6375-6386. https://doi.org/10.1007/s10853-012-6562-4.

[33] M.M. Mazidi, M.K.R. Aghjeh, F. Abbasi, Unstable fracture behavior of rubber toughened poly(styrene-co- acrylonitrile), J. Macromol. Sci. Part B Phys. 52 (2013) 1158-1182. https://doi.org/10.1080/00222348.2012.756325.

[34] B.A. Zai, M.A. Khan, S.Z. Khan, M. Asif, K.A. Khan, A.N. Saquib, A. Mansoor, M. Shahzad, A. Mujtaba, Prediction of Crack Depth and Fatigue Life of an Acrylonitrile Butadiene Styrene Cantilever Beam Using Dynamic Response, J. Test. Eval. 48 (2020) 20180674. https://doi.org/10.1520/jte20180674.

[35] B.A. Zai, M.A. Khan, K.A. Khan, A. Mansoor, A. Shah, M. Shahzad, The role of dynamic response parameters in damage prediction, Proc. Inst. Mech. Eng. Part C J. Mech. Eng. Sci. $233 \quad$ (2019) 4620-4636. https://doi.org/10.1177/0954406219841083. 
[36] M.A. Khan, D. Cooper, A. Starr, BS - ISO Helical Gear Fatigue Life Estimation and Wear Quantitative Feature Analysis, Strain. 45 (2009) 358-363. https://doi.org/10.1111/j.1475-1305.2008.00457.x.

[37] G. Ding, A.M. Karlsson, M.H. Santare, Numerical evaluation of fatigue crack growth in polymers based on plastically dissipated energy, Int. J. Fatigue. 94 (2017) 89-96. https://doi.org/10.1016/j.ijfatigue.2016.09.012.

[38] W. V Mars, A. Fatemi, A literature survey on fatigue analysis approaches for rubber, Int. J. Fatigue. 24 (2002) 949-961.

[39] Y. Marco, B. Huneau, I. Masquelier, V. Le Saux, P. Charrier, Prediction of fatigue properties of natural rubber based on the descriptions of the cracks population and of the dissipated energy, Polym. Test. 59 (2017) 67-74. https://doi.org/10.1016/j.polymertesting.2017.01.015.

[40] M. Brillhart, J. Botsis, Fatigue crack growth analysis in PEEK, Int. J. Fatigue. 16 (1994) 134-140. https://doi.org/10.1016/0142-1123(94)90103-1.

[41] K.S. Saib, W.J. Evans, D.H. Isaac, The role of microstructure during fatigue crack growth in poly(aryl ether ether ketone) (PEEK), Polymer (Guildf). 34 (1993) 3198-3203. https://doi.org/10.1016/0032-3861(93)90390-V.

[42] F. Sadeghi, B. Jalalahmadi, T.S. Slack, N. Raje, N.K. Arakere, A review of rolling contact fatigue, J. Tribol. 131 (2009) 1-15. https://doi.org/10.1115/1.3209132.

[43] H. Koike, K. Kida, T. Honda, K. Mizobe, S. Oyama, J. Rozwadowska, Y. Kashima, K. Kanemasu, Observation of crack propagation in PEEK polymer bearings under water-lubricated conditions, in: Adv. Mater. Res., 2012: pp. 109-114. https://doi.org/10.4028/www.scientific.net/AMR.566.109. 
[44] H. Fan, L.M. Keer, H.S. Cheng, Competition Between Fatigue Crack Propagation and Wear, J. Tribol. 115 (1993) 141-147.

[45] K. Itakura, T. Honda, S. Oyama, K. Kida, S. Hazeyama, Y. Kashima, Surface Profile Observation of PTFE Thrust Bearings under Rolling Contact Fatigue in Water, Adv. Mater. Res. $683 \quad$ (2013) 391-395. https://doi.org/10.4028/www.scientific.net/AMR.683.391.

[46] S. Oyama, H. Koike, Y. Kashima, K. Kida, Influence of load and rotation speed on life of PPS radial bearings under water lubricant conditions, Adv. Mater. Res. 683 (2013) 439-443. https://doi.org/10.4028/www.scientific.net/AMR.683.439.

[47] S. Oyama, K. Kida, E.C. Santos, H. Koike, T. Honda, Y. Kashima, Observations of Cracks from Microscopic Holes of PEEK Bearings under Rolling-Contact Fatigue in Water, Adv. Mater. Res. 566 (2012) 197-202. https://doi.org/10.4028/www.scientific.net/AMR.566.197.

[48] H. Koike, T. Honda, K. Kida, Influence of radial load on PEEK plastic bearings life cycle under water lubricated conditions, Adv. Mater. Res. 218 (2011) 12601265. https://doi.org/10.4028/www.scientific.net/AMR.217-218.1260.

[49] X. Shi, K. Kida, Y. Kashima, X. Shi, K. Kida, Y. Kashima, Surface crack and wear of PPS polymer thrust bearings under rolling contact fatigue in water Surface crack and wear of PPS polymer thrust bearings under rolling contact fatigue in water, $\begin{array}{lllll}\text { Mater. } & \text { Res. } & \text { Innov. } & 18 & \text { (2014). }\end{array}$ https://doi.org/10.1179/1432891714Z.000000000905.

[50] X. Shi, M. Ando, Y. Kashima, K. Kida, Crack observation of PPS polymer thrust bearings under RCF test in water, Adv. Mater. Res. 703 (2016) 178-182. 
https://doi.org/10.4028/www.scientific.net/KEM.703.178.

[51] M. IWAMOTO, E. JINEN, M. SUZUKI, Effects of crystallinity and temperature on fatigue crack growth behavior of polypropylene. Macroscopic considerations., J. Soc. Mater. Sci. Japan. 37 (1988) 807-812. https://doi.org/10.2472/jsms.37.807.

[52] M. Brillhart, J. Botsis, Fatigue fracture behaviour of PEEK: 2. Effects of thickness and temperature, Polymer (Guildf). $33 \quad$ (1992) 5225-5232. https://doi.org/10.1016/0032-3861(92)90805-7.

[53] M. Irfan-ul-Haq, N. Merah, Effect of Temperature on Fatigue Crack Growth in $\begin{array}{lllllll}\text { CPVC, J. } & \text { Press. }\end{array}$ https://doi.org/10.1115/1.1523070.

[54] N. Merah, M. Irfan-Ul-Haq, Z. Khan, Effects of injection molding weld on fatigue crack resistance of CPVC at different temperatures, J. Mater. Process. Technol. 155-156 (2004) 1261-1265. https://doi.org/10.1016/j.jmatprotec.2004.04.257.

[55] M.A. Khan, K.A. Khan, S.Z. Khan, S. Nisar, A. Starr, Fracture life estimation of Al-1050 thin beams using empirical data and a numerical approach, Insight NonDestructive Test. Cond. Monit. (2018). https://doi.org/10.1784/insi.2018.60.7.363.

[56] M.A. Khan, S.Z. Khan, W. Sohail, H. Khan, M. Sohaib, S. Nisar, Mechanical fatigue in aluminium at elevated temperature and remaining life prediction based on natural frequency evolution, Fatigue Fract. Eng. Mater. Struct. 38 (2015) 897903. https://doi.org/10.1111/ffe.12287.

[57] R.J. Wann, G.C. Martin, W.W. Gerberich, The Mechanical Behavior of Polyarylsulfone, 16 (1976).

[58] B. Ruellan, J. Le Cam, I. Jeanneau, F. Canévet, F. Mortier, E. Robin, Fatigue of 
natural rubber under different temperatures, Int. J. Fatigue. 124 (2019) 544-557. https://doi.org/10.1016/j.ijfatigue.2018.10.009.

[59] J.H. Waller, L. Lalande, Y. Leterrier, J.A.E. Månson, Modelling the effect of temperature on crack onset strain of brittle coatings on polymer substrates, Thin Solid Films. 519 (2011) 4249-4255. https://doi.org/10.1016/j.tsf.2011.02.029.

[60] Y. Zhang, A.P. Vassilopoulos, T. Keller, Effects of low and high temperatures on tensile behavior of adhesively-bonded GFRP joints, Compos. Struct. 92 (2010) 1631-1639. https://doi.org/10.1016/j.compstruct.2009.11.028.

[61] W. Luo, M. Li, Y. Huang, B. Yin, X. Hu, Effect of Temperature on the Tear Fracture and Fatigue Life of Carbon-Black-Filled Rubber, Polymers (Basel). 11 (2019)

[62] G.C. Martin, W.W. Gerberich, Temperature effects on fatigue crack growth in polycarbonate, J. Mater. Sci. 11 (1976) 231-238.

[63] Y.W. Mai, J.G. Williams, Temperature and enviromental effects on the fatigue fracture in polystyrene, J. Mater. Sci. 14 (1979) 1933-1940.

[64] H.-S. Kim, Y.-W. Mai, Effect of temperature on fatigue crack growth in unplasticized polyvinyl chloride, J. Mater. Sci. 28 (1993) 5479-5485.

[65] H.S. Kim, X.M. Wang, N.A.H.N.I.K. Abdullah, EFFECT OF TEMPERATURE ON FATIGUE CRACK GROWTH IN THE POLYMER ABS, Fatigue Fract. Eng. Mater. Struct. 17 (1994) 361-367.

[66] M. Lugo, J.E. Fountain, J.M. Hughes, J. Bouvard, M.F. Horstemeyer, Microstructure-Based Fatigue Modeling of an Acrylonitrile Butadiene Styrene ( ABS ) Copolymer, J. Appl. Polym. Sci. 131 (2014). 
https://doi.org/10.1002/app.40882.

[67] Y. Kuronuma, Y. Shindo, T. Takeda, F. Narita, Crack growth characteristics of carbon nanotube-based polymer composites subjected to cyclic loading, Eng. $\begin{array}{llll}\text { Fract. } & \text { Mech. } & 78 & \text { (2011) }\end{array}$ https://doi.org/10.1016/j.engfracmech.2011.09.006.

[68] N. Merah, Z. Khan, K. Mezghani, M.O. Budair, M. Younas, O. Olabisi, FATIGUE CRACK PROPAGATION IN WELD ZONE OF CPVC PIPE FITTINGS AT DIFFERENT TEMPERATURES, J. Polym. Eng. 21 (2001) 521-542.

[69] T.W. Bjerke, J. Lambros, Theoretical development and experimental validation of a thermally dissipative cohesive zone model for dynamic fracture of amorphous polymers, J. Mech. Phys. Solids. 51 (2003) 1147-1170. https://doi.org/10.1016/S0022-5096(02)00145-X.

[70] T. Bjerke, J. Lambros, Heating During Shearing and Opening Dominated Dynamic Fracture of Polymers, Exp. Mech. 42 (2002) 107-114.

[71] S. Basu, E. Van Der Giessen, A thermo-mechanical study of mode I, small-scale yielding crack-tip fields in glassy polymers, Int. J. Plast. 18 (2002) 1395-1423.

[72] A.G. Kotousov, On a thermo-mechanical effect and criterion of crack propagation, Int. J. Fract. 114 (2002) 349-358.

[73] R. Estevez, S. Basu, E. VAN DER Giessen, Analysis of temperature effects near mode I cracks in glassy, Int. J. Fract. 132 (2005) 249-273. https://doi.org/10.1007/s10704-005-2182-1.

[74] Y.T. Chen, K.X. Liu, Crack propagation in viscoplastic polymers : Heat generation in near-tip zone and viscoplastic cohesive model, Appl. Phys. Lett. 106 (2015). 
https://doi.org/10.1063/1.4908115.

[75] R.W. Hertzberg, J.A. Manson, M. Skibo, Frequency sensitivity of fatigue processes in polymeric solids, Polym. Eng. Sci. 15 (1975) 252-260. https://doi.org/10.1002/pen.760150404.

[76] J.A. Manson, R.W. Hertzberg, S.L. Kim, M. Skibo, The $\beta$ transition and frequency sensitivity in fatigue crack propagation of polymers, Polymer (Guildf). 16 (1975) 850-851. https://doi.org/10.1016/0032-3861(75)90121-4.

[77] R.W. Hertzberg, M.D. Skibo, J.A. Manson, J.K. Donald, Comments on "A model of fatigue crack growth in polymers", J. Mater. Sci. 14 (1979) 1754-1759.

[78] J.. Williams, A model of fatigue crack growth in polymers, J. Mater. Sci. 12 (1977) $2525-2533$.

[79] M.T. Hahn, R.W. Hertzberg, J.A. Manson, R.W. Lang, P.E. Bretz, Effect of test frequency and water content on localized crack-tip heating in nylon-6,6, Polymer (Guildf). 23 (1982) 1675-1679. https://doi.org/10.1016/0032-3861(82)90192-6.

[80] Y.F. Chou, C.T. Sun, Modeling of the frequency effect on fatigue crack propagation in PMMA, Eng. Fract. Mech. 17 (1983) 17-26.

[81] P. Dumpleton, C.B. Bucknall, Comparison of static and dynamic fatigue crack growth rates in high- density polyethylene, Int. J. 9 (1987) 151-155.

[82] M.G. WYZGOSKI, G.E. NOVAK, D.L. SIMON, Fatigue fracture of nylon polymers Part 1 Effect of frequency, J. Mater. Sci. 25 (1990) 4501-4510.

[83] M. Parsons, E. V Stepanov, A. Hiltner, E. Baer, Effect of strain rate on stepwise fatigue and creep slow crack growth in high density polyethylene, J. Mater. Sci. 5 
(2000) 1857-1866.

[84] M. Eftekhari, A. Fatemi, On the strengthening effect of increasing cycling frequency on fatigue behavior of some polymers and their composites: Experiments and modeling, Int. J. Fatigue. 87 (2016) 153-166. https://doi.org/10.1016/j.ijfatigue.2016.01.014.

[85] Y. Zhou, N. Brown, The Mechanism of Fatigue Failure in a Polyethylene Copolymer, Polym. Phys. 30 (1992) 477-487.

[86] S. Mortazavian, A. Fatemi, Fatigue behavior and modeling of short fiber reinforced polymer composites: A literature review, Int. J. Fatigue. 70 (2015) 297-321. https://doi.org/10.1016/j.ijfatigue.2014.10.005.

[87] S. Seichter, V. Archodoulaki, T. Koch, A. Holzner, A. Wondracek, Investigation of different in fl uences on the fatigue behaviour of industrial rubbers, Polym. Test. 59 (2017) 99-106. https://doi.org/10.1016/j.polymertesting.2017.01.018.

[88] A.C. Ford, H. Gramling, S.C. Li, J. V Sov, A. Srinivasan, L.A. Pruitt, Journal of the Mechanical Behavior of Biomedical Materials Micromechanisms of fatigue crack growth in polycarbonate polyurethane: Time dependent and hydration e ff ects, J. Mech. Behav. OfBiomedical Mater. $79 \quad$ (2018) 324-331. https://doi.org/10.1016/j.jmbbm.2018.01.008.

[89] T. Chandy, J. Van Hee, W. Nettekoven, J. Johnson, Long-Term In Vitro Stability Assessment of Polycarbonate Urethane Micro Catheters : Resistance to Oxidation and Stress Cracking, J. Biomed. Mater. Res. - Part B Appl. Biomater. 89 (2009) 314-324. https://doi.org/10.1002/jbm.b.31218.

[90] G. Hartwig, S. Knaak, Fatigue behaviour of polymers, Cryogenics (Guildf). 31 
(1991) 231-233.

[91] R. Shrestha, J. Simsiriwong, N. Shamsaei, R.D. Moser, Cyclic deformation and fatigue behavior of polyether ether ketone (PEEK), Int. J. Fatigue. 82 (2016) 411427. https://doi.org/10.1016/j.ijfatigue.2015.08.022.

[92] F. Saghir, N. Merah, Z. Khan, A. Bazoune, Modeling the combined effects of temperature and frequency on fatigue crack growth of chlorinated polyvinyl chloride (CPVC), J. Mater. Process. Technol. 164-165 (2005) 1550-1553. https://doi.org/10.1016/j.jmatprotec.2005.02.206.

[93] N. Merah, Z. Khan, A. Bazoune, F. Saghir, Temperature And Loading Frequency Effects On Fatigue Crack Growth In HDPE Pipe Material, Arab. J. Sci. Eng. 31 (2006) 19-30. https://doi.org/10.1016/S0924-0136(03)00567-3.

[94] N. Merah, F. Saghir, Z. Khan, A. Bazoune, A study of frequency and temperature effects on fatigue crack growth resistance of CPVC, Eng. Fract. Mech. 72 (2005) 1691-1701. https://doi.org/10.1016/j.engfracmech.2004.12.002.

[95] J.C. Radon, L.E. Culver, Effect of temperature and frequency in fatigue of polymers, Polym. Eng. Sci. 16 (1975) 539-544. https://doi.org/10.1016/00323861(75)90014-2.

[96] J.C. Radon, L.E. Culver, Fatigue crack growth in polymers. I. Effect of frequency and temperature, Polym. Eng. Sci. $15 \quad$ (1975) 500-506. https://doi.org/10.1002/pen.760150705.

[97] W.M. Cheng, G.A. Miller, J.A. Manson, R.W. Hertzberg, L.H. Sperling, Mechanical behaviour of poly ( methyl methacrylate ) The temperature and frequency effects on the fatigue crack propagation behaviour, J. Mater. Sci. 25 
(1990) 1924-1930.

[98] H.S. Kim, X.M. Wang, Temperature and frequency effects on fatigue crack growth of uPVC, J. Mater. Sci. 29 (1994) 3209-3214.

[99] H.O.S. Kim, X.M. Wang, Temperature and Frequency Effects on Fatigue Crack Growth in Acrylonitrile-Butadiene-Styrene ( ABS ), J. Appl. Polym. Sci. 57 (1995) $811-817$.

[100] M.N. Riddell, G.P. Koo, J.L. O’Toole, Fatigue Mechanisms of Thermoplastics, Polym. Eng. Sci. 6 (1966) 363-368.

[101] Z. Qi, L. Lu, L. Doan, B. Thota, D. Zeng, X. Su, Frequency Effects on HighDensity Polyethylene Failure under Cyclic Loading, in: SAE World Congr. Exp., 2017. https://doi.org/10.4271/2017-01-0332.Copyright.

[102] A. Takei, S. Matter, Crack propagation in porous polymer sheets with different

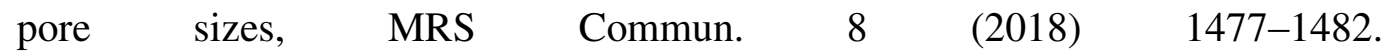
https://doi.org/10.1557/mrc.2018.222.

[103] J. Ding, E.W. Remij, J.J.C. Remmers, J.M. Huyghe, Effects of Intrinsic Properties on Fracture Nucleation and Propagation in Swelling Hydrogels, Polymers (Basel). 11 (2019) 1-12. https://doi.org/10.3390/polym11050926.

[104] J. Poduška, P. Hutař, J. Kučera, J. Sadílek, A. Frank, G. Pinter, L. Náhlík, The Effect of Residual Stress on the Process of Crack Growth Rate Determination in Polymer Pipes, in: 8th Int. Conf. Mater. Struct. Micromechanics Fract., 2017: pp. 174-177. https://doi.org/10.4028/www.scientific.net/SSP.258.174.

[105] W. V. MARS, A. FATEMI, FACTORS THAT AFFECT THE FATIGUE LIFE OF RUBBER, Rubber Chem. Technol. 77 (2004) 391-412. 
[106] Y.L. Tee, M.S. Loo, A. Andriyana, Recent advances on fatigue of rubber after the literature survey by Mars and Fatemi in 2002 and 2004, Int. J. Fatigue. 110 (2018) 115-129. https://doi.org/10.1016/j.ijfatigue.2018.01.007.

[107] J. Zhang, X.D. He, B. Suo, S.Y. Du, Elastic - plastic finite element analysis of the effect of compressive loading on crack tip parameters and its impact on fatigue crack propagation rate, Eng. Fract. Mech. 75 (2008) 5217-5228. https://doi.org/10.1016/j.engfracmech.2008.08.006.

[108] D.A. Baker, R.S. Hastings, L. Pruitt, Compression and tension fatigue resistance of medical grade ultra high molecular weight polyethylene: The effect of morphology, sterilization, aging and temperature, Polymer (Guildf). (2000). https://doi.org/10.1016/S0032-3861(99)00199-8.

[109] A. Shah, E. V. Stepanov, A. Hiltner, E. Baer, M. Klein, Correlation of fatigue crack propagation in polyethylene pipe specimens of different geometries, Int. J. Fract. 84 (1997) 159-173. https://doi.org/10.1023/A:1007354600584.

[110] A. Shah, E. V. Stepanov, M. Klein, A. Hiltner, E. Baer, Study of polyethylene pipe resins by a fatigue test that simulates crack propagation in a real pipe, J. Mater. Sci. (1998). https://doi.org/10.1023/A:1013229128686.

[111] M. Parsons, E. V. Stepanov, A. Hiltner, E. Baer, Correlation of fatigue and creep slow crack growth in a medium density polyethylene pipe material, J. Mater. Sci. (2000). https://doi.org/10.1023/A:1004789522642.

[112] L. Pruitt, L. Bailey, Factors affecting near-threshold fatigue crack propagation behavior of orthopedic grade ultra high molecular weight polyethylene, Polymer (Guildf). 39 (1998) 1545-1553. https://doi.org/10.1016/S0032-3861(97)00448-5. 
[113] J. Foyos, R. Noorani, M. Mendelson, R. Marloth, B.A. Pregger, Effect of Layer Orientation on Mechanical Properties of Rapid Prototyped Samples, Mater. Manuf. Process. 15 (2000) 107-122. https://doi.org/10.1080/10426910008912976.

[114] S. Ahn, M. Montero, D. Odell, S. Roundy, P.K. Wright, M. Montero, P.K. Wright, Anisotropic material properties of fused deposition modeling ABS Sung-Hoon Ahn, Rapid $\quad$ Prototyp. $\quad$ J. $\quad 8 \quad$ (2002) 248-257. https://doi.org/10.1108/13552540210441166.

[115] B.H. Lee, J. Abdullah, Z.A. Khan, Optimization of rapid prototyping parameters for production of flexible ABS object, J. Mater. Process. Technol. 169 (2005) 5461. https://doi.org/10.1016/j.jmatprotec.2005.02.259.

[116] K.C. Ang, K.F. Leong, C.K. Chua, M. Chandrasekaran, Investigation of the mechanical properties and porosity relationships ..., Rapid Prototyp. J. 12 (2006) $100-105$.

[117] M. Shojib Hossain, D. Espalin, J. Ramos, M. Perez, R. Wicker, Improved Mechanical Properties of Fused Deposition Modeling-Manufactured Parts Through Build Parameter Modifications, J. Manuf. Sci. Eng. 136 (2014) 061002. https://doi.org/10.1115/1.4028538.

[118] A.R. Torrado, C.M. Shemelya, J.D. English, Y. Lin, R.B. Wicker, D.A. Roberson, Characterizing the Effect of Additives to ABS on the Mechanical Property Anisotropy of Specimens Fabricated by Material Extrusion 3D Printing, Addit. Manuf. 6 (2015) 16-29. https://doi.org/10.1016/j.addma.2015.02.001.

[119] F. Ning, W. Cong, Y. Hu, H. Wang, Additive manufacturing of carbon fiberreinforced plastic composites using fused deposition modeling : Effects of process 
parameters on tensile properties, J. Compos. Mater. 51 (2017) 451-462. https://doi.org/10.1177/0021998316646169.

[120] D. Türk, F. Brenni, M. Zogg, M. Meboldt, Mechanical characterization of 3D printed polymers for fiber reinforced polymers processing, Mater. Des. 118 (2017) 256-265. https://doi.org/10.1016/j.matdes.2017.01.050.

[121] D. Popescu, A. Zapciu, C. Amza, F. Baciu, R. Marinescu, FDM process parameters in fl uence over the mechanical properties of polymer specimens: A review, $\begin{array}{lllll}\text { Polym. } & \text { Test. } & 69 & \text { (2018) }\end{array}$ https://doi.org/10.1016/j.polymertesting.2018.05.020.

[122] J.F. Rodriguez, J.P. Thomas, J.. Renaud, Mechanical behavior of acrylonitrile butadiene styrene ( ABS ) fused deposition materials . Experimental investigation, Rapid Prototyp. J. 7 (2001) 148-158.

[123] J.F. Rodríguez, J.P. Thomas, J.E. Renaud, Mechanical behavior of acrylonitrile butadiene styrene fused deposition materials modeling, Rapid Prototyp. J. 9 (2003) 219-230. https://doi.org/10.1108/13552540310489604.

[124] M. Bertoldi, M.A. Yardimci, C.M. Pistor, S.I. Guyeri, G. Sala, Mechanical Characterization of Parts Processed via Fused Deposition, in: Int. Solid Free. Fabr. Symp., 1998: pp. 557-566.

[125] A. Bellini, S. Güçeri, Mechanical characterization of parts fabricated using fused deposition modeling, Rapid Prototyp. J. 9 (2003) 252-264. https://doi.org/10.1108/13552540310489631.

[126] C.G. Schirmeister, T. Hees, E.H. Licht, R. Mülhaupt, 3D printing of high density polyethylene by fused fi lament fabrication, Addit. Manuf. 28 (2019) 152-159. 
https://doi.org/10.1016/j.addma.2019.05.003.

[127] H. Zhang, L. Cai, M. Golub, Y. Zhang, X. Yang, K. Schlarman, J. Zhang, Tensile , Creep, and Fatigue Behaviors of 3D-Printed Acrylonitrile Butadiene Styrene, J. Mater. Eng. Perform. 27 (2018) 57-62. https://doi.org/10.1007/s11665-017-29617.

[128] N. Aliheidari, R. Tripuraneni, J. Christ, A. Ameli, N. Aliheidari, R. Tripuraneni, C. Hohimer, J. Christ, The impact of nozzle and bed temperatures on the fracture resistance of FDM printed materials, in: Proc. SPIE - Int. Soc. Opt. Eng., 2017. https://doi.org/10.1117/12.2260105.

[129] J.P. Isaac, H. V Tippur, Quasi-Static and Dynamic Fracture Behaviors of Additively Printed ABS Coupons Studied Using DIC : Role of Build Architecture and Loading Rate, in: Conf. Proc. Soc. Exp. Mech. Ser., 2019: pp. 11-19.

[130] M.F. Rabbi, V.B. Chalivendra, A Novel Approach to Increase Dynamic Fracture Toughness of Additively Manufactured Polymer, Exp. Mech. (2019).

[131] N.S.F. Jap, G.M. Pearce, A.K. Hellier, N. Russell, W.C. Parr, W.R. Walsh, The effect of raster orientation on the static and fatigue properties of filament deposited ABS polymer, Int. J. Fatigue. $124 \quad$ (2019) 328-337. https://doi.org/10.1016/j.ijfatigue.2019.02.042.

[132] A. Imeri, I. Fidan, M. Allen, D.A. Wilson, S. Canfield, Fatigue analysis of the fiber reinforced additively manufactured objects, Int. J. Adv. Manuf. Technol. 98 (2018) $2717-2724$.

[133] M. Rybachuk, C. Alice Mauger, T. Fiedler, A. Öchsner, Anisotropic mechanical properties of fused deposition modeled parts fabricated by using acrylonitrile 
butadiene styrene polymer, J. Polym. Eng. $37 \quad$ (2017) 1-8. https://doi.org/10.1515/polyeng-2016-0263.

[134] J.A. Suresh, G. Saravana Kumar, P. Ramu, J. Rengaswamy, Fatigue Life Characterization of Additively Manufactured Acrylic like Poly-Jet Printed Parts, Adv. Struct. Integr. (2017) 623-632.

[135] M.F. Afrose, S.H. Masood, P. Iovenitti, M. Nikzad, I. Sbarski, Effects of part build orientations on fatigue behaviour of FDM-processed PLA material, Prog. Addit. Manuf. 1 (2015) 21-28. https://doi.org/10.1007/s40964-015-0002-3. 


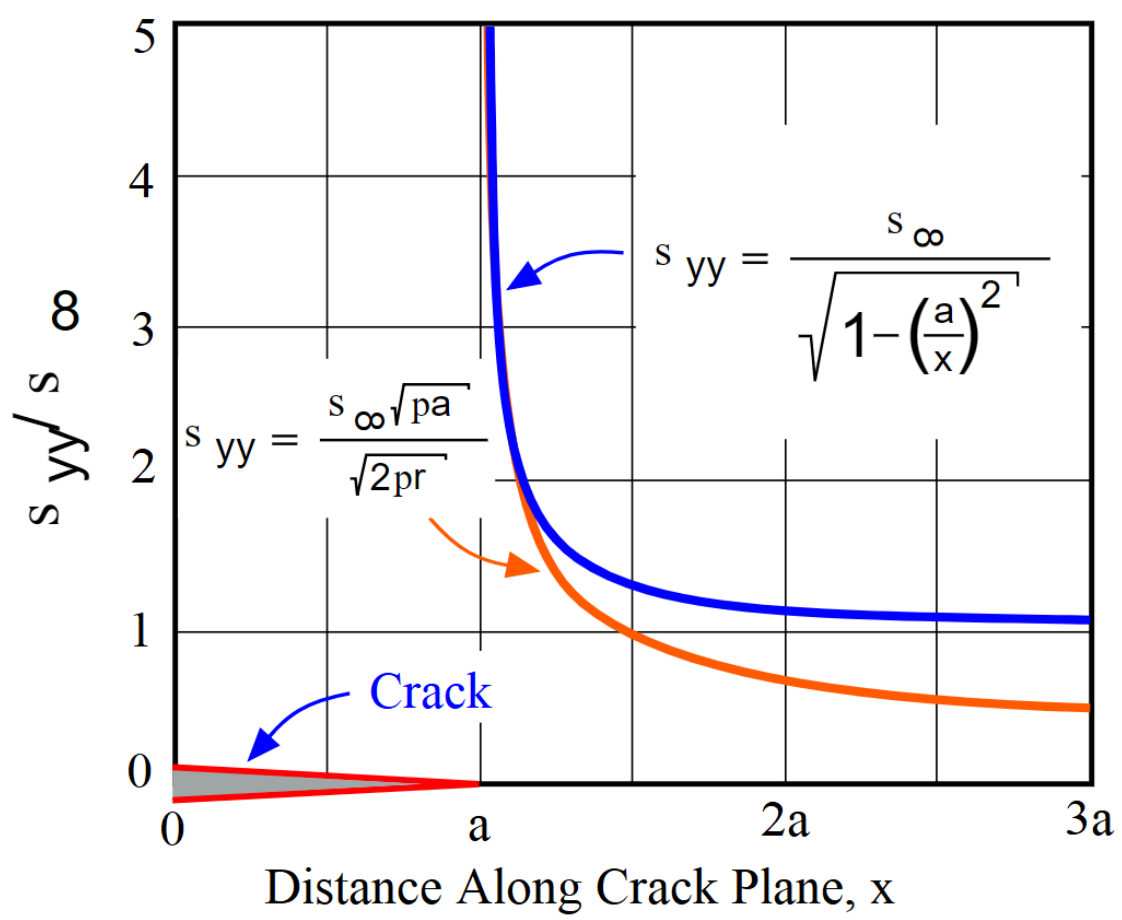

Figure 3-1 Stress modelling near crack tip [18] 


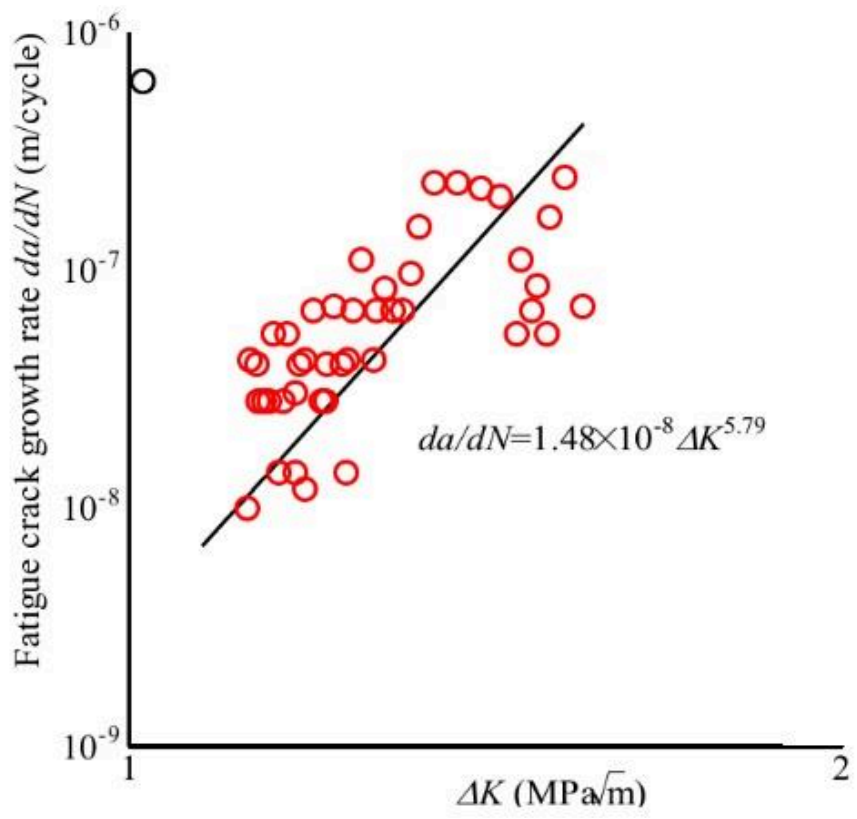

Figure 4-1 da/dN - $\Delta \mathrm{K}$ relation of Dicyclopentadiene material (replotted) [2] 


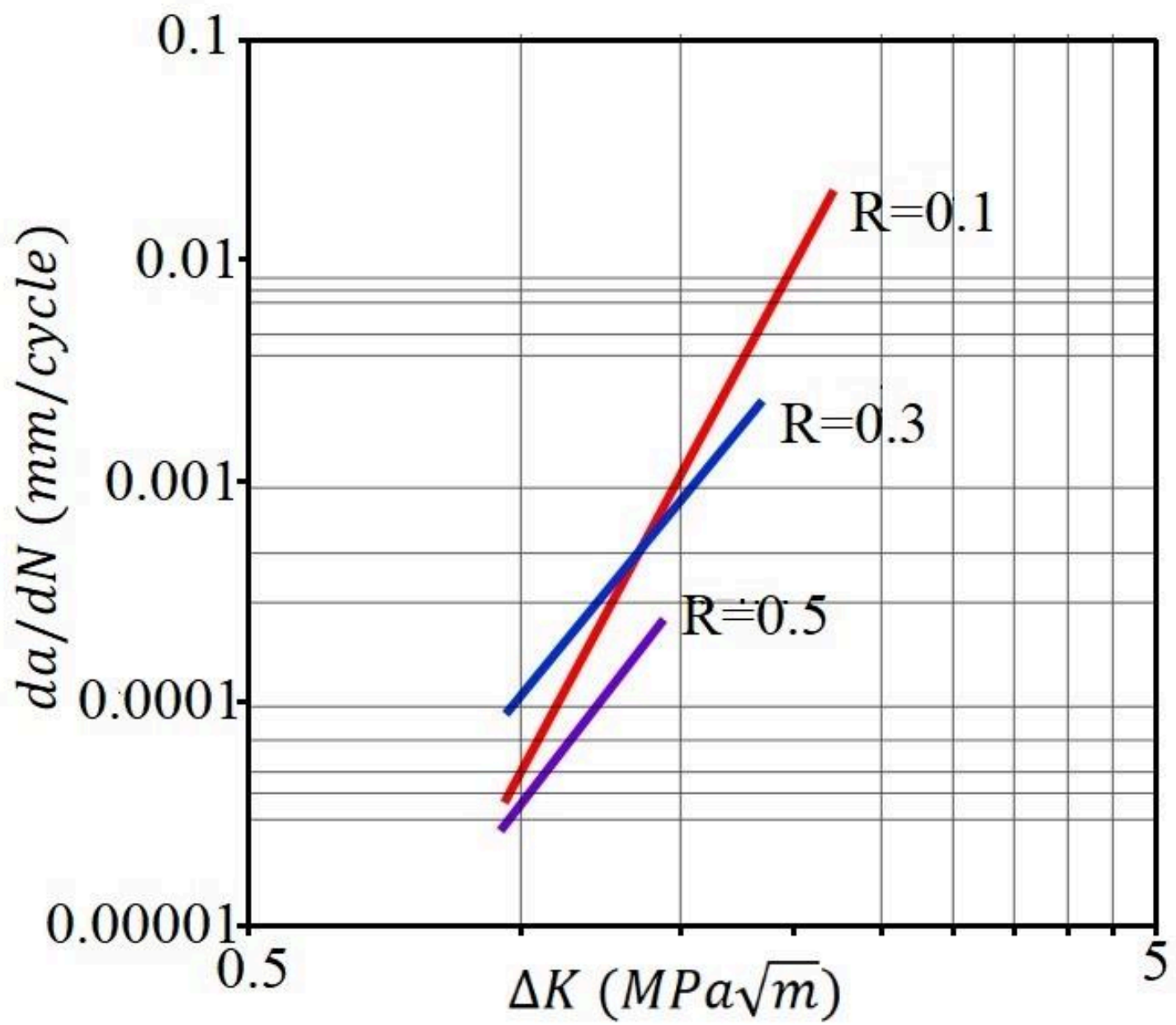

Figure 4-2 Effect of load ratio on fatigue crack behaviour (replotted) [25] 


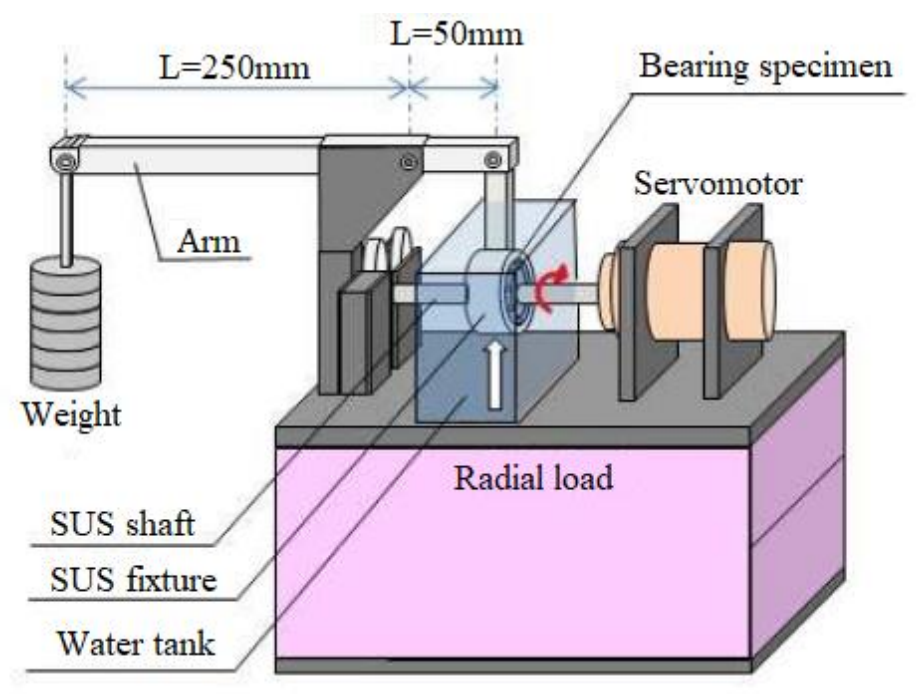

Figure 4-3 RCF test machine scheme [42] 

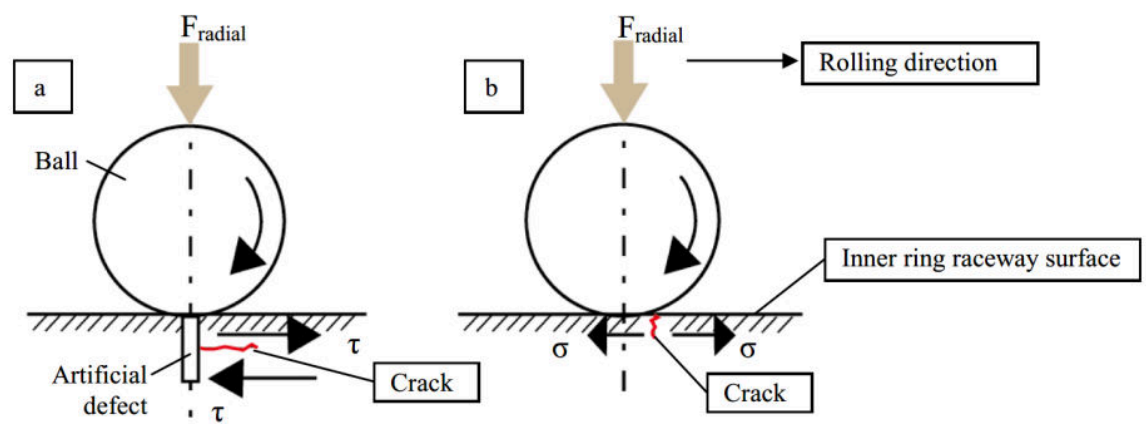

Figure 4-4 Two different crack types and associated growth directions: (a) subsurface cracks,

(b) semi-circular cracks[42] 


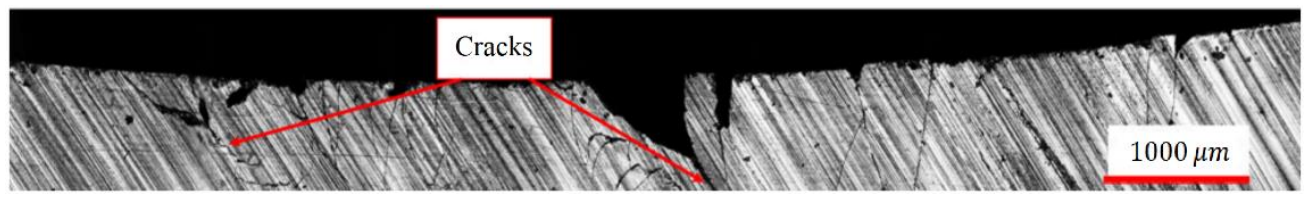

Figure 4-5 Crack observation in cross section of top race track [48] 


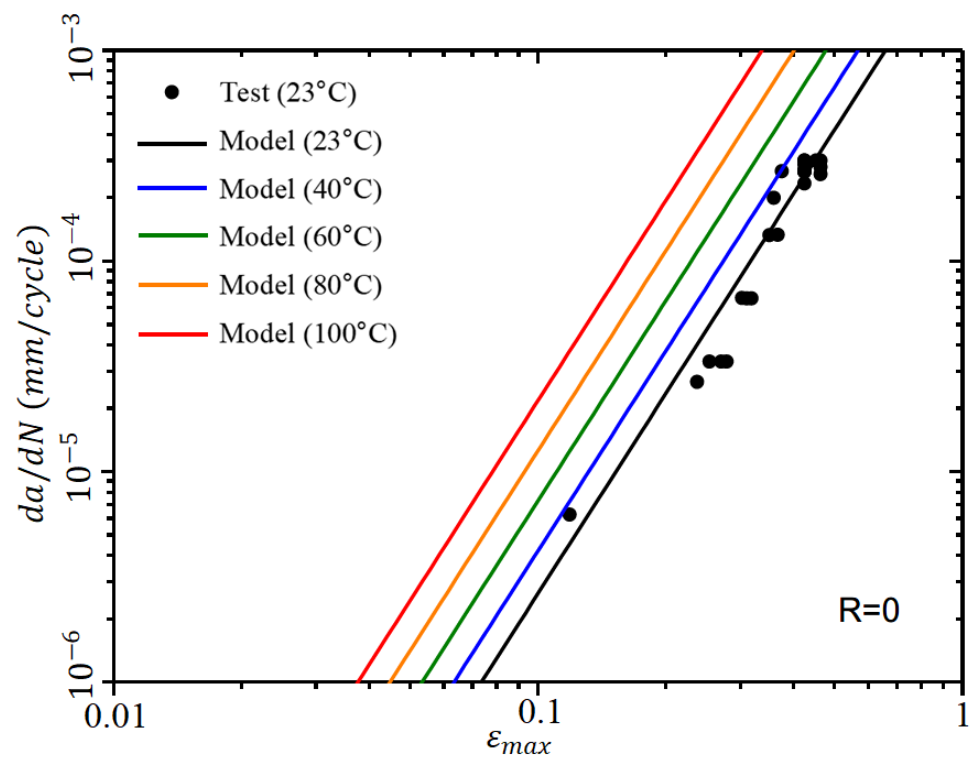

Figure 5-1 Modelling results of FCG rate at temperatures above $23{ }^{\circ} \mathrm{C}$ [60] 


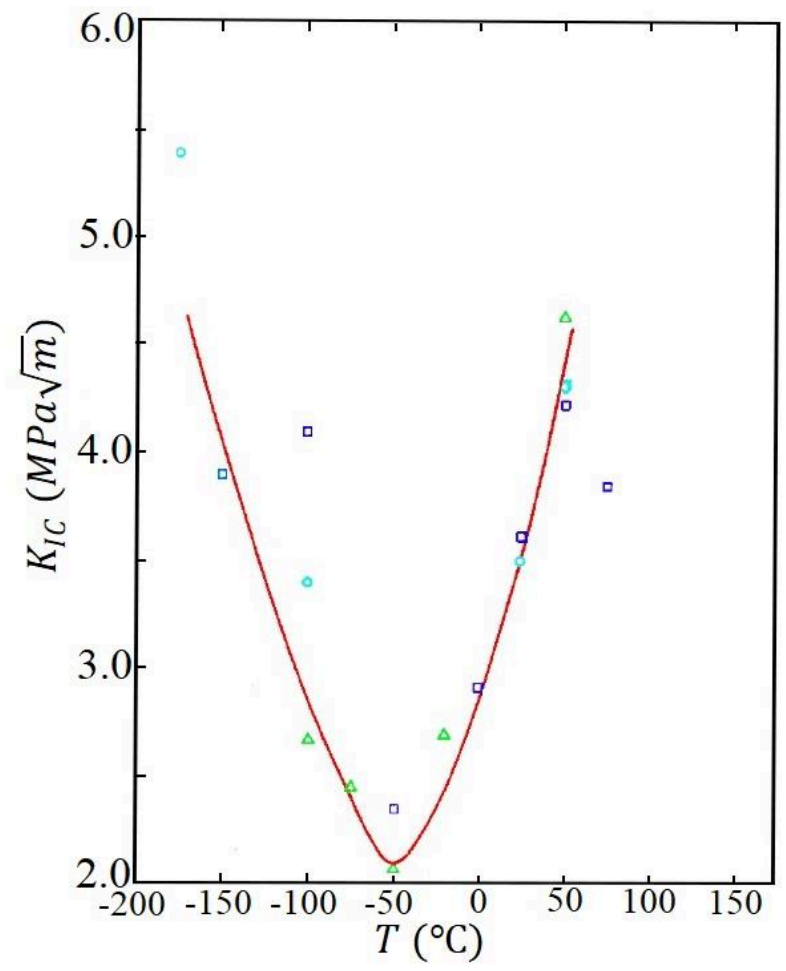

Figure 5-2 Fracture toughness variation with the temperature for PC (replotted) [61] 

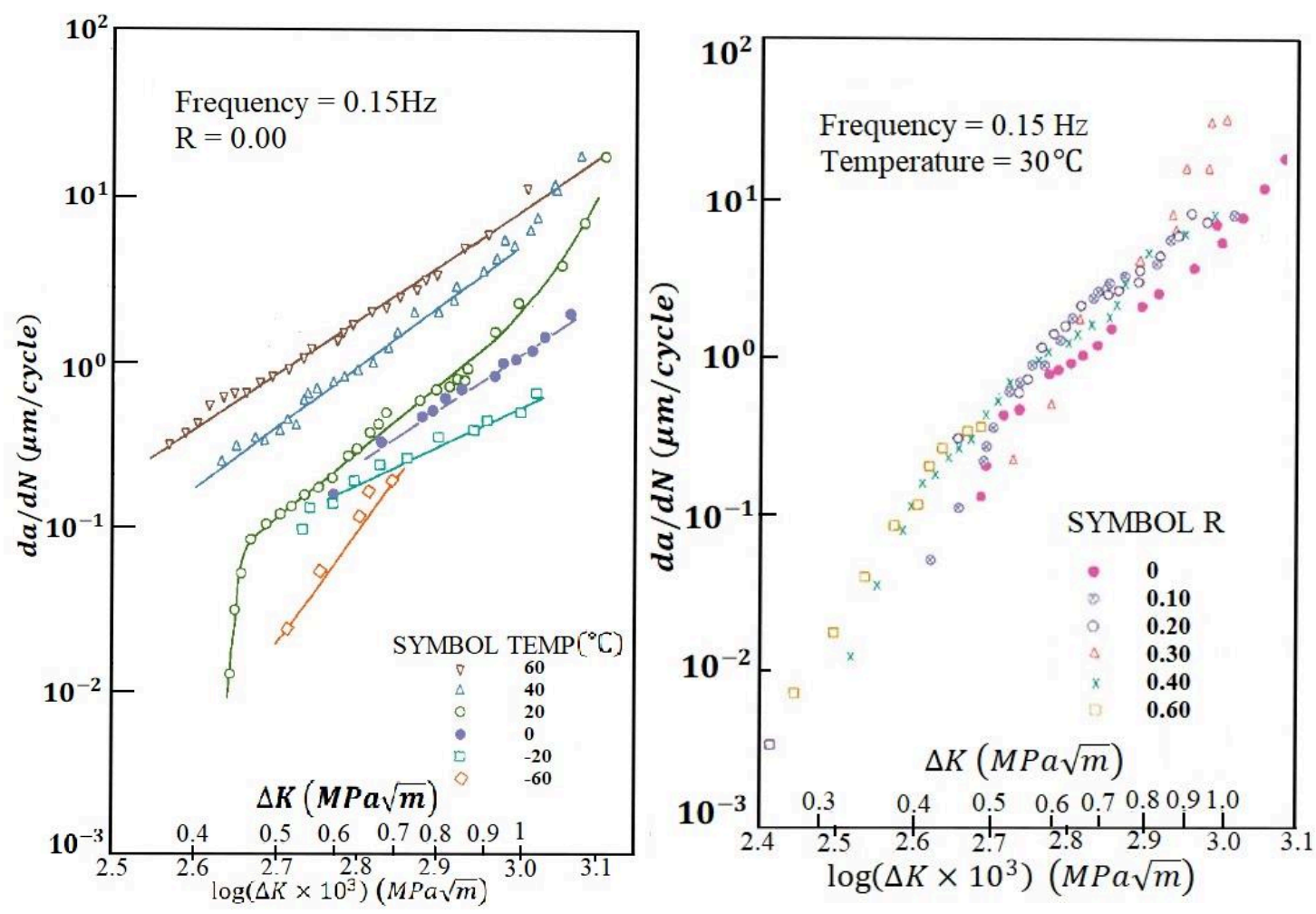

Figure 5-3 Influence of temperature and R Ratio to da/dN (replotted) [62] 


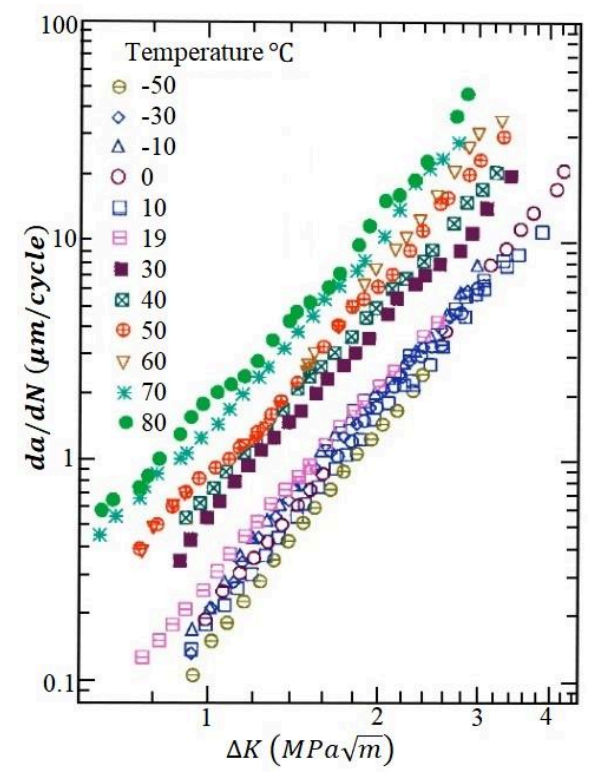

Figure 5-4 Effect of temperature to da/dN of ABS (replotted) [64] 


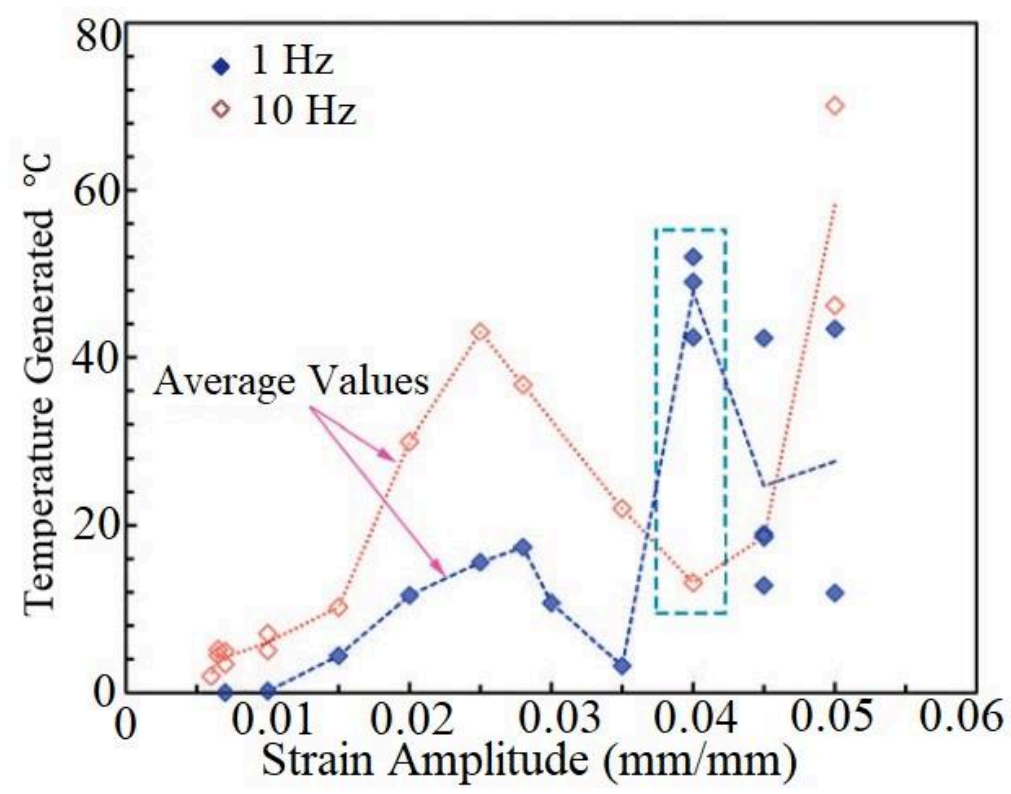

Figure 5-5 Self-heating effect in the test (replotted) [65] 


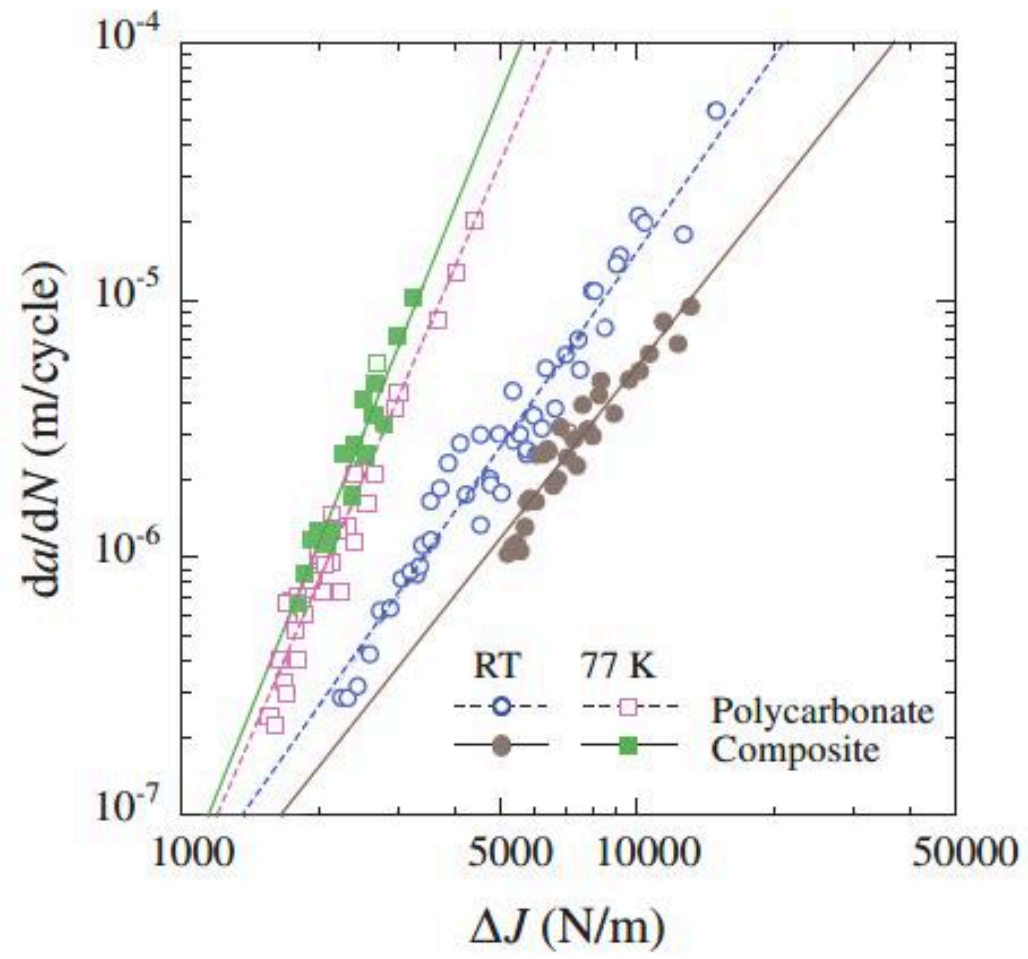

Figure 5-6 da/dN of PC at Different Temperature (replotted) [66] 


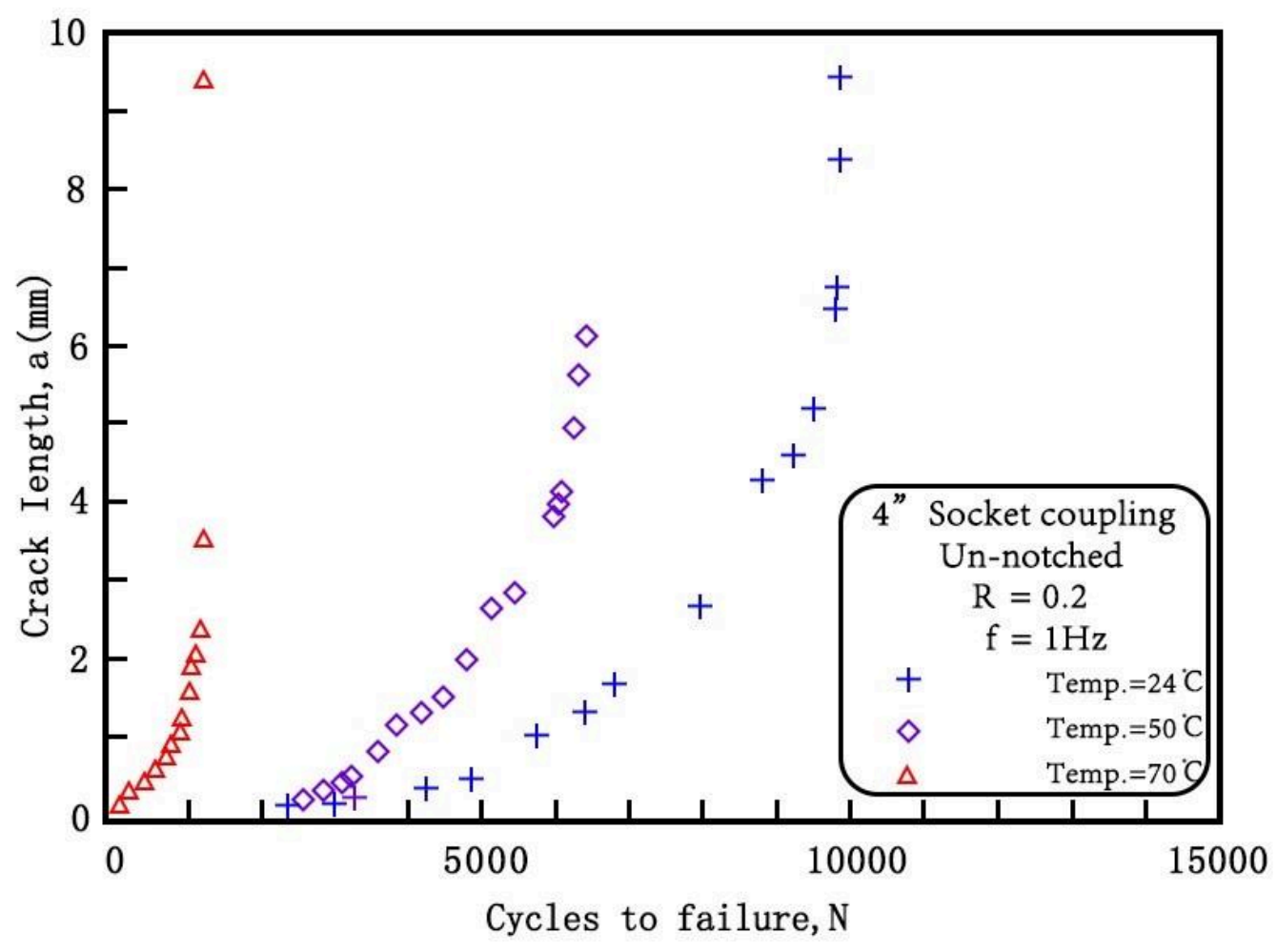

Figure 5-7 Temperature influence on FCG in CPVC fitting (replotted) [67] 


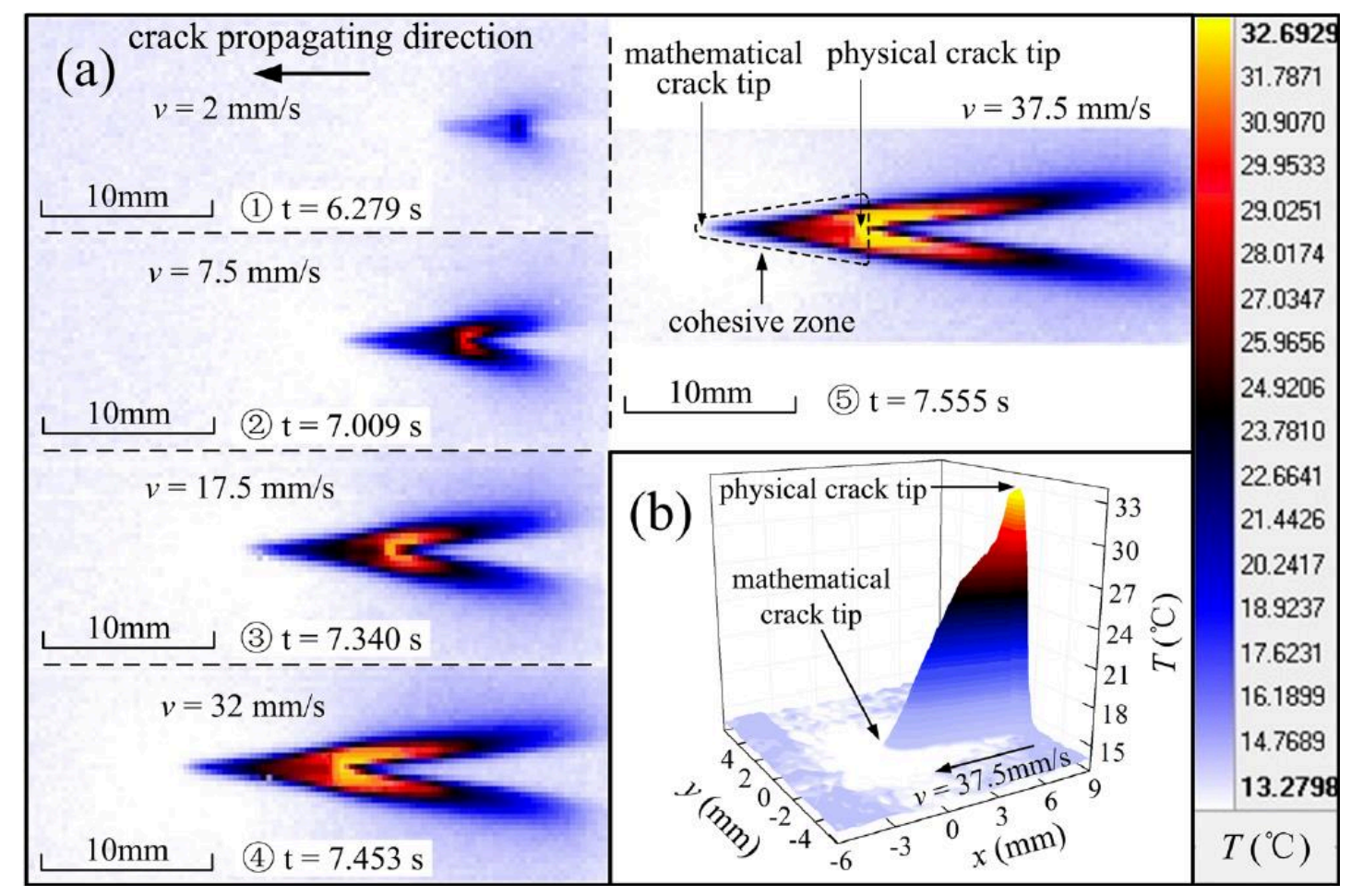

Figure 5-8 Contour map for the thermal distributions close to crack tip [73] 

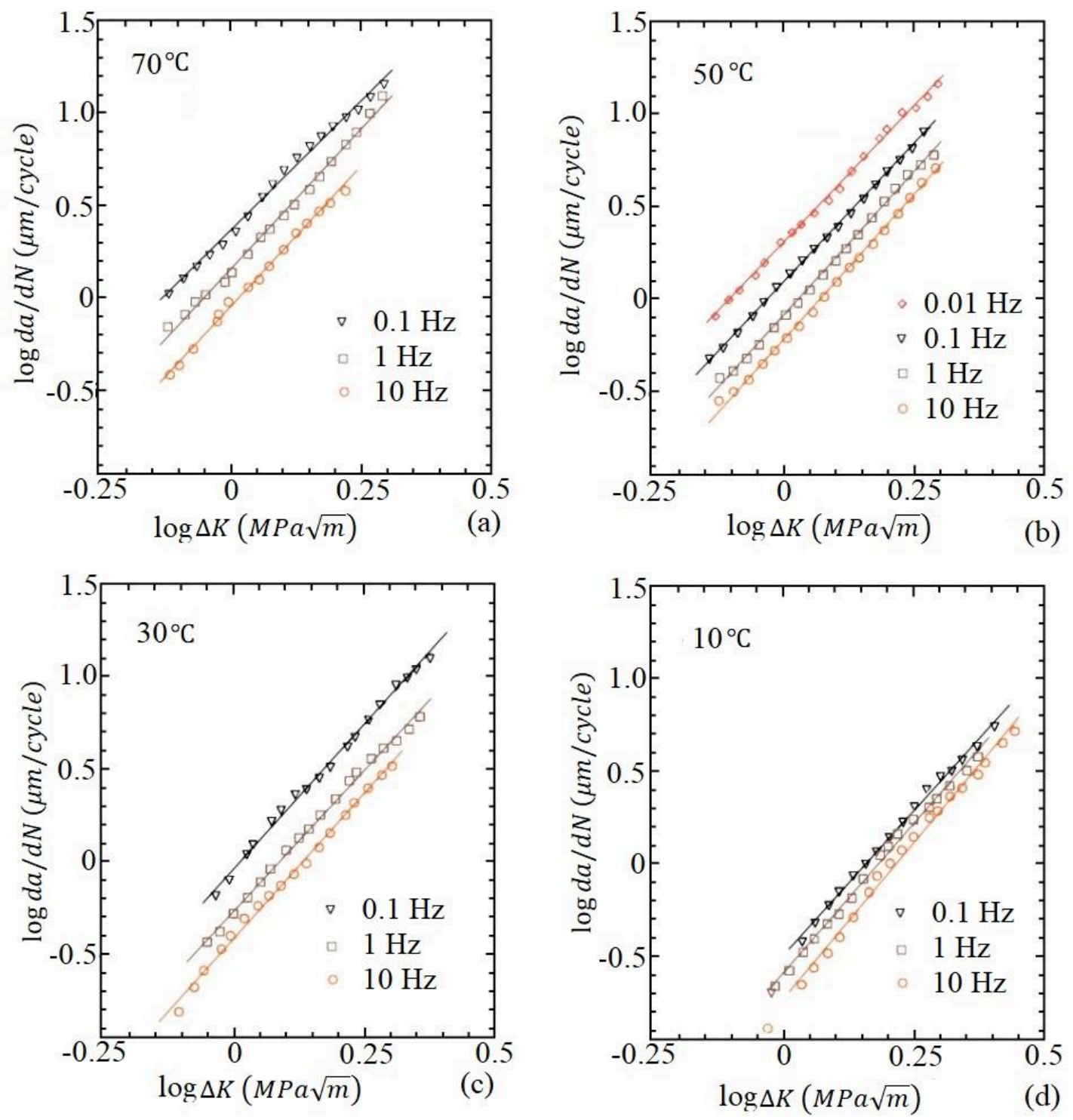

Figure 5-9 FCG rates of ABS at different frequencies and temperatures (replotted) [98] 


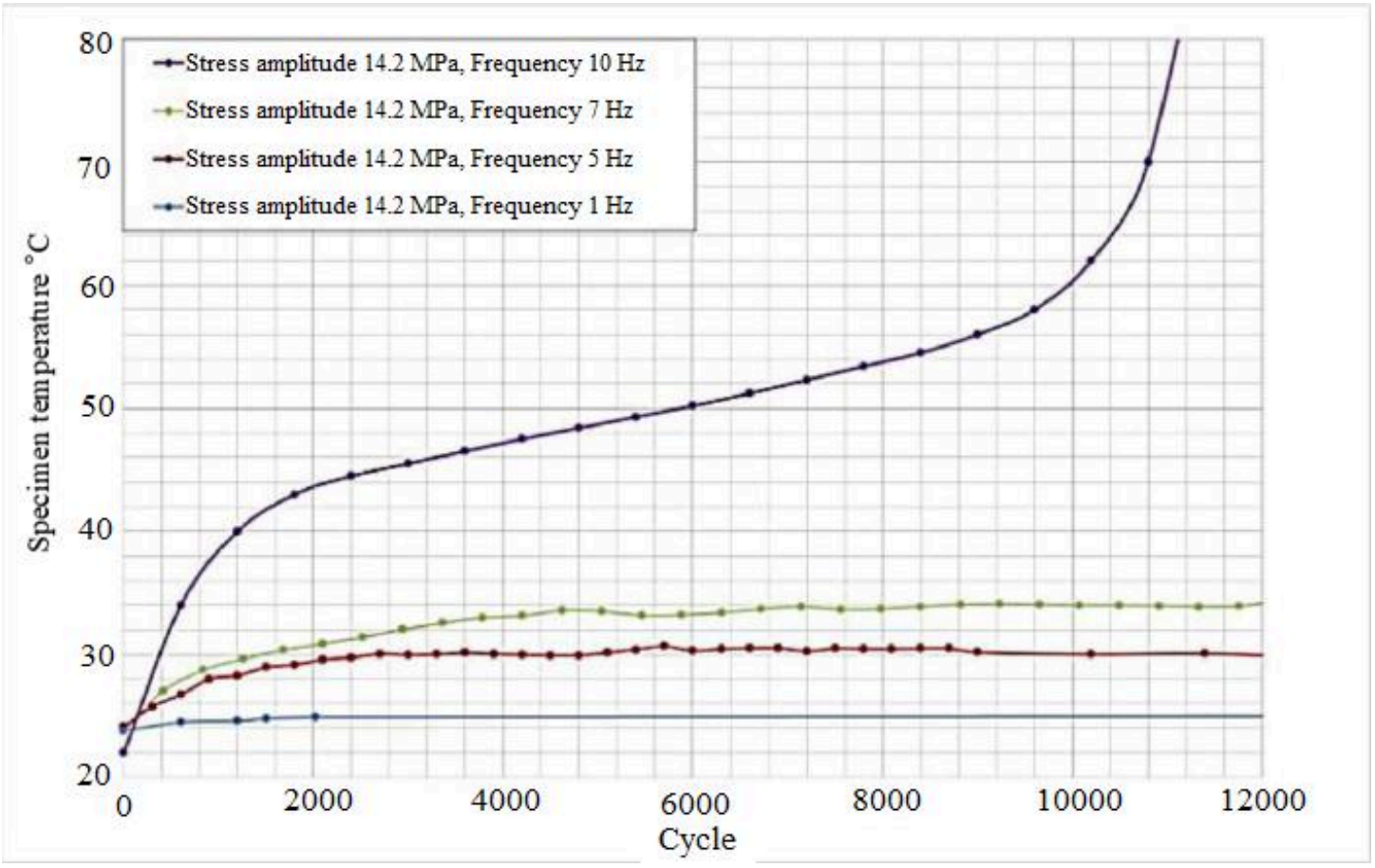

Figure 5-10 Frequency effect on the temperature of specimen under same stresses during whole fatigue lifes [100] 


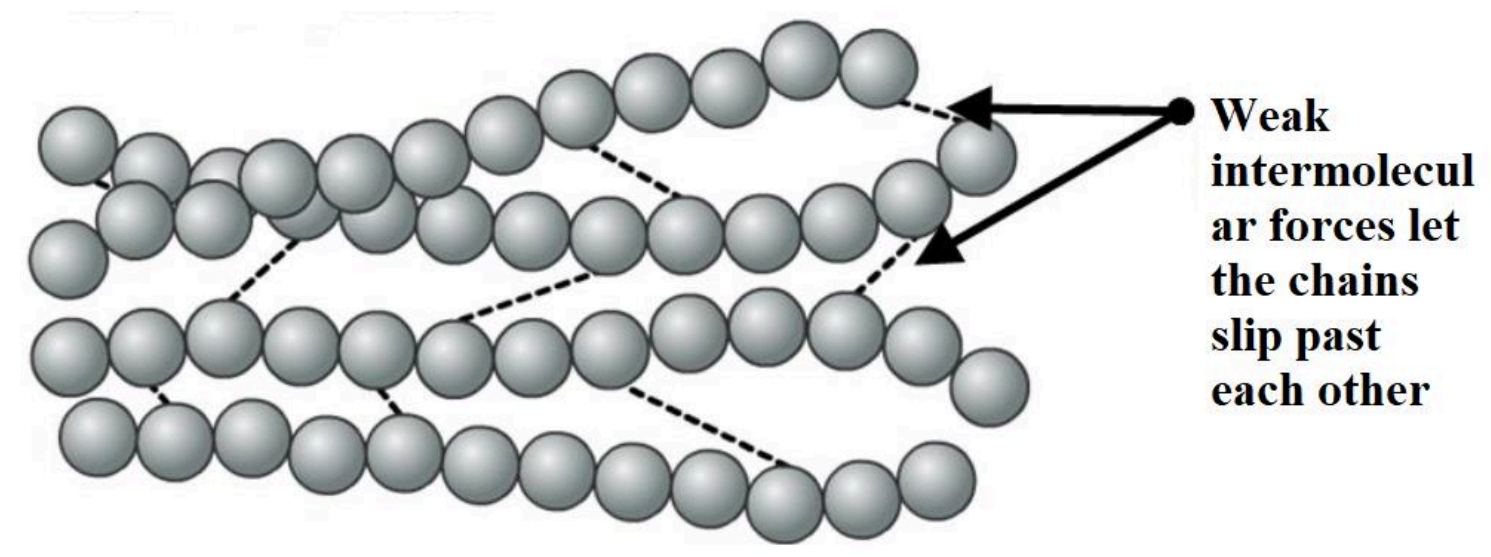

Figure 5-11 Chain slippage in thermoplastic polymers 


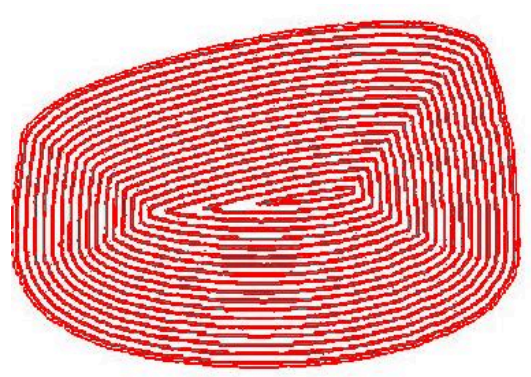

(a)

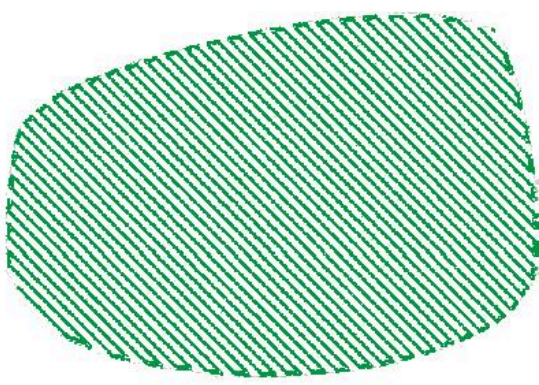

(b)

Figure 7-1 Different building path [124] 


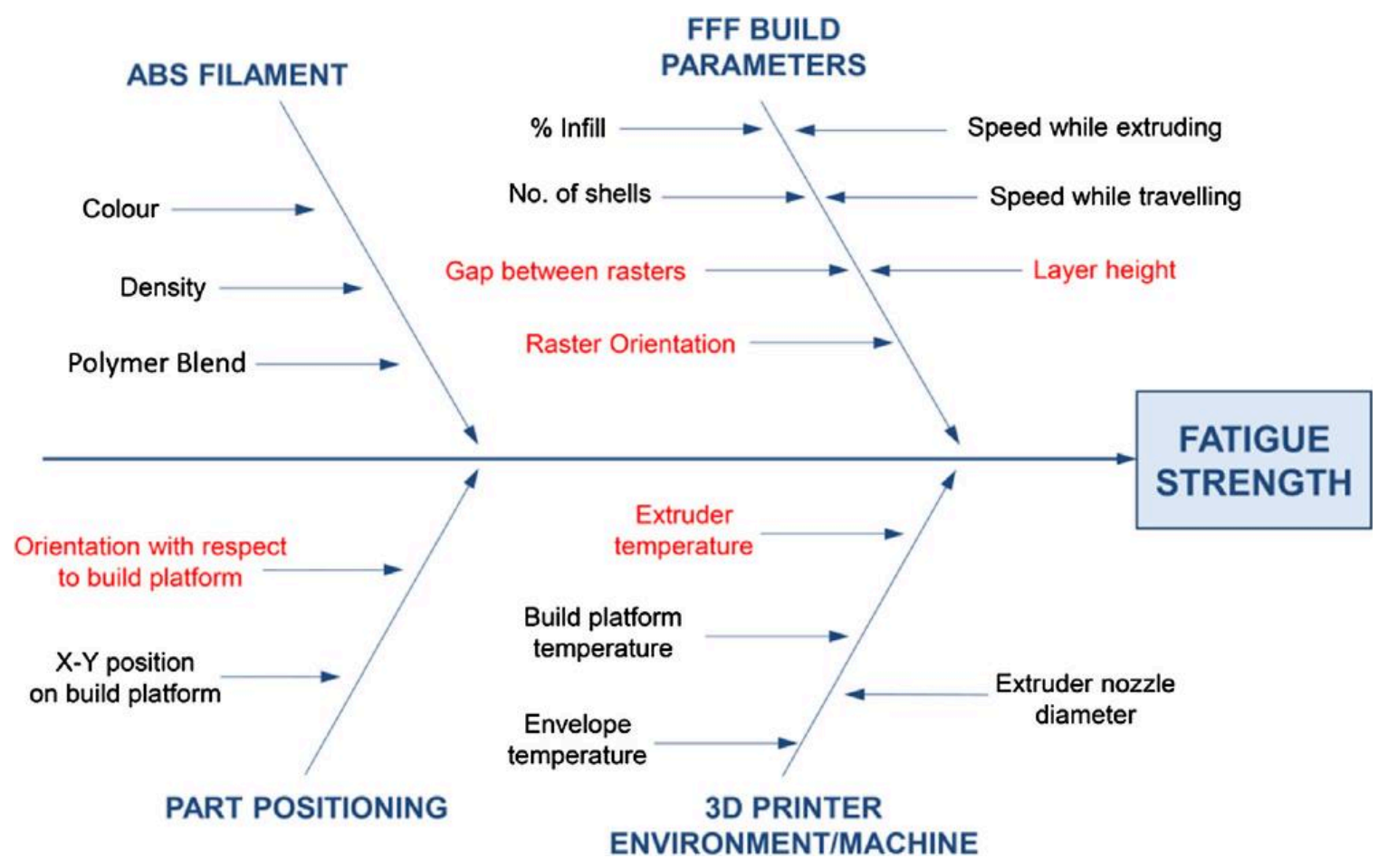

Figure 7-2 Influence parameters to fatigue strength [130] 


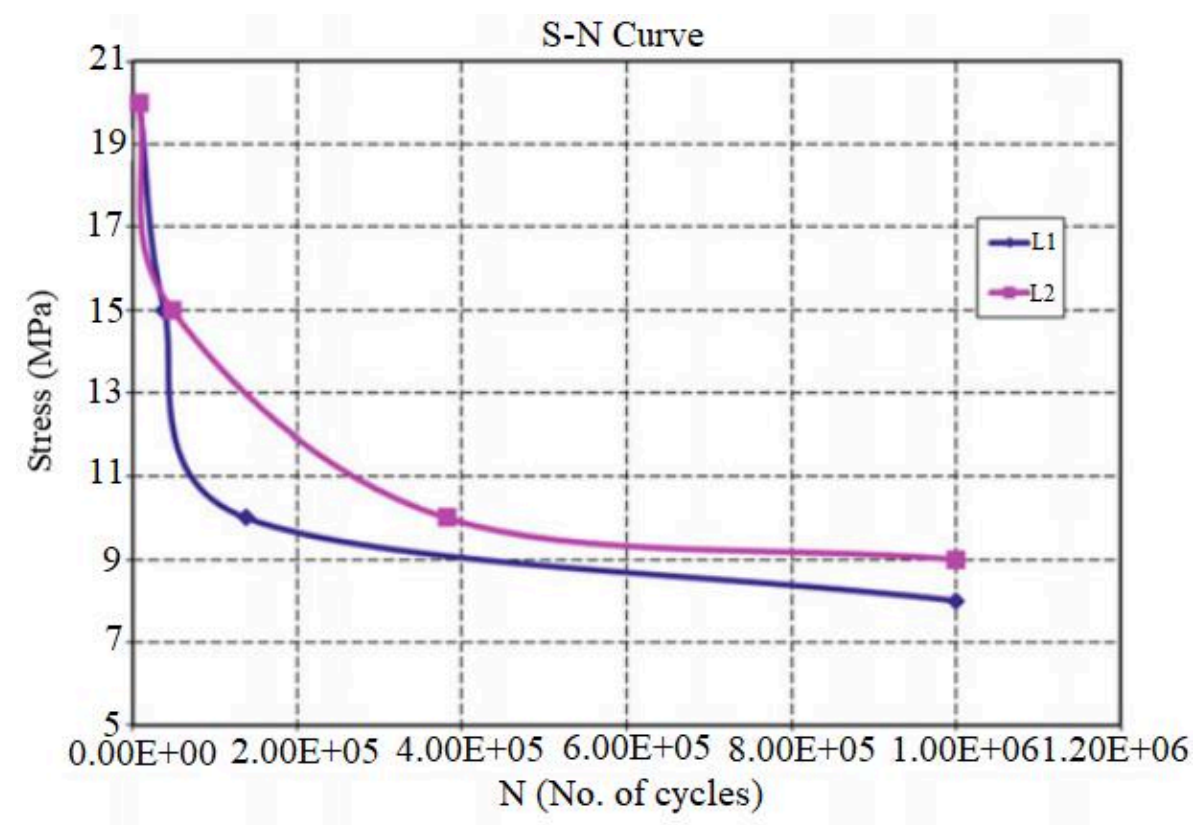

Figure 7-3 Fatigue life of the structures with different build orientation (L1: parallel oriented;

L2: perpendicular orientation) [133] 


\section{Declaration of interests}

$\bigotimes$ The authors declare that they have no known competing financial interests or personal relationships that could have appeared to influence the work reported in this paper.

$\square$ The authors declare the following financial interests/personal relationships which may be considered as potential competing interests:

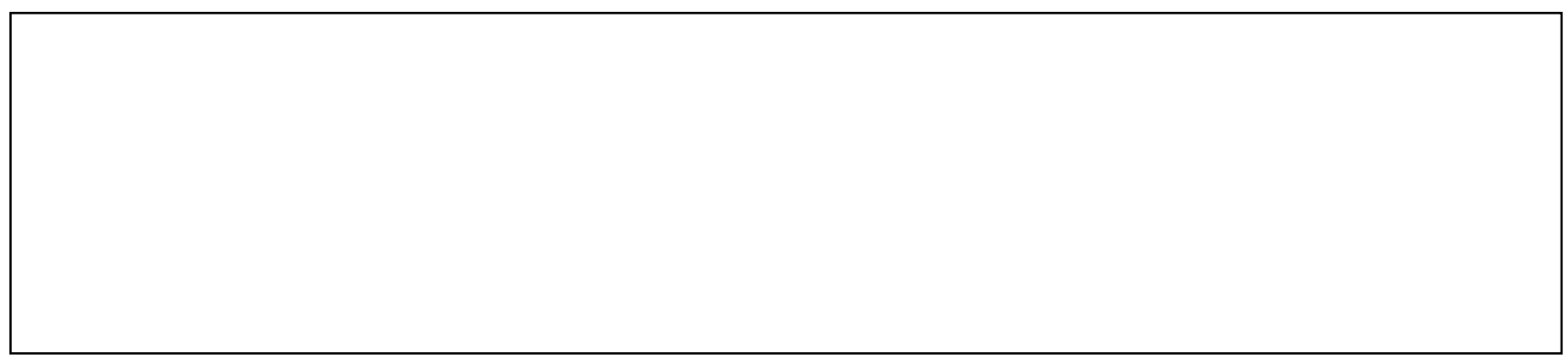


- High temperature and low frequency boost the fatigue crack growth of most polymers

- Chain slippage is easier and more frequent in polymers at high temperature

- High loading frequency causes the stiffer physical state of polymers

- Analytical crack growth model for polymers under thermo-mechanical loads is a gap

- Effect of 3D printing parameters on crack growth in polymers needs further research 
2021-02-01

\section{Evolution and new horizons in modeling crack mechanics of 3D printing polymeric structures}

He, Feiyang

Elsevier

He F, Kumar VK, Khan M. (2021) Evolution and new horizons in modelling crack mechanics of 3D printing polymeric structures. Materials Today Chemistry, Volume 20, June 2021, Article number 100393

https://doi.org/10.1016/j.mtchem.2020.100393

Downloaded from Cranfield Library Services E-Repository 